T.C.

AYDIN ADNAN MENDERES UNIVERSITY

GRADUATE SCHOOL OF NATURAL AND APPLIED SCIENCES

MASTER'S PROGRAMME IN CIVIL ENGINEERING

2021-YL-029

\title{
AXIAL BEHAVIOR OF CONCRETE CONFINED WITH FLAX FIBER-REINFORCED POLYMERS
}

MAROUF RASHIDI

MASTER'S THESIS

SUPERVISOR

Assoc. Prof. Dr. Emre AKIN 


\section{ACKNOWLEDGEMENTS}

First and foremost, I would like to express my sincere gratitude to my supervisor, Assoc. Prof. Dr. Emre AKIN for giving me the opportunity to do my master's degree under his supervision. His invaluable advice, continuous support, and patience encouraged me in my academic research and daily life.

My sincere thanks and appreciation also goes to Instr. Dr. Burhan Aleessa Alam for his excellent collaboration while conducting tensile coupon tests at the Middle East Technical University.

I would like to extend my thanks to my family and friends for their support and encouragement all through my studies.

Finally, I would like to thank the reviewers for their detailed comments and suggestion for my thesis. 


\section{TABLE OF CONTENTS}

ACCEPTANCE AND APPROVAL .............................................................................ii

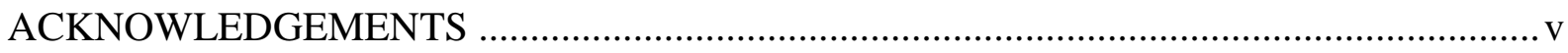

TABLE OF CONTENTS ........................................................................................... vi

LIST OF SYMBOLS AND ABBREVIATIONS ............................................................viii

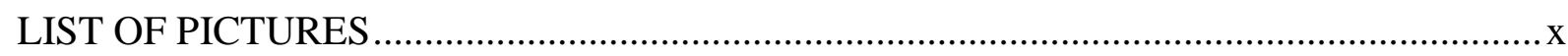

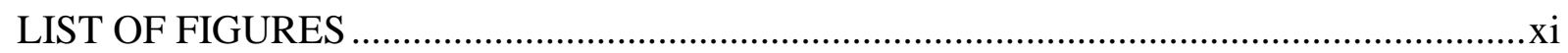

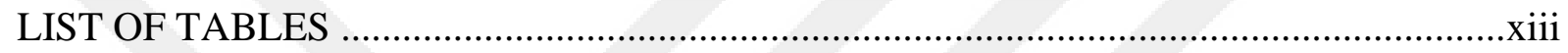

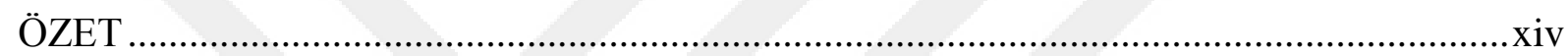

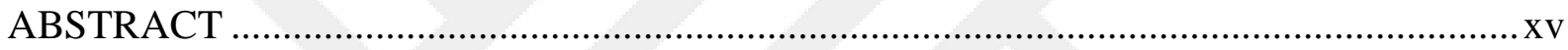

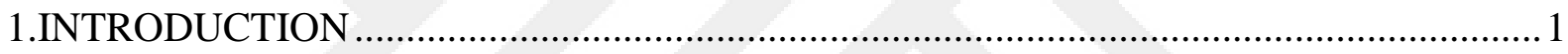

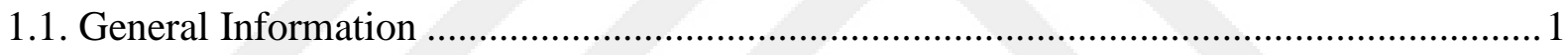

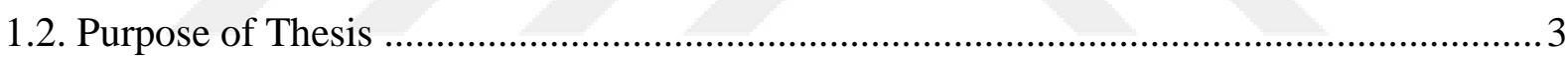

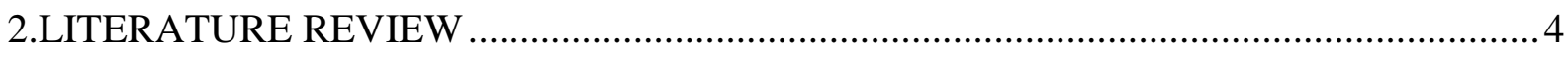

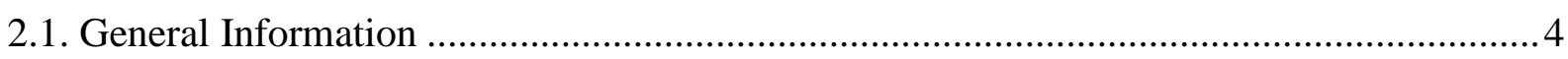

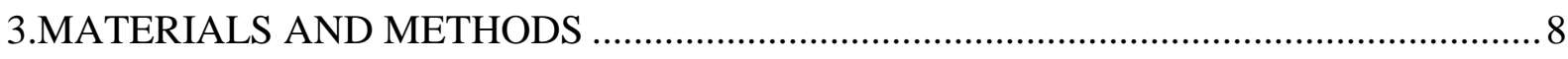

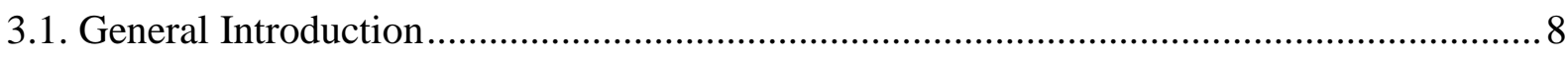

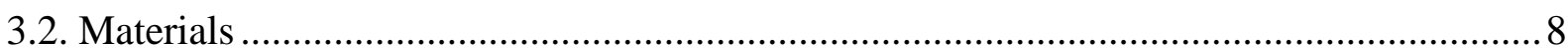

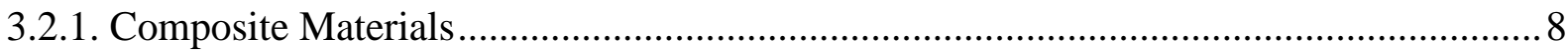

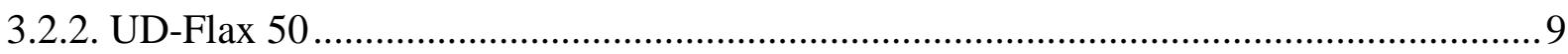

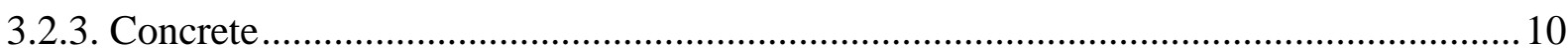

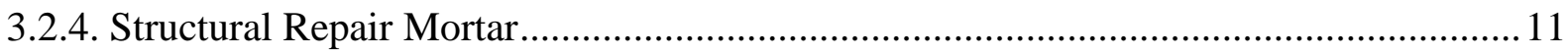

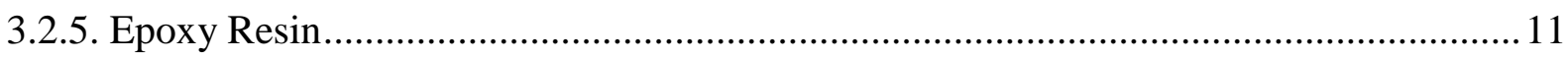

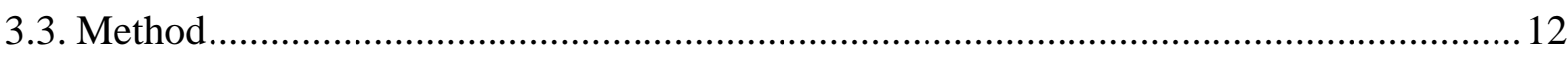

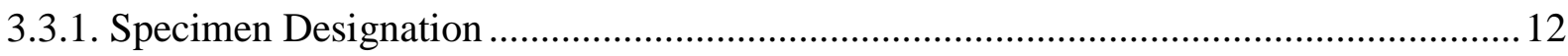




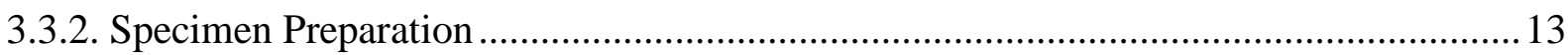

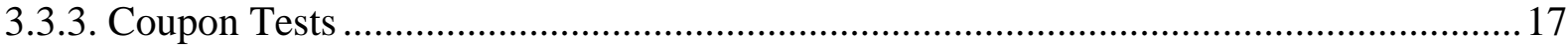

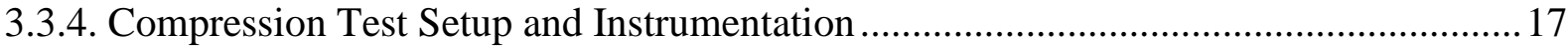

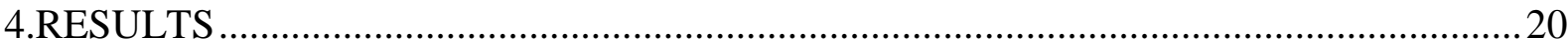

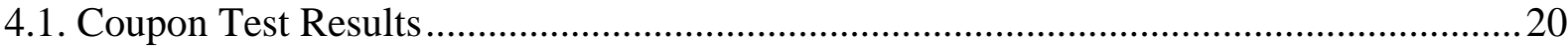

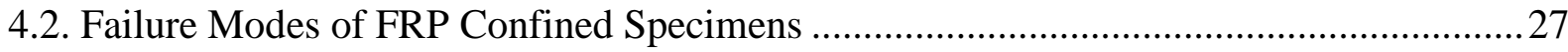

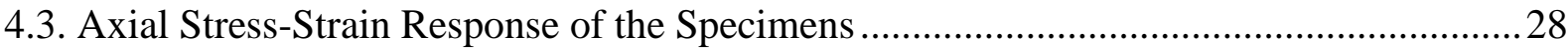

4.4. Effects of Applied Confinement on the Stress-Strain Curves ......................................... 34

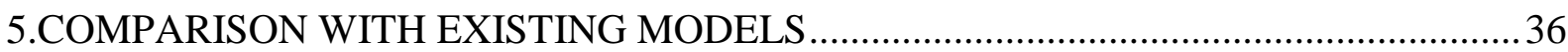

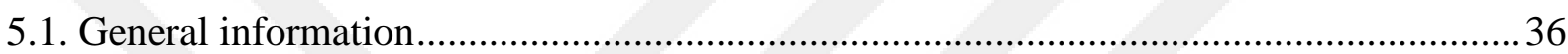

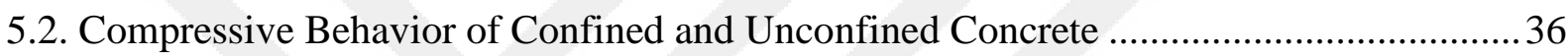

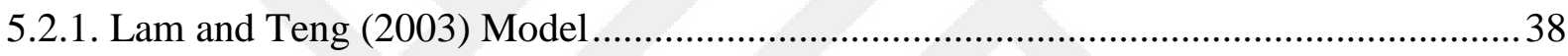

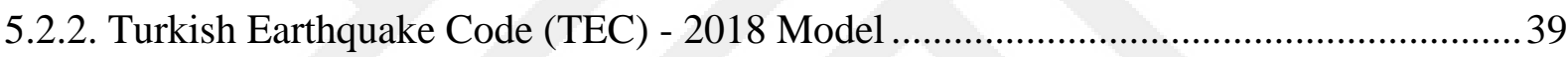

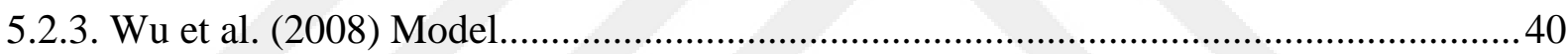

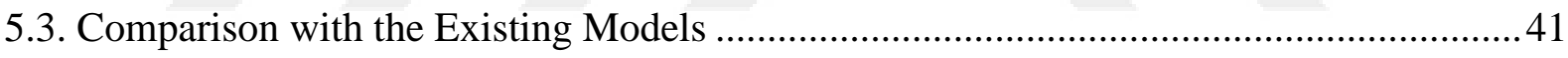

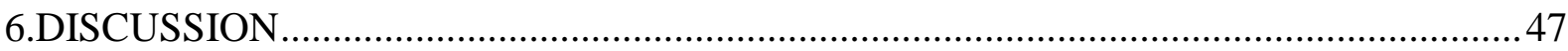

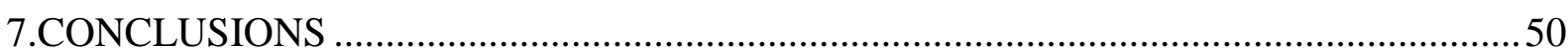

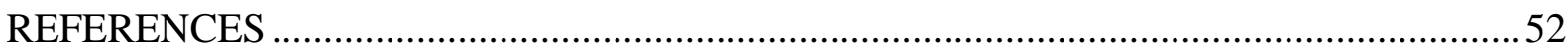

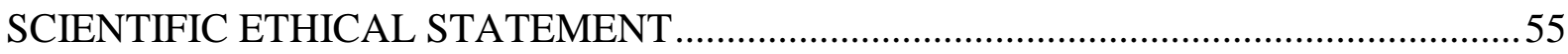

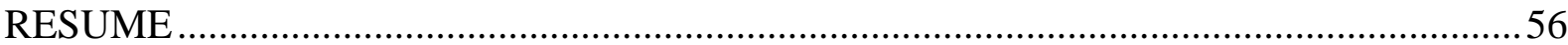




\section{LIST OF SYMBOLS AND ABBREVIATIONS}

$\mathbf{f}_{\boldsymbol{c o}} \quad$ : Peak axial compressive stress of unconfined concrete (MPa)

$\mathbf{f}_{\boldsymbol{c c}} \quad$ : Peak axial compressive stress of FRP confined concrete (MPa)

$\mathbf{f}_{\mathbf{c u}} \quad$ : Ultimate axial compressive stress of confined concrete at failure (MPa)

$\mathbf{f}_{\text {lu }} \quad$ : Radial confining pressure (MPa)

$\mathbf{f}_{\text {lu,a }} \quad$ : Actual lateral confining pressure at ultimate

$\mathbf{f}_{\mathbf{c m}}$ : Unconfined concrete strength (MPa) according to the TEC - 2018

$\mathbf{f}_{\mathbf{f 1}} \quad$ : Ultimate strength of the high ductility FRP sheet

$\mathbf{f}_{\mathbf{f} 2} \quad$ : Ultimate strength of the low ductility FRP sheet

$\boldsymbol{\varepsilon}_{\mathrm{cc}} \quad$ : Peak axial strain of FRP confined concrete

$\boldsymbol{\varepsilon}_{\mathrm{cu}} \quad$ : Ultimate axial strain of confined concrete at failure

$\boldsymbol{\varepsilon}_{\mathbf{h}, \text { rup }}:$ Hoop rupture strain of FRP shell

$\boldsymbol{\varepsilon}_{\mathrm{fu}} \quad$ : Tensile strain of FRP

$\boldsymbol{\varepsilon}_{\boldsymbol{c}} \quad$ : Strain values of confined concrete at any step of axial loading

$\varepsilon_{\mathrm{t}} \quad$ : Strain value of confined concrete at transition point

$\boldsymbol{\varepsilon}_{\mathbf{f u}} \quad$ : Ultimate tensile strain of fibers obtained from the coupon test

$\mathbf{E}_{\mathbf{f}} \quad$ : Modulus of elasticity (MPa)

$\mathbf{E}_{\mathbf{1}} \quad$ : Initial slope of axial stress-strain curve of FRP-confined concrete (MPa)

$\mathbf{E}_{2} \quad$ : Slope of the second branch of axial stress-strain curve of FRP-confined concrete $(\mathrm{MPa})$

k : Strength-enhancement coefficient

$\mathbf{k}_{\boldsymbol{\varepsilon}} \quad$ : Hoop strain reduction factor

$\mathbf{k}_{\mathbf{1}} \quad$ : Axial strength enhancement coefficient

$\mathbf{k}_{\mathbf{2}} \quad$ : Axial strain enhancement coefficient

$\boldsymbol{\kappa}_{\mathbf{a}} \quad$ : Cross-sectional shape efficiency coefficient

$\mathbf{t}_{\mathbf{f}} \quad$ : Total thickness of FRP material (mm)

$\mathbf{t}_{\mathbf{f 1}} \quad$ : The thickness of the high ductility FRP sheet

$\mathbf{t}_{\mathbf{f 2}} \quad$ : The thickness of the low ductility FRP sheet

D : Diameter of the circular concrete cross-section 
$\boldsymbol{\sigma}_{\mathbf{c}} \quad$ : Stress values of confined concrete at any step of axial loading (MPa)

$\beta$ : Confinement strength ratio of hybrid confinement

$\boldsymbol{v}_{\boldsymbol{u}} \quad$ : Ultimate Poisson's ratio

$\boldsymbol{\rho}_{f}:$ Volumetric ratio of FRP

FRP : Fiber-reinforced polymer

CFRP : Carbon fiber

GFRP : Glass fiber

AFRP : Aramid fiber

FFRP : Flax fiber

BFRP : Bazalt fiber

CFFT : Concrete-filled fiber-reinforced polymer tube

LVDT : Linear Variable Displacement Transducers

SG : Strain gauge 


\section{LIST OF PICTURES}

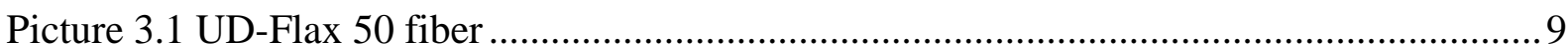

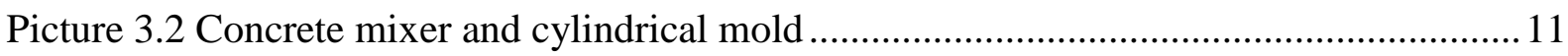

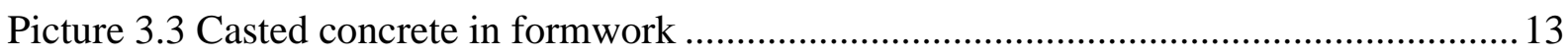

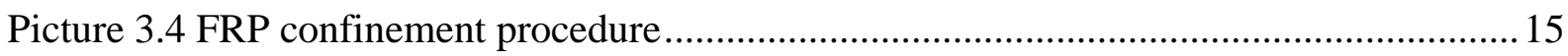

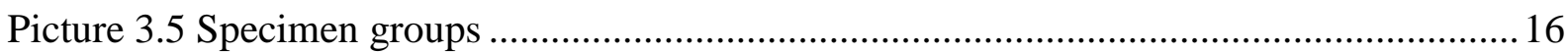

Picture 3.6 (a) Tensile test setup, (b) Tensile test specimens ............................................... 18

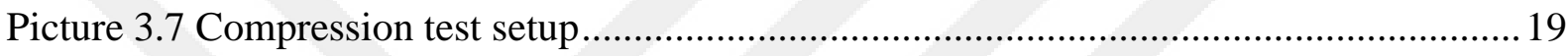

Picture 4.1 Failure mode of FFRP; (a) Lateral failure type, (b) Long splitting failure type ....23

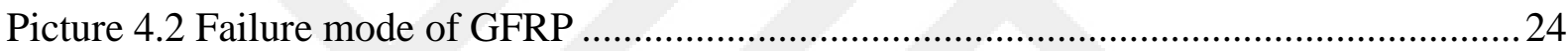

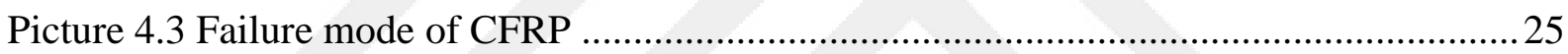

Picture 4.4 Failure mode for FFRP groups ................................................................ 27

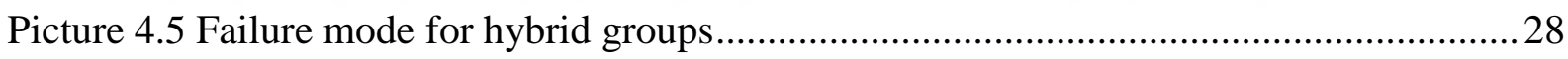




\section{LIST OF FIGURES}

Figure 3.1 Planar view of hybrid FRP wrapping in the FFG test group .............................. 16

Figure 3.2 Dimensions of tensile testing specimen (Wu et al., 2008) ................................... 17

Figure 3.3 Planar view of strain gauges and LVDTs ..................................................... 19

Figure 4.1 Average tensile strength of coupon specimens ................................................. 21

Figure 4.2 Average rupture strain capacity of coupon specimens.....................................22

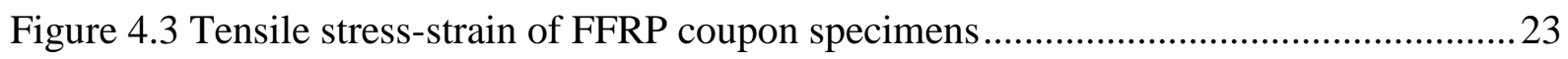

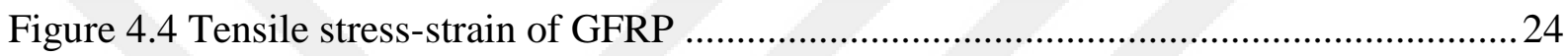

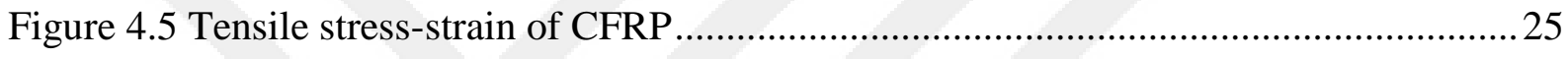

Figure 4.6 Comparison of Tensile stress-strain diagram of CFRP, GFRP and FFRP.............26

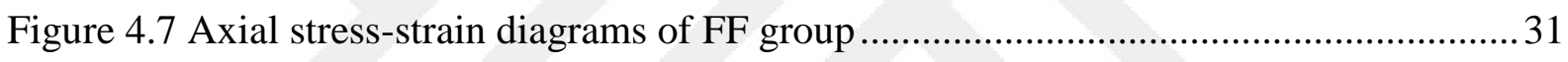

Figure 4.8 Axial stress-strain diagrams of FFF group................................................... 31

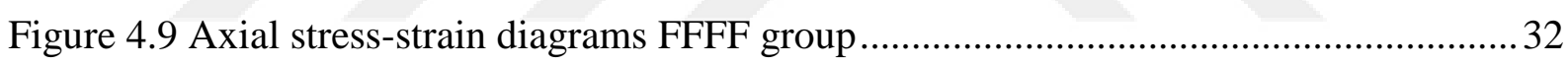

Figure 4.10 Axial stress-strain diagrams FG group.................................................... 32

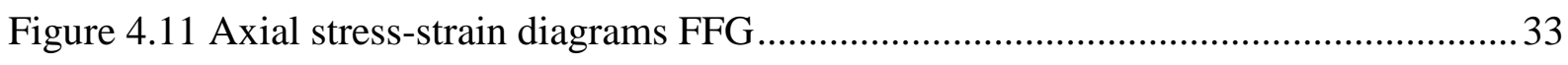

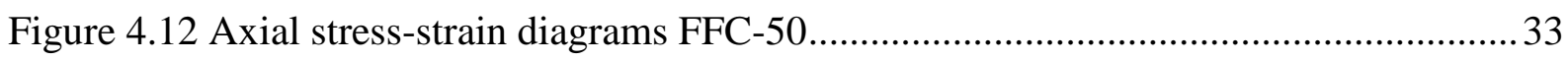

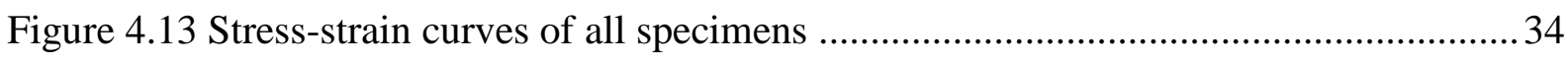

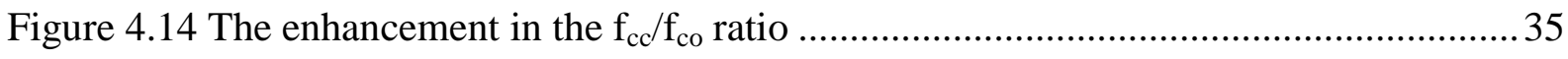

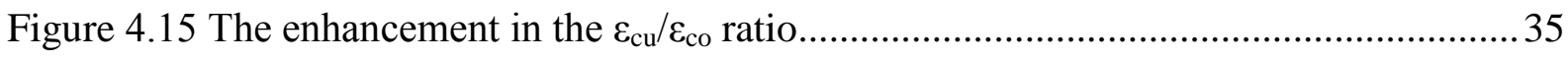

Figure 5.1 The confining action of FRP-confined concrete (Ozbakkaloglu et al., 2013) ........ 37

Figure 5.2 Behavior of confined and unconfined concrete under monotonic axial loading .... 37

Figure 5.3 Model presented by Lam and Teng (2003) for the axial behavior of FRP confined

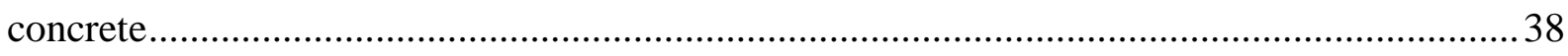

Figure 5.4 Axial compressive strength of FRP confined concrete …................................. 42

Figure 5.5 Axial compressive strain of FRP confined concrete ........................................ 42 
Figure 5.6 Comparison of the model predictions of strength- and strain-enhancement ratios with the experimental results

Figure 5.7 Comparison of the axial stress-strain curves with Lam and Teng (2003) model ...45

Figure 5.8 Experimental results and Lam and Teng (2003) model prediction. 46 


\section{LIST OF TABLES}

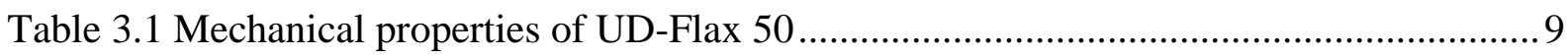

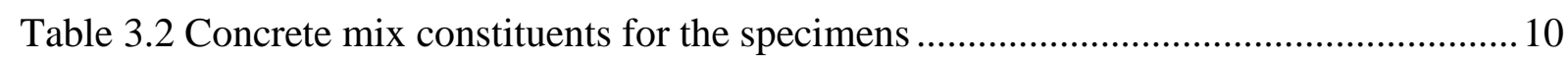

Table 3.3 Properties of structural repair mortar, MasterEmaco S 488 ................................... 11

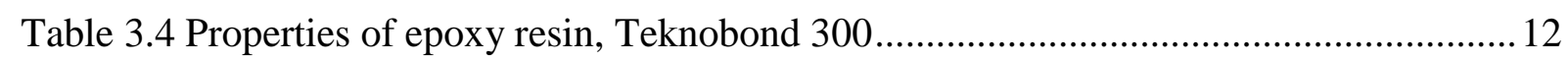

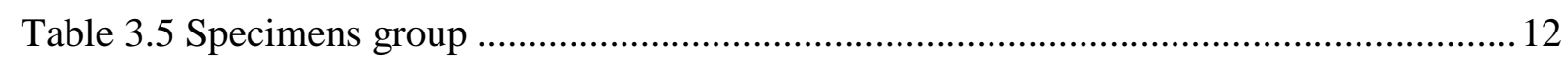

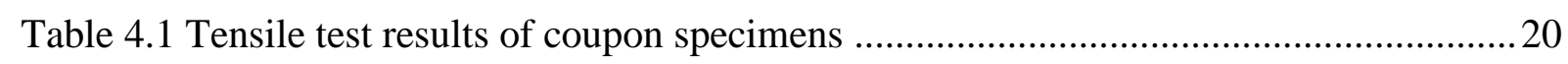

Table 4.2 Details of the specimens and main test results ................................................. 30

Table 5.1 Experimental and model prediction comparison of $\mathrm{f}_{\mathrm{cc}} / \mathrm{f}_{\mathrm{co}}$ and $\varepsilon_{\mathrm{cu}} / \varepsilon_{\mathrm{co}} \ldots \ldots \ldots \ldots \ldots \ldots \ldots . . . . . . . . .46$ 


\title{
ÖZET
}

\section{KETEN ELYAF KATKILI POLIMER KOMPOZITLERLE SARGILANMIŞ BETONUN EKSENEL DAVRANIŞI}

\author{
Rashidi M. Aydın Adnan Menderes Üniversitesi, Fen Bilimleri Enstitüsü, İnşaat \\ Mühendislik Program, Yüksek Lisans Tezi, Aydın, 2021.
}

Amaç: Bu araştırma, tek yönlü keten elyaf (FFRP) ile tek başına veya cam elyaf (GFRP) ve karbon elyaf (CFRP) ile hibritlenmiş biçimde sargılama yapıldığında düşük dayanımlı betonun eksenel davranışını incelemek amacıyla yapılmıştır.

Materyal ve Yöntem: Bu araştırmada, sargılama türü (tek malzemeyle veya hibrit) ve sarg1 sayısı çalışmanın ana parametreleridir. Elyaf malzemeler, beton silindir numunelere elle yatırma yöntemi kullanılarak ve epoksi reçineyle yapıştırılarak sarılmış ve bu yolla sargılama sağlanmıştır. Sargılanan beton numuneler monotonik eksenel basınç altında test edilmişlerdir.

Bulgular: $\mathrm{Bu}$ çalışmada toplam 23 adet beton silindirik numune test edilmiştir. Sonuçlar, sadece keten elyaf ile sınırlandırılmış numuneler için bile beton numune mukavemetinin ve nihai birim deformasyon kapasitesinin önemli ölçüde arttı̆̆ını göstermektedir. Hibrit sargılama sonucunda davranışta daha da yüksek bir iyileşme elde edilebilmiştir.

Sonuç: Bu çalışmada, kullanılan keten elyaf malzemenin, sargı katman sayısına bağlı olarak düşük dayanımlı betonun eksenel mukavemetini ve sünekliğini önemli ölçüde artırabileceği sonucuna varılmıştır.

Anahtar Kelimeler: Doğal lifler, keten, FRP, sargılama, eksenel davranış 


\begin{abstract}
AXIAL BEHAVIOR OF CONCRETE CONFINED WITH FLAX FIBER-REINFORCED POLYMER

\author{
Rashidi M. Aydin Adnan Menderes University, Graduate School of Natural and Applied \\ Science, Civil Engineering Program, Master's Thesis, Aydin, 2021.
}

Objective: This research was carried out to investigate the axial behaviour of low-strength concrete which is confined with unidirectional flax fiber reinforced polymer (FFRP) alone or in the hybrid form with glass FRP (GFRP) and carbon FRP (CFRP).

Material and Methods: In this research, the type of confinement (using single material or hybrid) and number of confining layers constitute the main testing parameters. The FRP materials were wrapped around the concrete cylinder specimens with epoxy resin using the hand lay-up method and thus confinement is provided. The confined concrete specimens were tested under monotonic axial compression.

Results: A total number of 23 concrete cylindrical specimens were tested within this study. The results demonstrate that strength and ultimate strain capacity of the concrete specimen increase significantly even for the specimens confined only with the FFRP. In the hybrid form, a higher enhancement in the axial behavior could be achieved.

Conclusion: In this study, it was concluded that FFRP materials could increase the axial strength and ductility of low strength concrete significantly depending on the number of confining layers.

Key Words: Natural fibers, flax, FRP, confinement, axial behavior. 


\section{INTRODUCTION}

\subsection{General Information}

Many existing reinforced concrete (RC) structures which had been designed and constructed improperly showed low resistance against the lateral loads in the previous earthquakes. There are different reasons for this issue, such as low-quality concrete, poor transverse reinforcement details, and insufficient strength during seismic excitation. The system rehabilitation or member strengthening strategies may be applied for such structures if demolishing and reconstruction is not an option. Mostly, the traditional rehabilitation methods have been chosen to overcome the problems in deficient structures. Some of these methods are replacing infill walls with shear walls, steel jacketing, mortar jacketing, exterior coupled shear walls, and pre-stressed cables embedded in the concrete layers. However, these methods are costly, time-consuming, and have difficult implementation procedures. To ease and facilitate retrofitting methods, FRP (Fiber reinforced polymer) composite materials were introduced as being more user-friendly in the construction sector to rehabilitate structural elements. These composite materials are available in different types with various mechanical properties, such as Carbon fiber (CFRP), Glass fiber (GFRP), Aramid fiber (AFRP), and Bazalt fiber (BFRP).

In the last two decades, synthetic fiber-reinforced polymer materials have been widely used in the construction industry, especially in the repair and strengthening of reinforced concrete structures due to their superior mechanical properties, lightweight, corrosion resistance, and the ability to give the desired shape. Carbon fibers, among these synthetic materials, stand out with their superior mechanical properties. One of the applications where these materials are most effective in strengthening against earthquakes is column confinement. Significant improvements in the axial behavior of concrete columns can be achieved by applying epoxy-based adhesive to perfectly bond fiber polymers composite to the concrete surface. Despite their advantages, synthetic fiber- polymer composites are pretty expensive, especially carbon fiber, which is the most widely used type. Thus, the cost of structural rehabilitation using these materials is generally higher compared to traditional methods. Besides, high energy consumption and carbon dioxide emissions occur during the 
production of synthetic FRP materials. For example, it is noted that energy consumption of about $800 \mathrm{MJ} / \mathrm{kg}$ is required during the production of fiber material having a carbon fiber content of 50 percent by volume. In comparison, the amount of energy required for the production of steel is expressed as approximately $50 \mathrm{MJ} / \mathrm{kg}$ (Sunter et al., 2015). This is one of the most significant disadvantages of carbon fibers, alarming sustainability and environmental awareness. Furthermore, toxic substances such as furan and dioxin in the content of glass and carbon fibers raise questions about the use of these fibers in buildings and their long-term effects on human health (Yan, 2016).

In recent years, especially in Europe, the production of composite materials using natural fibers has been encountered in many academic studies (Faruk et al., 2014; Yan, 2016; Yan and Chouw, 2013; Yan, Chouw, and Jayaraman, 2014). Considerable efforts are being made to use these types of natural fibers in the aviation and automotive sectors. The main reasons for the growing trend to use these biofiber materials are their low cost, low weight, and ease of recycling. Besides, the plants which produce bio-based fibers are renewable and sustainable; in fact, they save our planet and direct it into a greener environment. There are many types of natural fibers, such as flax, jute, hemp, ramie, and kenaf. Among these, flax fiber is the most widely used type in the composites area.

Some studies have been carried out on the use of natural materials instead of synthetic fiber materials, particularly as concrete confinement materials (Ghalieh et al., 2017; Tan et al., 2017; Yan and Chouw, 2014; Yan et al., 2014). In some of these studies, it has been stated that with two layers of flax fiber, the axial compressive strength was improved by 1.5 times and ductility by 8.5 times compared to unconfined concrete (Yan and Chouw, 2014). However, the materials used in these studies are commercially available woven flax fabrics or flax/jute yarns. When conventional woven fabrics are used for confinement purposes, tensile stress concentration and small voids occur in the folds where the yarns cross over each other and in the yarns' twists themselves. These stress concentrations and voids in the composite material constitute an obstacle to achieving the desired confining effect. It is considered that more efficient results can be achieved with a composite material that goes through a production process similar to synthetic fibers, which eliminates the problems of stress concentrations and yarn twisting. 


\subsection{Purpose of Thesis}

This study aims to show the efficiency of unidirectional flax fiber-reinforced composite material in the concrete confinement and provide an alternative for the synthetic FRP materials. In the previous studies, the conventional woven flax fabrics were used for strengthening purposes. However, in this experimental study, the unidirectional flax fiber composite materials (FFRP) - free of any stress concentration are used for concrete confinement. These FFRP composites are produced by a novel one-step continuous process that eliminates the weaving and stitching of the yarns. In the confinement process, the FFRP composite materials are wrapped and bonded to the concrete surface in multiple layers, either alone or in hybrid with other synthetic polymers (e.g., glass or carbon). In this way, the behavior of the concrete is examined under monotonic axial compressive loading. After examining the test results, the strength- and strain-enhancement ratios of the test specimens are compared with the corresponding model predictions of Lam and Tang, (2003), Wu et al. (2008), and TEC-2018. As a result of this comparison, the applicability of existing models are evaluated and discussed. 


\section{LITERATURE REVIEW}

\subsection{General Information}

Carbon/glass/aramid/basalt fiber reinforced synthetic polymer materials have become widely used in the construction sector, especially in the repair and strengthening reinforced concrete structures due to their unique mechanical properties, lightweight, corrosion resistance, and ability to give the desired shape. In the last twenty-five years, many academic studies have been carried out, in particular using carbon fiber materials for member strengthening and system improvement. Column confinement with FRP material is a part of these studies, which have been discussed in some experimental and analytical studies by considering different parameters. These studies are classified into two parts by researchers:

- Experimental studies

- Theoretical studies

In experimental studies, researchers examined the behavior of FRP confined concrete under axial monotonic/cyclic loading and investigated the effect of mechanical properties of FRP materials and the contribution of FRPs to the strength and ductility of reinforced concrete elements. In theoretical studies, scientists focused on the analytical model predictions that are compatible with results obtained from experimental studies. Some of these studies are explained below:

Mirmiran and Shahawy (1997) aimed to assess the behavior of concrete confined with FRP composite under the uniaxial compression test in their study. A total of twenty-four $152.5 \times 305 \mathrm{~mm}$ cylindrical concrete-filled FRP tube specimens were tested. The materials consist of glass fiber with a tensile strength of $1420 \mathrm{MPa}$, and the average concrete strength was between 29.6 to $32 \mathrm{MPa}$. This study indicated that the FRP materials could improve the strength and ductility of concrete significantly. Besides, it was also shown that FRP materials curtail the dilation rate of the concrete core. They compared their results with the available steel-encased concrete models in the literature. They found that the available models are generally unable to estimate the dilatancy of FRP confined concrete and overestimate the 
strength of the FRP-encased concrete. Therefore, they provided a better framework to predict the behavior of FRP confined concrete

Lam and Teng (2003) assembled the test results of 76 FRP-wrapped plain concrete circular specimens from an extensive survey of the open literature. The samples included in the database had diameters from $100 \mathrm{~mm}$ to $200 \mathrm{~mm}$ confined with different types of FRPs, and the strength of concrete varied from 26.2 to $55.2 \mathrm{MPa}$. Based on careful analysis and findings of the test data for designing purposes, a new stress-strain model was proposed for FRP confined concrete with fibers primarily in the hoop direction. This model is simple, and it captures all the main characteristics of the stress-strain behavior of concrete confined by different types of FRP. Besides, for the development of this model, some important parameters such as hoop rupture, the sufficiency of FRP confinement, and jacket stiffness were carefully examined and appropriately resolved. The predicted models were consistent with the test data.

Fam and Rizkalla (2001) introduced an analytical model to predict the behavior of axially loaded circular concrete columns confined by the FRP tubes. Equilibrium, compatibility, and biaxial failure of FRP tubes are the main parameters of this model. The experimental results reported by the authors match the model. A parametric study was also presented to investigate the effect of the inner hole, stiffness, and axial load on FRP. The study showed that increasing the hole size and axial load on the FRP tube reduces the effect of confinement. However, increasing the stiffness of the tube improves the confinement.

Tepfers and Rousakis (2002) investigated the mechanical behavior of confined concrete cylinder specimens wrapped with a high E-modulus carbon sheet (377 GPa). The concrete strength was $25.2 \mathrm{MPa}$ and $51.8 \mathrm{MPa}$ confined with 1,2,3, and 5 layers of CFRP subjected to monotonic and cyclic axial compressive loading. To study the effect of overlap length of FRP, three specimens were wrapped by one layer of CFRP with different overlap lengths of 50mm, $100 \mathrm{~mm}$, and $150 \mathrm{~mm}$. The results revealed that a $100 \mathrm{~mm}$ overlap length was enough to avoid debonding or premature failure. Additionally, it was also shown that the strain at failure of the jacket fibers is lower than the nominal tensile elongation at failure of the carbon fibers.

Ozbakkaloglu and Akın (2011) tested a total number of 24 aramids and carbon FRP wrapped normal strength concrete (NSC) and high strength concrete (HSC) cylindrical specimens under monotonic and cyclic loading. In regard to the trend and ultimate condition of the axial stress-strain behavior of FRP confined concrete, they reported that the envelope 
stress-strain curve of FRP confined concrete follows closely the same path in both cyclic and monotonic loading. Besides, the strength and strain-enhancement ratios decrease as the unconfined concrete strength increases for a given actual confinement ratio. They also stated that CFRP and AFRP jackets that provide the same level of actual confining pressure result in a similar level of concrete strength enhancement, but AFRP confinement increases the ultimate strain significantly.

Ozbakkaloglu (2013) investigated the behavior of FRP tubes filled with concrete under the axial compression test in a comprehensive experimental study. This study presented the results from a group of 92 selected circular, square, and rectangular concrete-filled fiberreinforced polymer tubes (CFFTs) and discussed the effect of critical column parameters on the compression behavior CFFTs. These parameters include concrete strength, quantity, and type of FRP tube material, method of manufacturing the tubes, size and shape of the CFFTs. In addition to conventional FRP tubes, new types of FRP reinforced tubes have been designed and tested. The results show that concrete strength, cross-sectional shape, and quantity, and type of tube material significantly affect the behavior of CFFTs. Furthermore, FRP-reinforced newly developed square and rectangular CFFTs show significantly improved behavior compared to conventional CFFTs.

Joshia et al. (2004) identified the critical factors that natural fiber can be an alternative to glass fiber in their review study of life cycle comparison assessment between natural fiber and glass fiber composite. They revealed the following reasons, which make natural fibers environmentally superior to glass fiber composites. (1) the production of natural fibers have a lower impact on the environment compared to glass fiber; (2) the fiber content of natural fibers are higher than glass fiber, and this causes a reduction in the amount of polluting base polymers; (3) lower weight of natural fiber composites improve fuel efficiency and reduce the emission especially in automotive use; (4) unlike glass fiber, natural fibers incineration provide energy and carbon credit after their useful life.

Yan and Chouw (2013) investigated the axial compressive behavior of flax FRP (FFRP) and coir FRP (CFRC) confined plain concrete cylinder. A total number of 24 FFRP and CFRC specimens were tested and compared with a total of 23 existing design-oriented and analysis-oriented models to predict the strains and the ultimate axial strength of confined concrete. Their study reveals that flax and coir composites provide significant axial compressive strength and ductility. Besides, the results also confirmed that existing designand analysis-oriented models predicted the ultimate strengths of the flax fiber confined 
cylinders accurately. However, the available strain models did not match the ultimate strains of these specimens. Therefore, they proposed two new equations to evaluate the ultimate axial strain of flax fiber.

$\mathrm{Wu}$ et al. (2008) investigated the behavior of concrete cylinders confined with hybrid FRP composites. A total of 35 concrete cylindrical specimens where 12 specimens were confined with one kind of FRP sheet and 20 specimens confined with hybrid FRP sheets were tested under monotonic axial load. Different types of FRPs with different layers and different kinds of hybridization were included in their experimental program. They concluded that the hybrid ratio is a critical factor for concrete cylinders confined in hybrid form. The hybridization will be inefficient if the ratio of the confinement strength of the high ductility FRP sheet to the low ductility FRP sheet is too low, and it will not be economical if the ratio is too high. Besides, by combining a high-strength FRP sheet with a high ductility FRP sheet, the ultimate strength of FRP-confined concrete can be increased. However, the ultimate strain remains the same as the specimens of the counterpart confined only with the high ductility FRP sheets. 


\section{MATERIALS AND METHODS}

\subsection{General Introduction}

The first part of this chapter explains the properties of materials that are used in this study. The second part describes specimen designation, specimen preparation procedure, test equipment, test setup, and instrumentation.

\subsection{Materials}

In this research, low strength concrete, flax, glass, and carbon fibers constitute the main testing materials. Epoxy, primer, and structural repair mortars are used as adhesive and repairing materials, respectively. The mechanical properties of these materials are discussed within this part in detail.

\subsubsection{Composite Materials}

Composite materials are combined of two or more materials with different physical, chemical, and mechanical properties. Fiber Reinforced Polymer (FRP) is a type of composite material which have been utilized to improve the load capacity of the existing structures with substandard characteristics. FRP is generally a combination of two substances. The first part is matrix made of some chemical materials such as epoxy resins and polyester, and the second part is fiber. Epoxy holds the fibers together and plays a binding role. Besides, they protect fibers against environmental factors, and damage. Fibers are assumed to provide sufficient mechanical resistance to FRP's. In the last decades, synthetic FRP's such as carbon, glass, and aramid has been widely used to rehabilitate and strengthen concrete structures. However, 
due to environmental and sustainability issues, natural fibers are emerging as an alternative to synthetic composite materials in different applications. Natural fibers such as hemp, jute, flax, and many more have the potential to replace synthetic materials since they have attractive physical and mechanical properties (Sen and Jagannatha Reddy, 2014). In this research, flax fiber composite is used as confining materials either alone or in hybrid form together with carbon and glass. The mechanical properties of these materials (ultimate strength, elasticity modulus, and rupture strain) are determined by the coupon tensile test.

\subsubsection{UD-Flax 50}

UD-Flax 50 is a polypropylene-based unidirectional organosheet/prepreg reinforced with flax fibers and performing unique mechanical properties. These materials are processed and produced by B-Preg Composite \& Textile Inc. The UD-Flax $50\left(325 \mathrm{~g} / \mathrm{m}^{2}\right)$ is manufactured in rolls up to $100 \mathrm{~cm}$ wide and $50 \mathrm{~m}$ long with the flexibility to shape into the desired geometry. The mechanical properties of UD-Flax 50 provided by the manufacturer are presented in Table 3.1.

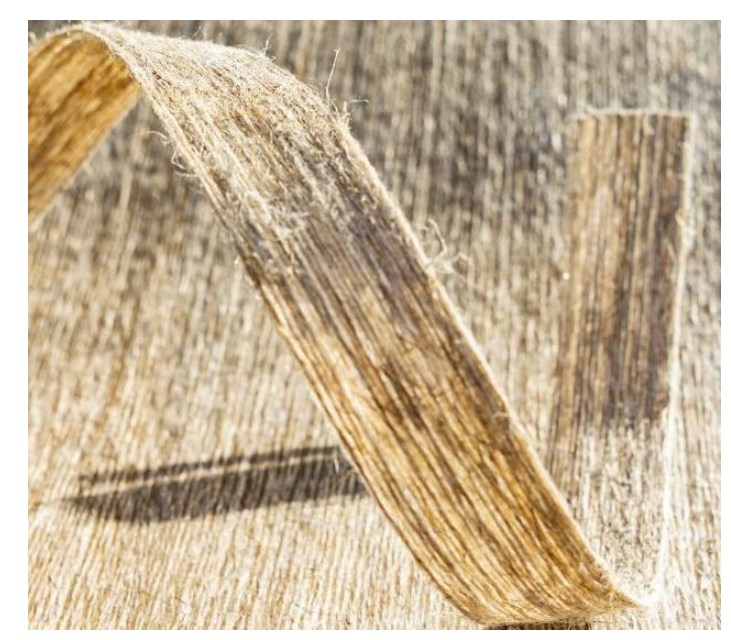

Picture 3.1 UD-Flax 50 fiber

Table 3.1 Mechanical properties of UD-Flax 50 provided by the manufacturer

\begin{tabular}{|l|l|}
\hline Tensile Modulus & $15.5 \pm 1 \mathrm{GPa}$ \\
\hline Tensile Strength & $160 \pm 15 \mathrm{MPa}$ \\
\hline Elongation at Break & $1.5-2 \%$ \\
\hline
\end{tabular}




\begin{tabular}{|l|l|}
\hline Flexural Modulus & $8.7 \pm 0.5 \mathrm{GPa}$ \\
\hline Flexural Strength & $130 \pm 20 \mathrm{MPa}$ \\
\hline
\end{tabular}

\subsubsection{Concrete}

Low strength concrete with the target characteristic compressive strength of $10 \mathrm{MPa}$ was produced for the specimens. This strength level has been chosen to represent the average concrete quality of substandard reinforced concrete buildings aimed for confinement applications (Bal et al., 2008). The concrete was produced by a pan-type concrete mixer with a capacity of 56 liters (Picture 3.2) in Aydin Adnan Menderes University (ADU) Civil Engineering Laboratory. The mixing ratios used in accordance with the target strength level of the concrete are shown in Table 3.2 (Emre Akın, 2011).

Table 3.2 Concrete mix constituents for the specimens

\begin{tabular}{|l|l|l|l|l|l|}
\hline Materials & $\begin{array}{l}\text { Fine } \\
\text { aggregate }\end{array}$ & $\begin{array}{l}\text { Coarse } \\
\left(\text { maximum } \begin{array}{l}\text { aggregate } \\
\text { aggregate } \\
\text { diameter }=\mathbf{~ 1 5 ~} \mathbf{~ m m})\end{array}\right.\end{array}$ & Cement & Water & Total \\
\hline $\begin{array}{l}\text { Weight } \\
\text { ratio }(\%)\end{array}$ & 19 & 58 & 12 & 11 & 100 \\
\hline
\end{tabular}




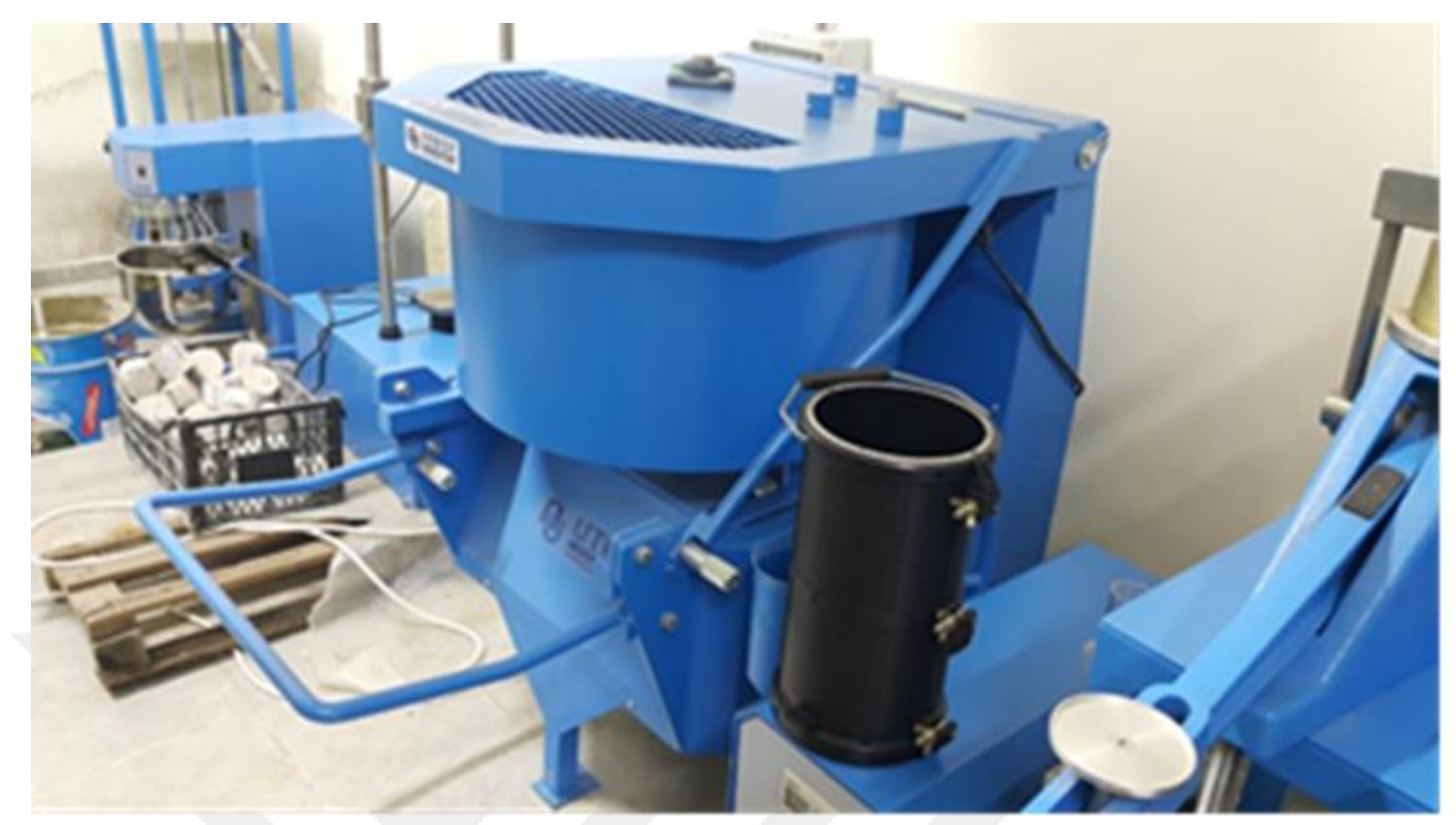

Picture 3.2 Concrete mixer and cylindrical mold

\subsubsection{Structural Repair Mortar}

MasterEmaco S 488 PG cement-based and fiber-reinforced high strength structural repair mortar was selected for the purpose of capping on the top and bottom of the specimens. The thickness of the caps was approximately $5 \mathrm{~mm}$ and tended to provide uniform axial load distribution on the top and bottom surfaces of the specimens. Table 3.3 demonstrate the technical properties of MasterEmaco S 488 PG, which is provided by the manufacturer.

Table 3.3 Properties of structural repair mortar, MasterEmaco S 488

\begin{tabular}{llll}
\hline $\begin{array}{l}\text { Compressive strength } \\
(\mathrm{MPa})\end{array}$ & $\begin{array}{l}\text { Modulus of elasticity } \\
(\mathrm{GPa})\end{array}$ & $\begin{array}{l}\text { Bonding } \\
\text { concrete } \\
(\mathrm{MPa})\end{array}$ & strength to \\
\hline$>20$ (1days) & $>20(28$ days $)$ & $>2(28$ days $)$ \\
$>50$ (7days $)$ & & \\
$>60$ (28 days) & & \\
\hline
\end{tabular}

\subsubsection{Epoxy Resin}


The adherence of FRP materials to the test specimens was provided by Teknobond 300 Epoxy resin. Teknobond 300 is a two-component, low viscosity, solvent-free epoxy resin primer used for bonding FRP fiber material to reinforced concrete elements. The twocomponent materials are mixed with a low-speed mixer for a period of 2-3 minutes until a homogeneous color is obtained. The technical properties of the epoxy material used in the experimental study are given in Table 3.4.

Table 3.4 Properties of epoxy resin, Teknobond 300

\begin{tabular}{|l|l|}
\hline Compressive Strength & $\geq 80 \mathrm{MPa}$ \\
\hline Component & 2 \\
\hline Mixing ration (weight) & 2 unit A : 1 unit B \\
\hline Mix density & $1.10 \pm 0.02 \mathrm{~g} / \mathrm{ml}$ \\
\hline color & Transparent Yellowish Liquid \\
\hline Full strength & 7 day $\left(\right.$ at $\left.+20^{\circ} \mathrm{C}\right)$ \\
\hline Application period & $\begin{array}{l}\geq 30 \mathrm{~min} \quad \text { (Depend on the weather } \\
\text { condition) }\end{array}$ \\
\hline
\end{tabular}

\subsection{Method}

\subsubsection{Specimen Designation}

The specimens in Table 3.5 are divided into four groups. The first group is the reference group labeled as "REF" to provide the results of unconfined concrete. The second group specimens are confined only with flax fibers (FFRP). In the third group, the specimens are confined in the hybrid form of flax and glass, whereas the fourth group of specimens are wrapped with flax fibers and $50 \mathrm{~mm}$ carbon strips with a spacing of $75 \mathrm{~mm}$. The letters $\mathrm{F}, \mathrm{C}$, and G represent flax, carbon, and glass FRP, respectively. Each of these letters represents one layer of FRP. For instance, FFG is the specimen confined with two layers of FFRP and one layer of GFRP fiber. As another example, FFFF labels the specimens confined by four layers of FFRP only.

Table 3.5 Specimens group

\begin{tabular}{|l|l|l|}
\hline Specimen & Number & Description \\
\hline REF & 3 & Reference specimens without wrapping \\
\hline
\end{tabular}




\begin{tabular}{|l|l|l|}
\hline FF & 4 & Specimens wrapped with two layers of flax fiber \\
\hline FFF & 3 & Specimens wrapped with three layers of flax fiber \\
\hline FFFF & 3 & Specimens wrapped with four layers of flax fiber \\
\hline FG & 3 & $\begin{array}{l}\text { Specimens wrapped with one layer of flax and one layer of glass } \\
\text { fiber }\end{array}$ \\
\hline FFG & 4 & $\begin{array}{l}\text { Specimens wrapped with two layers of flax and one layer of glass } \\
\text { fiber }\end{array}$ \\
\hline FFC-50 & 3 & $\begin{array}{l}\text { Specimens wrapped with two layers of flax and 50mm carbon fiber } \\
\text { strips with a spacing of 75mm }\end{array}$ \\
\hline
\end{tabular}

\subsubsection{Specimen Preparation}

A total number of 23 concrete cylindrical specimens with a diameter of $150 \mathrm{~mm}$ and height of $300 \mathrm{~mm}$ were manufactured using low strength concrete and tested under monotonic axial compression. Concrete was produced by a pan-type concrete mixer, as shown in Picture 3.2. The specimens were cast and kept in the mold (Picture 3.3) for four days in order to get the required strength to avoid any disturbance that may be caused while removing from the molds. Then, with the help of an air compressor, the specimens were removed from the molds and kept at room temperature under normal conditions until the day of the experiment.

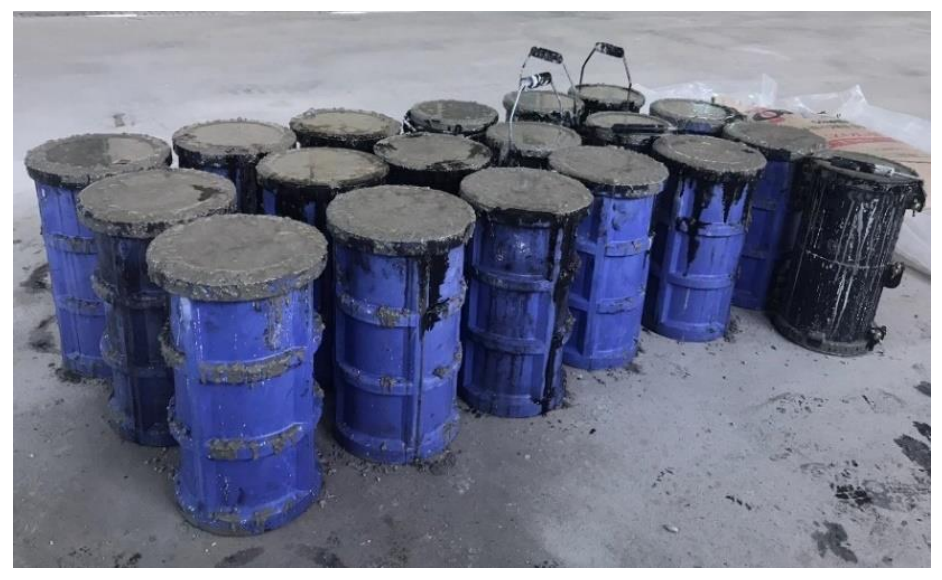

Picture 3.3 Cast concrete in formwork

Generally, the substandard reinforced concrete structures aimed for confinement applications have low-strength concrete. For this purpose, the curing period was kept shorter compared to regular concrete to avoid undesirable strength gain. Accordingly, the water was sprayed on the concrete surface for three days only, and the specimens were left in dry 
laboratory conditions afterward. After this curing period, the intended average unconfined concrete compressive strength was obtained from the reference specimens (10.9 MPa).

A shell layer of structural mortar with a thickness of $5 \mathrm{~mm}$ was applied to the top and bottom of the specimens two weeks after concrete casting. The aim of applying these mortar layers was to ensure that specimens have smooth, parallel, and uniform surfaces that are perpendicular to the axial compressive stress during testing. In the next step, the specimens were properly cleaned, and epoxy primer material was applied to the concrete surface to produce a finish surface and implement a sealing behavior between the concrete and FRP (Picture 3.4.a). The FRP sheets were prepared with the specified dimensions (Picture 3.4.b and c), and epoxy impregnation of the prepared sheets was provided by using a roller (Picture 3.4.d). Following that, the epoxy impregnated FRP sheets were tightly wrapped around the specimens in the hoop direction by the hand lay-up method (Picture 3.4.e). In all confined specimens, a $5 \mathrm{~mm}$ wide gap was provided on both sides of the specimens to ensure that the composite material operates only in the lateral direction without being exposed to axial stresses. 


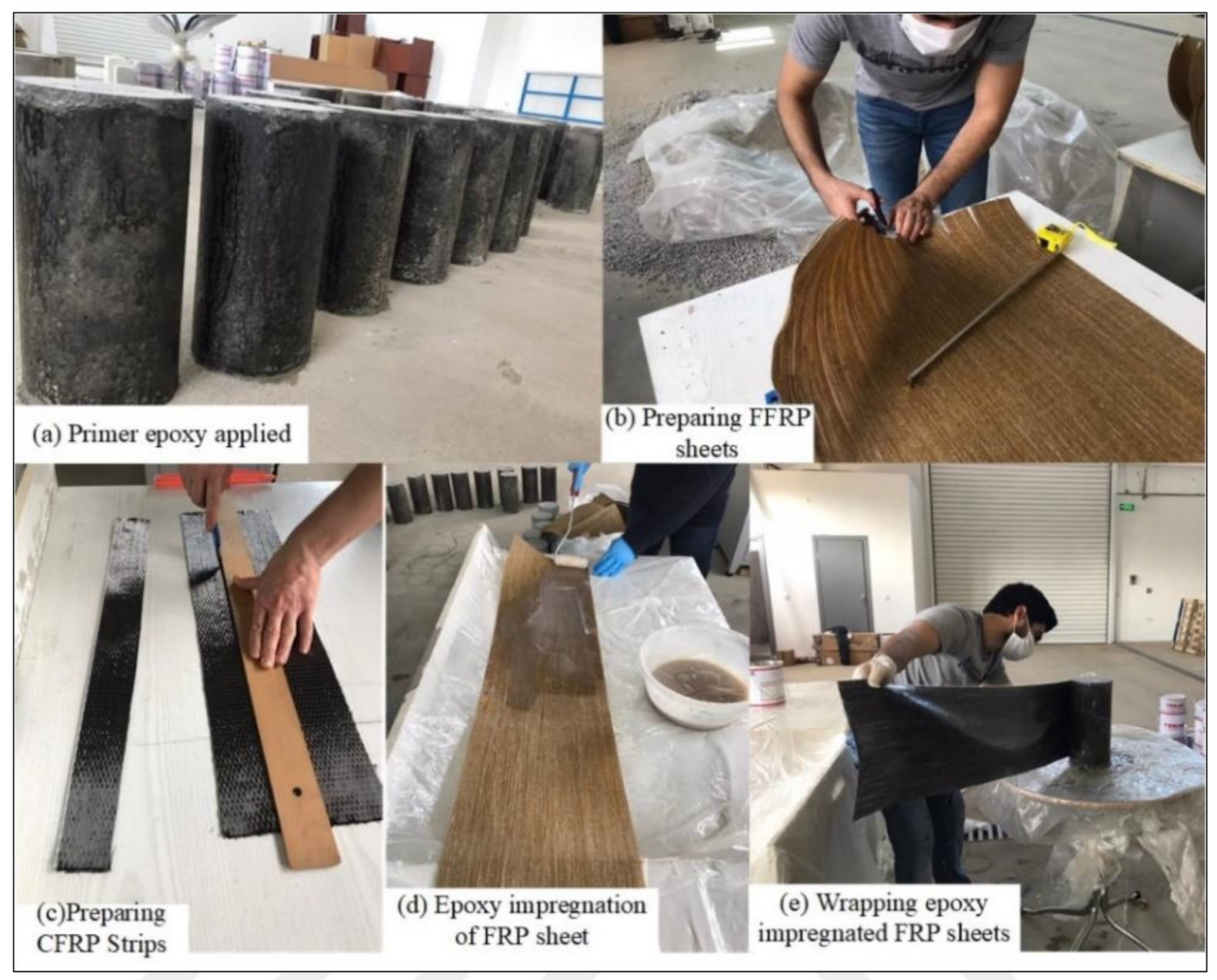

Picture 3.4 FRP confinement procedure

After wrapping each layer, the air bubbles were saturated using an epoxy roller. An overlapping length of $150 \mathrm{~mm}$ was provided at the end of wrapping to ensure that no premature debonding takes place before the rupture of FRP. All FFRP confined specimens were wrapped by a single sheet continuously such that they have one overlapping region. In the same manner, two overlapping regions were provided for the hybrid specimens since two types of sheets are wrapped on the same specimen, as demonstrated in Figure 3.1. The FFRP is a stiffer material compared to the synthetic FRP's. Therefore, the confinement process was not as easy as synthetic materials, which are usually softer. To overcome this problem, the FFRP strings that were obtained by the disintegration of the extra FFRP sheets were used for fastening the confining jacket at various locations along with the height of the specimens, as demonstrated in Picture 3.5. However, in the hybrid groups, the FFRP strings were not required. In these hybrid confinements, the epoxy impregnated GFRP, or CFRP layers prevented disentangle of the FFRP sheet. 


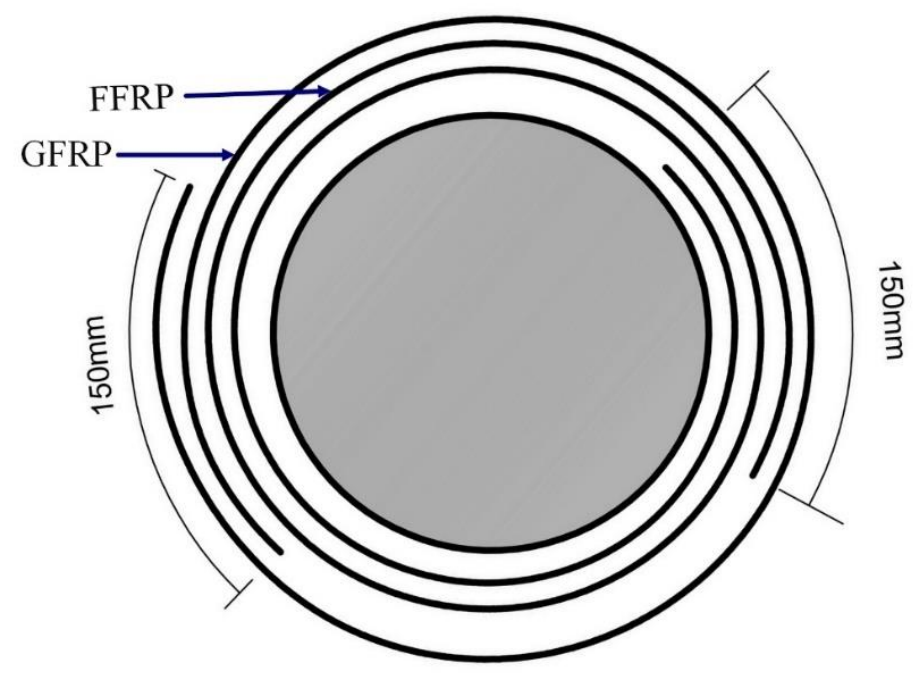

Figure 3.1 Planar view of hybrid FRP wrapping in the FFG test group

Three specimens that constitute the reference group (i.e. REF) were kept without confining. In the FFRP groups where flax fibers are used alone, the number of FFRP layers are considered to be two, three, or four (i.e. FF, FFF, FFFF). In the hybrid group of flax and glass, either one or two layers of FFRP were supported by one layer of GFRP (i.e. FG, FFG). In the last group, one layer of CFRP strips was wrapped over two layers of FFRP (i.e. FFC50). The width and spacing of the CFRP strips were $50 \mathrm{~mm}$ and $75 \mathrm{~mm}$, respectively. The test matrix with the details of the specimens are shown in Table 3.5.

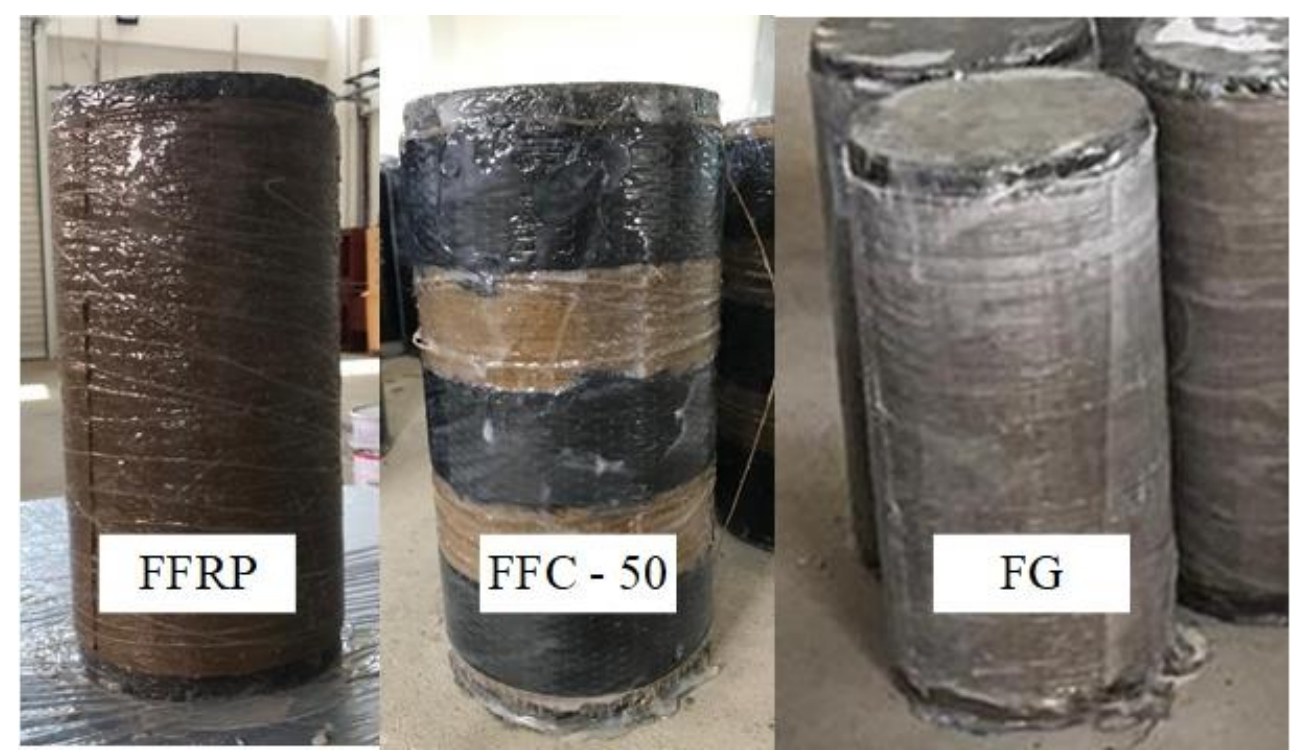

Picture 3.5 Specimen groups 


\subsubsection{Coupon Tests}

The mechanical properties (tensile strength, modulus of elasticity, and rupture strain) of the flax, glass, and carbon FRP materials were determined by the tensile coupon test in accordance with ASTM D3039. For each material, five specimens were prepared with dimensions of $15 \mathrm{~mm}$ width and $250 \mathrm{~mm}$ length (Figure 3.2). The specimens were impregnated using epoxy materials.

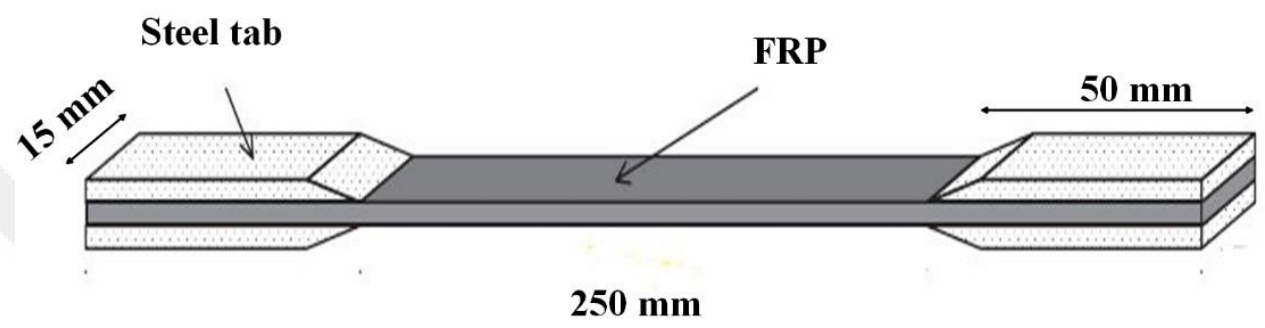

Figure 3.2 Dimensions of tensile testing specimen (Wu et al., 2008)

To prevent gripping damage and unexpected ruptures due to stress accumulation at the tip of the specimens, $50 \mathrm{~mm}$ long steel tabs were bonded using epoxy at both ends of each specimen, as shown in Figure 3.2. These steel tabs were placed in between the grips of the tensile testing machine (Picture 3.6.a). The thickness of FRP material ( $\mathrm{t}_{\mathrm{f}}$ ) was determined by using digital calipers. The resulting thicknesses of CFRP, GFRP, and FFRP fibers were 0.25 $\mathrm{mm}, 0.20 \mathrm{~mm}$, and $0.40 \mathrm{~mm}$, respectively. The coupon test setup and specimens before the test are demonstrated in Picture 3.6.

\subsubsection{Compression Test Setup and Instrumentation}

The compression test is a common testing method that plays an essential role in determining the mechanical properties of materials. This testing method aims to determine the response of materials and measure the fundamental variables such as stress, strain, and deformations. In this experimental study, a compression test machine with an axial load capacity of $3000 \mathrm{kN}$ was used for the monotonic compression tests of the specimens. A separate load cell with an axial load capacity of $600 \mathrm{kN}$ was placed under the specimens, 
which dictated the overall load capacity of the test setup (Picture 3.7). A high-strength circular steel disk with the same diameter as the specimens (i.e. $150 \mathrm{~mm}$ ) was installed on the load cell to transfer loading on the core concrete and prevented the formation of axial stresses on the confining jacket. The axial loading was applied at a constant rate of $4 \mathrm{kN} / \mathrm{s}$ on all the specimens. Two linear variable displacement transducers (LVDTs) were fixed on the magnetic base perpendicular to the supporting plate of the testing machine and located 180 degrees apart. The average of the deformations recorded by the LVDT's were used to estimate the average axial strains along the specimen height. Three unidirectional strain gauges with a gauge length of $10 \mathrm{~mm}$ were bonded horizontally on the surface of FRP jackets to measure hoop strain. The strain gauges were equally spaced by $120^{\circ}$ in the mid-height of the specimens around the circumference without being placed in the overlapping region (Figure 3.3).

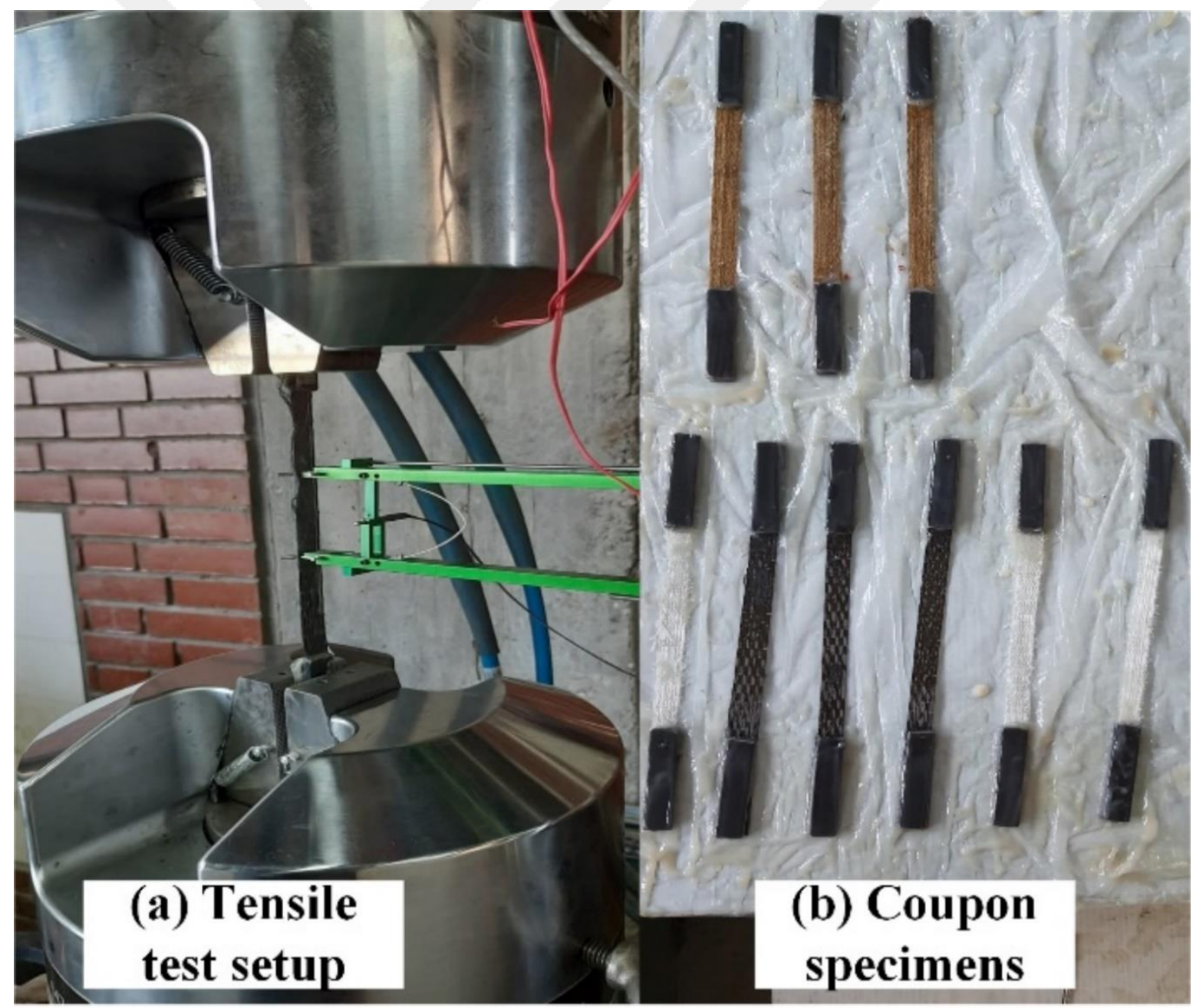

Picture 3.6 (a) Tensile test setup, (b) Tensile test specimens 
In some of the specimens, the hoop strains could not be appropriately measured due to a technical problem. Consequently, the hoop-rupture strain of the FRP jacket could not be obtained in these specimens. Therefore, they were replaced with new specimens of the same group such that the strain could be obtained at least in two specimens.

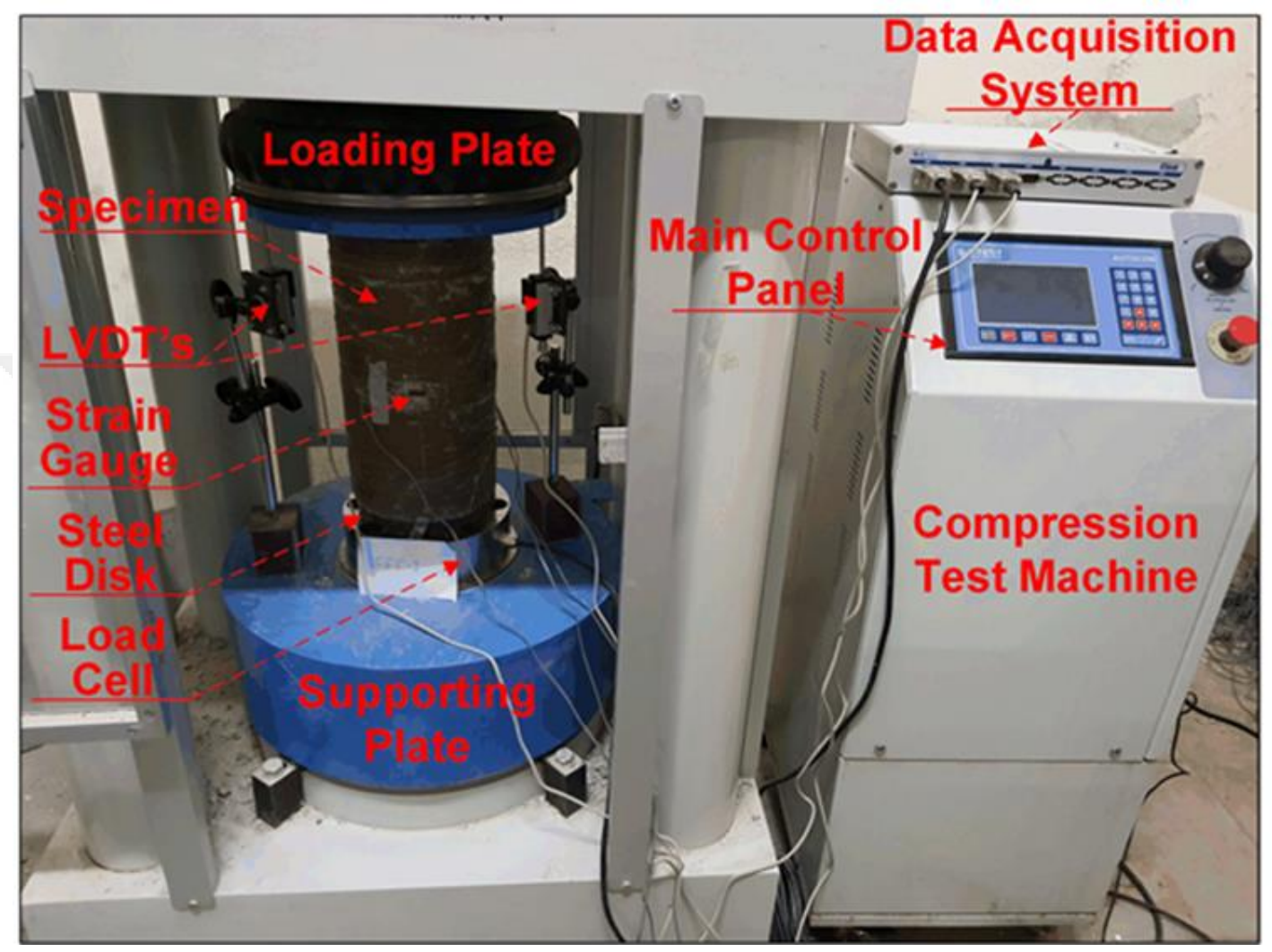

Picture 3.7 Compression test setup

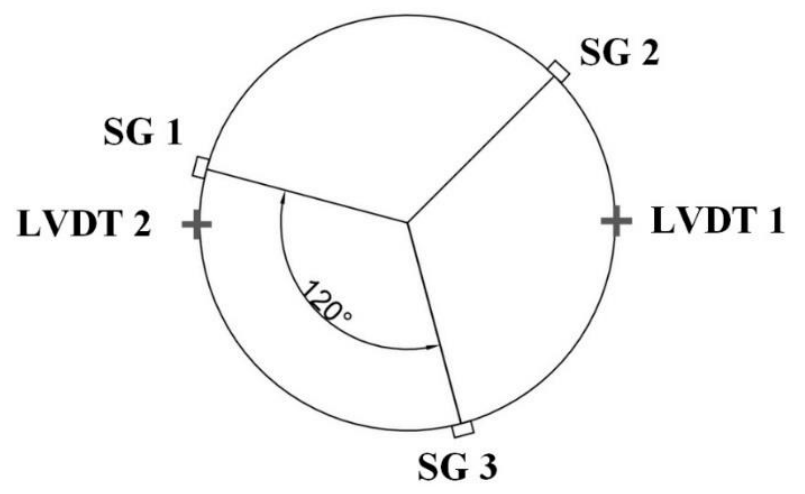

Figure 3.3 Planar view of strain gauges and LVDTs 


\section{RESULTS}

\subsection{Coupon Test Results}

For all specimens, the test data were analyzed to obtain tensile strength, rupture strain and modulus of elasticity. The coupon test results are presented in Table 4.1. The specimens which experienced premature failure were excluded from the results. The ultimate tensile strength of FFRP is extremely lower compared to CFRP and GFRP materials. The tensile strength of FFRP is approximately 7.6 and 2.0 times smaller than those of the CFRP and GFRP, respectively (Table 4.1).

Table 4.1 Tensile test results of coupon specimens

\begin{tabular}{|c|c|c|c|c|c|c|}
\hline $\begin{array}{l}\text { Coupon } \\
\text { Specimens }\end{array}$ & $\begin{array}{l}\text { Tensile } \\
\text { Strength } \\
\text { (MPa) }\end{array}$ & $\begin{array}{l}\text { (Avg.) } \\
\text { Tensile } \\
\text { Strength } \\
\text { (MPa) }\end{array}$ & $\begin{array}{l}\text { Rupture } \\
\text { Strain } \\
\text { Capacity } \\
(\%)\end{array}$ & $\begin{array}{l}\text { (Avg.) } \\
\text { Rupture } \\
\text { Strain } \\
\text { Capacity } \\
(\%)\end{array}$ & $\begin{array}{l}\text { Modulus } \\
\text { of } \\
\text { Elasticity } \\
\text { (GPa) }\end{array}$ & $\begin{array}{l}\text { Avg. Modulus } \\
\text { of Elasticity } \\
\text { (GPa) }\end{array}$ \\
\hline CFRP-1 & 1053.9 & \multirow{4}{*}{1301.9} & 1.35 & \multirow{4}{*}{1.48} & 81320 & \multirow{4}{*}{85110} \\
\hline CFRP-2 & 1671.1 & & 1.66 & & 87580 & \\
\hline CFRP-3 & 1126.6 & & 1.53 & & 68540 & \\
\hline CFRP-4 & 1356 & & 1.38 & & 103000 & \\
\hline GFRP-1 & 327.9 & \multirow{4}{*}{344.8} & 1.97 & \multirow{4}{*}{2.00} & 18600 & \multirow{4}{*}{17240} \\
\hline GFRP-2 & 358.2 & & 2.23 & & 17780 & \\
\hline GFRP-3 & 436.6 & & 2.12 & & 16900 & \\
\hline GFRP-4 & 256.5 & & 1.66 & & 15670 & \\
\hline FFRP-1 & 142.3 & \multirow{3}{*}{171.8} & 1.29 & \multirow{3}{*}{1.18} & 11800 & \multirow{3}{*}{18400} \\
\hline FFRP-2 & 187.6 & & 1.17 & & 19400 & \\
\hline FFRP-3 & 185.6 & & 1.07 & & 24000 & \\
\hline
\end{tabular}

However, the differences between the rupture strain capacities of all three materials are lower. The lowest rupture strain was experienced by FFRP, which was $41 \%$ lower than GFRP coupon specimens that attained the highest rupture strain values (i.e. 0.002) as shown in Figure 4.2. In the results of the test group with hybrid confinement, the FFRP will be termed as "low-strain fiber" due to their lower rupture strain capacity, and the other FRP (i.e. GFRP or CFRP) will be mentioned as "high-strain fiber". 
1400

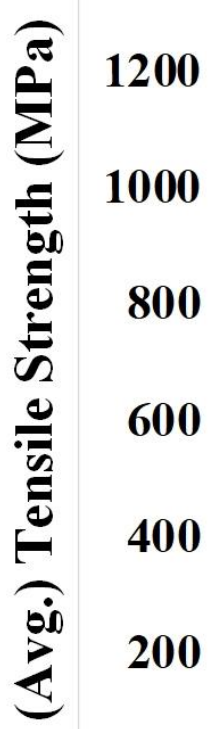

0

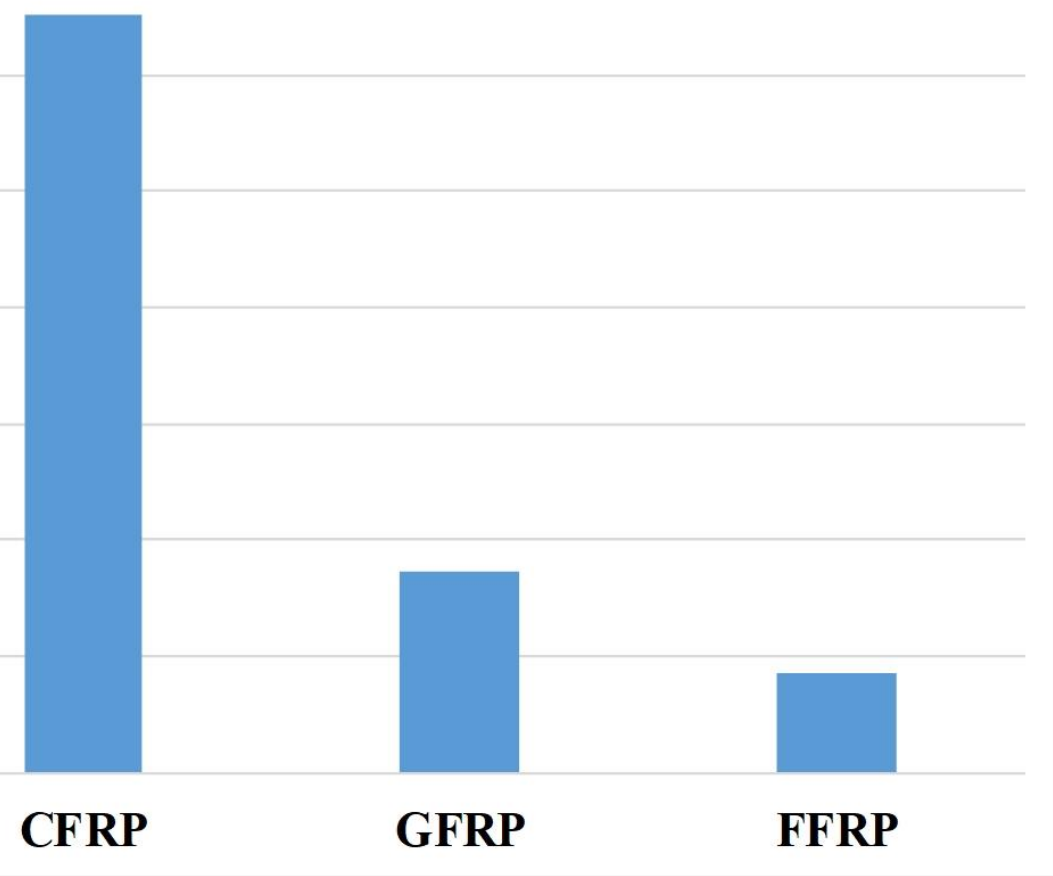

Coupon Specimens

Figure 4.1 Average tensile strength of coupon specimens
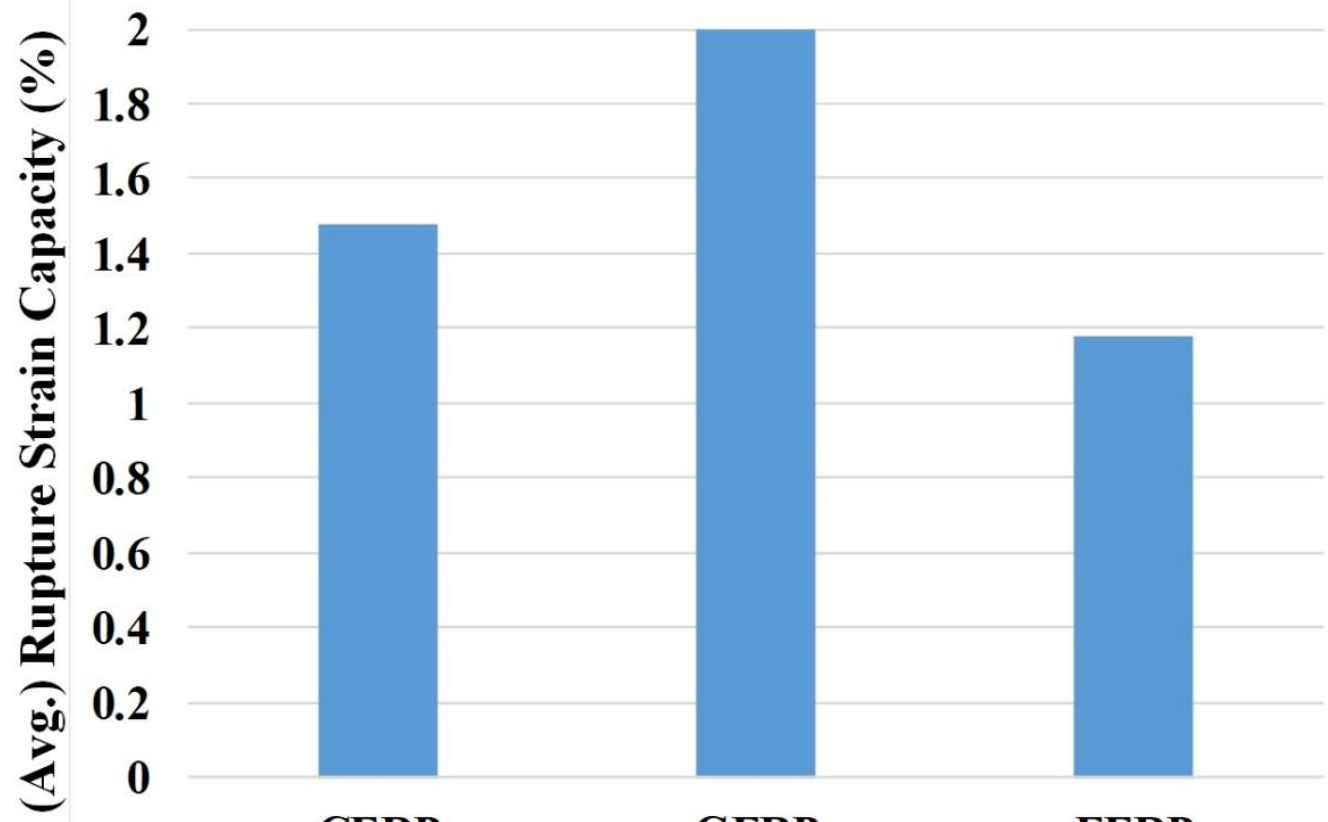

CFRP

GFRP

FFRP

\section{Coupon Specimens}

Figure 4.2 Average rupture strain capacity of coupon specimens 
The observed failure modes for the coupon specimens differ depending on the type of FRP. The failure location was arbitrary along the length of the specimens. As shown in Picture 4.1, the lateral or long splitting failure mode was observed in the FFRP coupon specimens. The tensile stress-strain graph of all FFRP coupon specimens are presented in Figure 4.3.

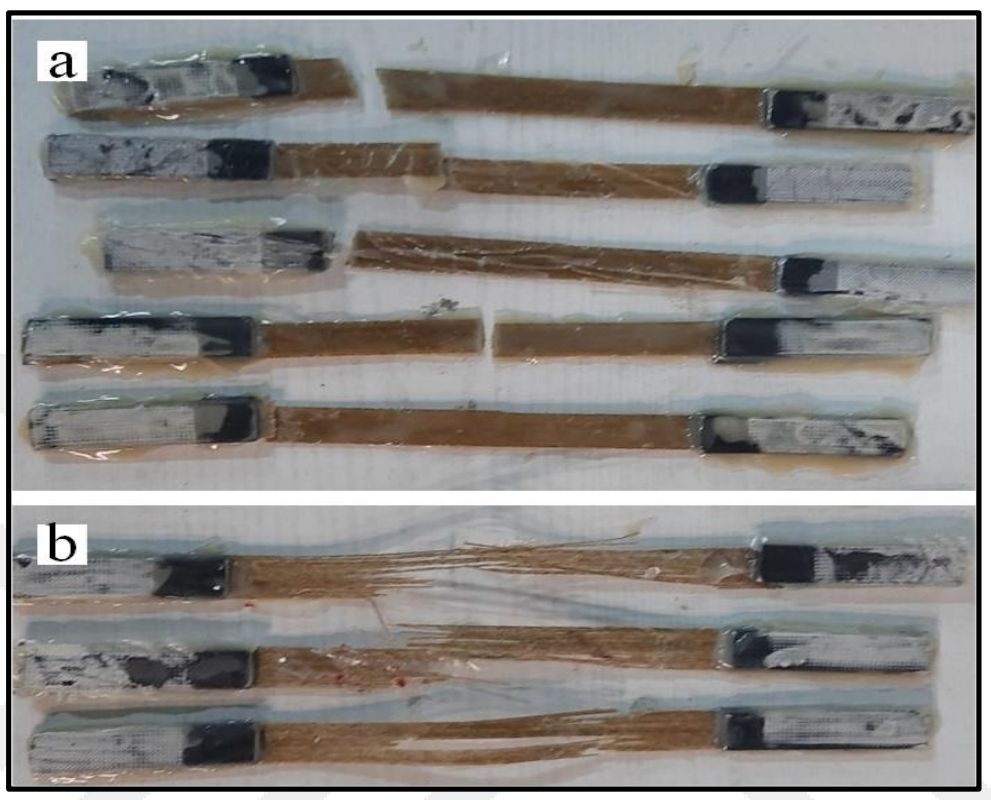

Picture 4.1 Failure mode of FFRP; (a) Lateral failure type, (b) Long splitting failure type

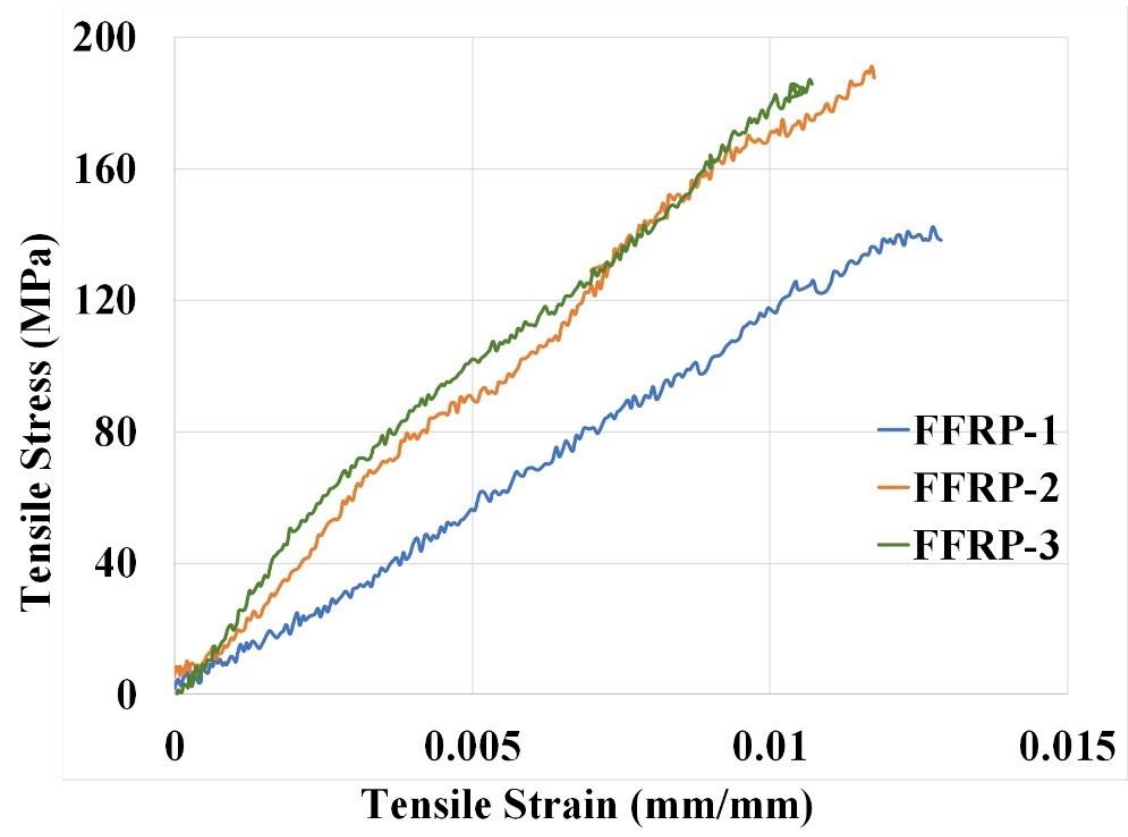

Figure 4.3 Tensile stress-strain of FFRP coupon specimens 
In the GFRP group, most of the specimens demonstrated long splitting failure mode where the tensile force split the fibers and generally initiate breaking from the edges of the specimens (Picture 4.2). The tensile stress-strain diagram of GFRP specimens are presented in Figure 4.4. GFRP materials provided higher strain capacity and more ductile behavior compared to FFRP and CFRP materials.

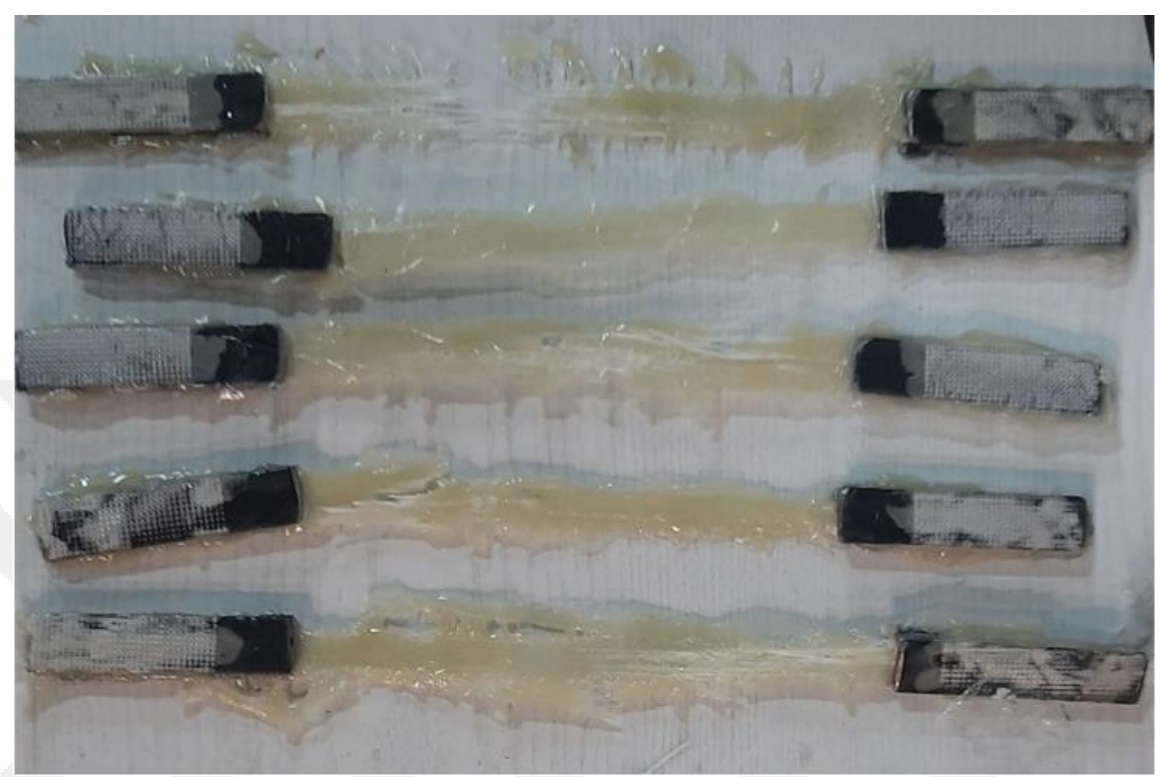

Picture 4.2 Failure mode of GFRP

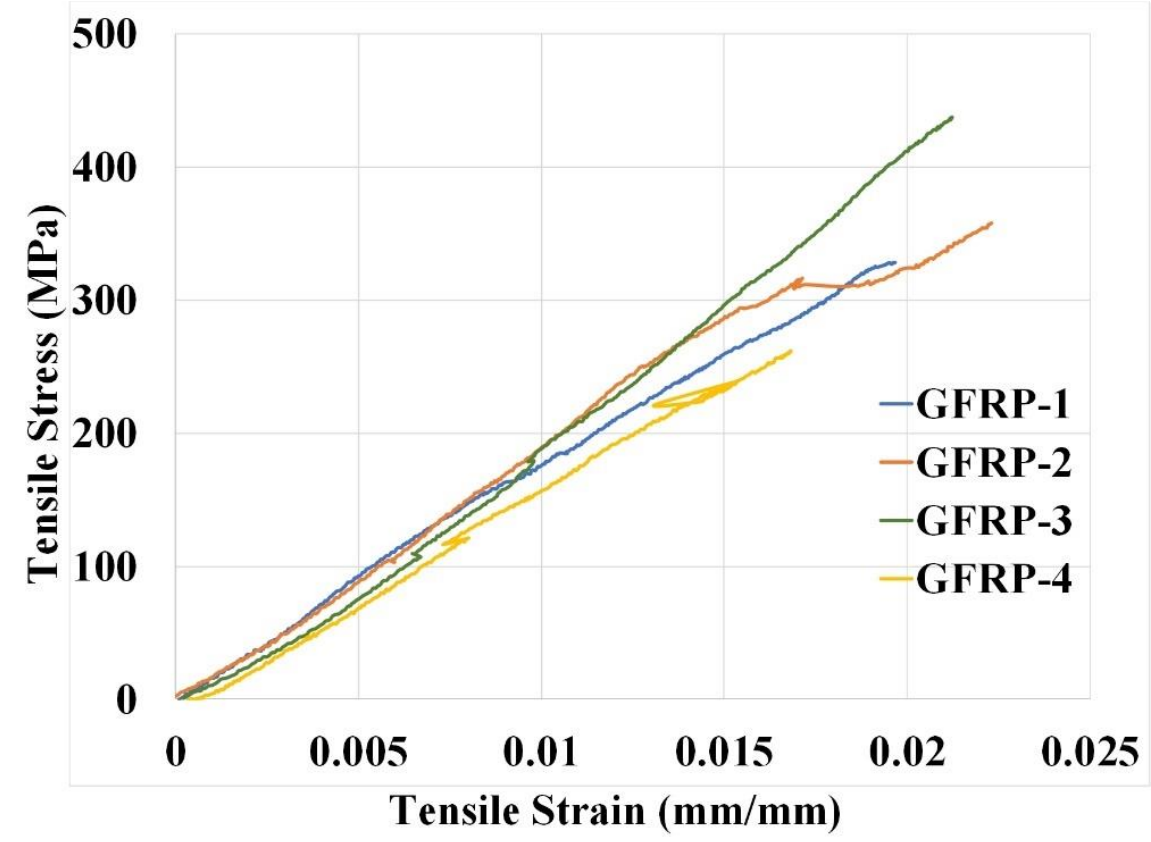

Figure 4.4 Tensile stress-strain of GFRP 
In the CFRP coupon specimens, an explosive and multi-mode failure was observed, as shown in Picture 4.3. This may be due to their high strength capacity, which causes sudden and brittle failure mechanisms. CFRP materials demonstrated high tensile strength compared to GFRP and FFRP materials.

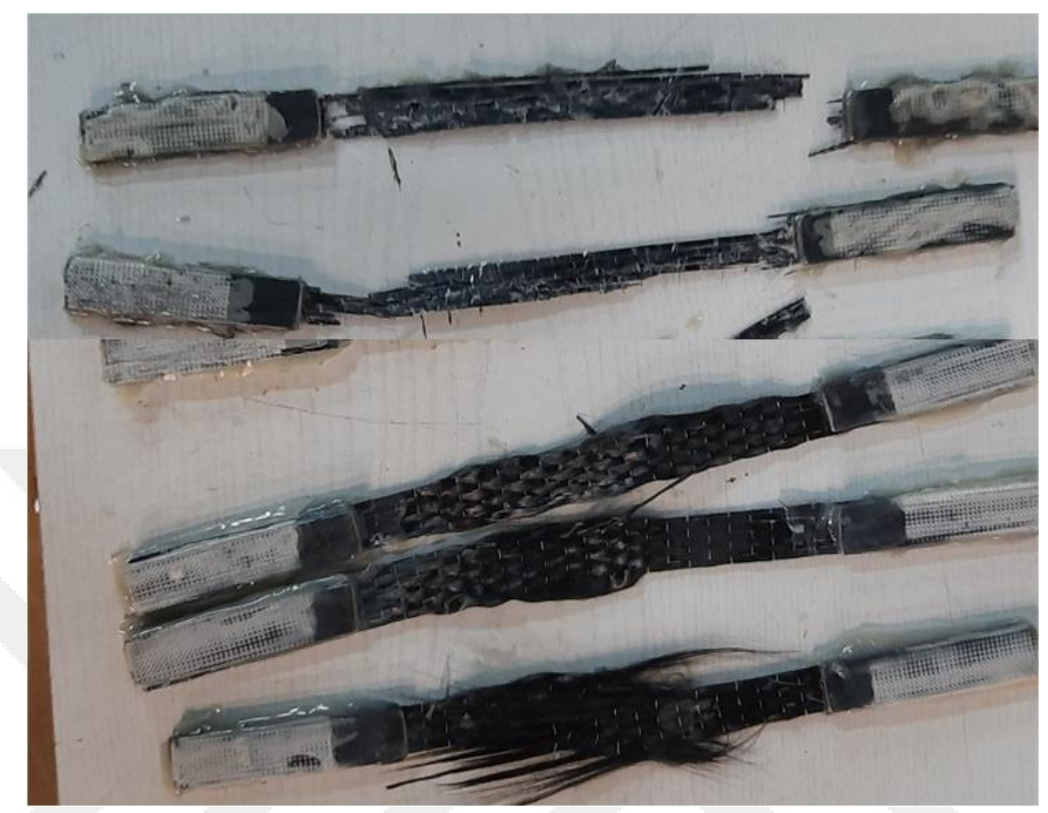

Picture 4.3 Failure mode of CFRP

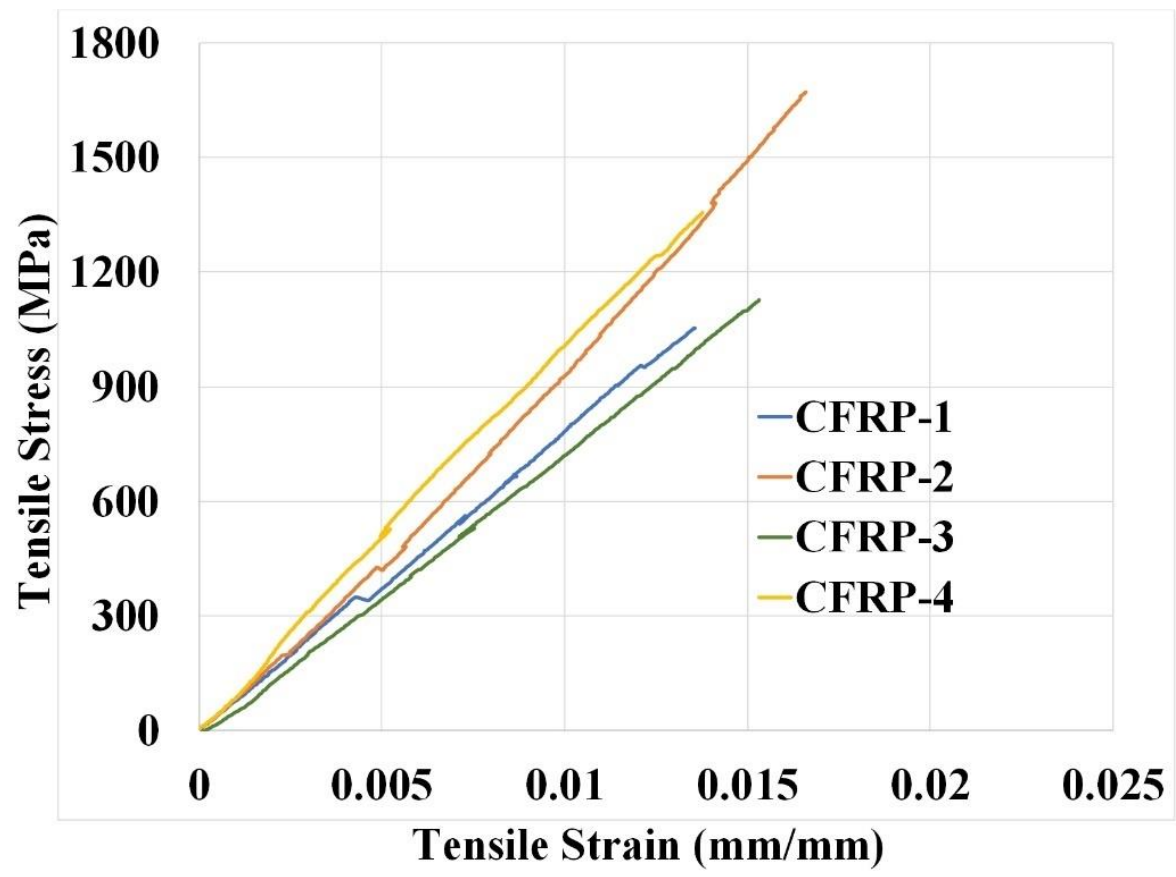

Figure 4.5 Tensile stress-strain of CFRP 
For comparison purpose, all stress-strain diagrams of CFRP, GFRP and FFRP materials are presented in Figure 4.6.

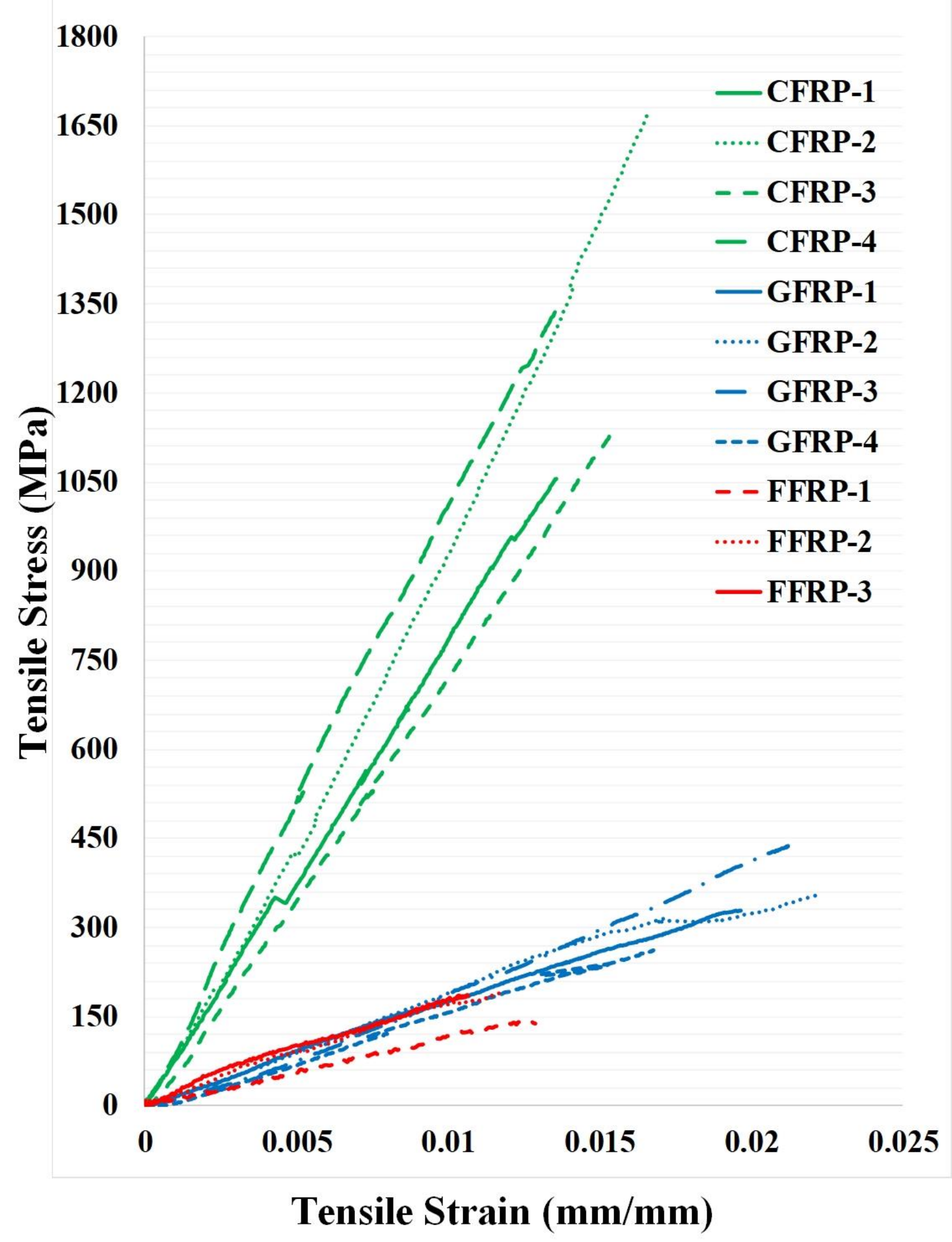

Figure 4.6 Comparison of Tensile stress-strain diagram of CFRP, GFRP and FFRP 


\subsection{Failure Modes of FRP Confined Specimens}

The failure mode of FFRP confined specimens are presented in Picture 4.4. The FFRP confined specimens experienced a very sudden explosive failure with a sound arising from FRP rupture. In all cases, the FFRP jacket ruptured vertically along the height of the specimens, as shown in Picture 4.4.a, b, and c. Due to the gradual crushing of concrete, shear cone formation took place in the FFRP confined group. In the hybrid groups where the specimens were confined with an inner layer of FFRP and the outer layer of GFRP, the confining jacket's failure was more localized, and no sudden explosive failure was observed. Additionally, the rupture of the confining jacket was inclined (Picture 4.5). This may be related to the restraining effect of the outer GFRP sheet that led to the formation of shear stresses on the inner FFRP fabric. Both materials' rupture took place simultaneously, and no slippage between FRP sheets or sequential failure was observed. In the FFC-50 test group, the FFRP and CFRP jackets could resist the lateral expansion of core concrete until a certain level, after which the failure of FFRP occurred between CFRP strips. This failure was more prolonged without being ruptured suddenly. No damage was observed on the CFRP strips.

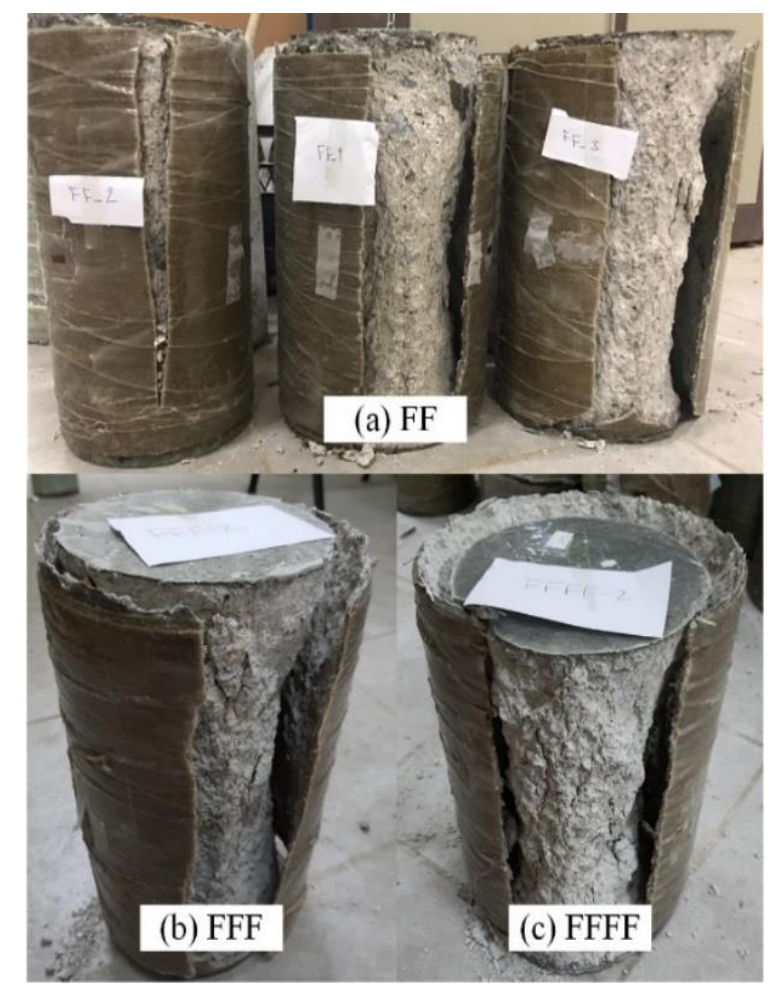

Picture 4.4 Failure mode for FFRP groups 


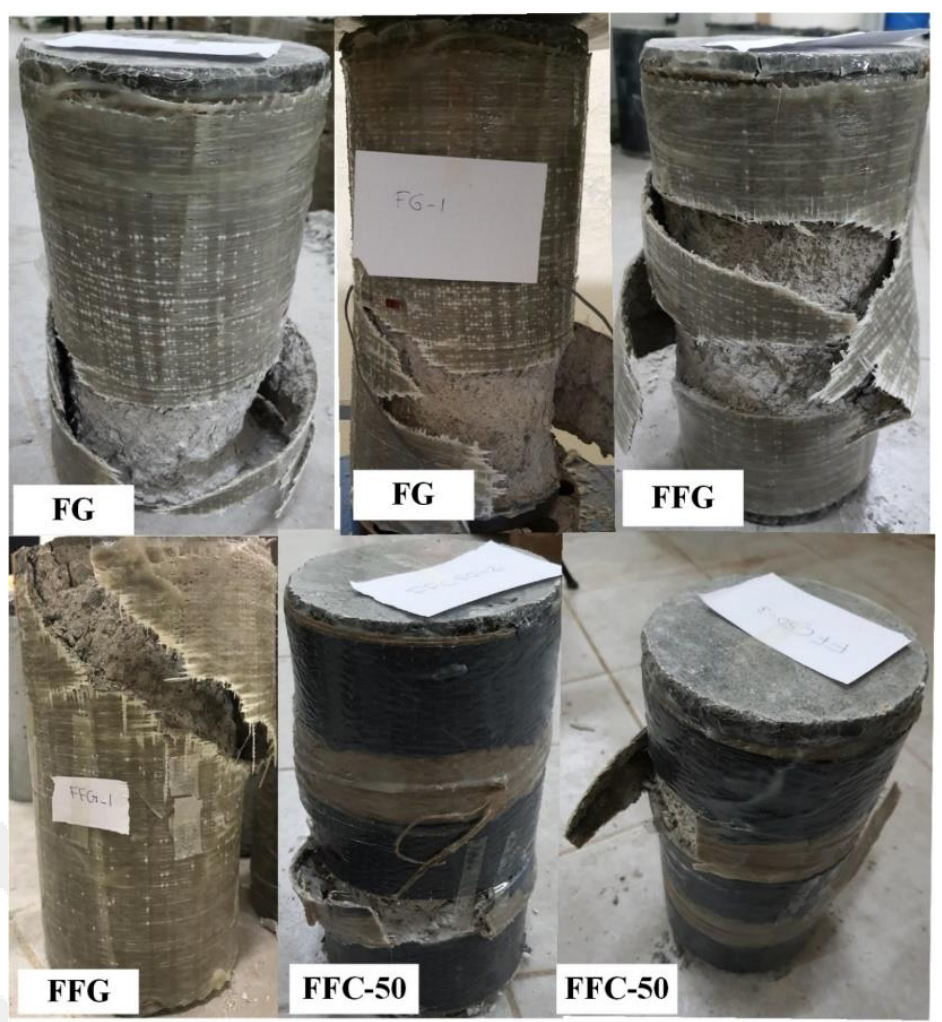

Picture 4.5 Failure mode for hybrid groups

\subsection{Axial Stress-Strain Response of the Specimens}

The axial compressive stress and strain of the FRP confined concrete specimens are calculated from the measurements of the load cell and average displacement values of the two LVDT's, respectively. The results of stress-strain diagrams are shown in Figure 4.7-4.11. The ultimate compressive strength of the specimens $\left(f_{c o}\right.$ for the unconfined reference and $f_{c c}$ for the confined specimens) and axial strain capacities $\left(\varepsilon_{\mathrm{cu}}\right)$ are summarized in Table 4.2 with the strength- and strain-enhancement ratios $\left(\mathrm{f}_{\mathrm{cc}} / \mathrm{f}_{\mathrm{co}}\right.$ and $\left.\varepsilon_{\mathrm{cu}} / \varepsilon_{\mathrm{co}}\right)$. In these results, the average concrete strength, $\mathrm{f}_{\mathrm{co}}$, and corresponding axial strain, $\varepsilon_{\mathrm{co}}$ of the unconfined reference specimens were considered as $10.9 \mathrm{MPa}$ and 0.0032, respectively. The FRP hoop-rupture strains $\left(\varepsilon_{\mathrm{h}, \text { rupt }}\right)$ which are obtained as the average of the measurements of strain gauges corresponding to the failure, are also provided in Table 4.2.

The ultimate confinement ratios $\left(\mathrm{f}_{\mathrm{lu}} / \mathrm{f}_{\mathrm{co}}\right)$ provided by FRP materials are calculated by Eqn. 1 by assuming that the confining effect is uniformly distributed over the cross-section. These ratios are also presented in Table 4.2. 
$\frac{f_{l u}}{f_{c o}}=\frac{2 \times E_{f} \times t_{f} \times \varepsilon_{f u}}{D \times f_{c o}}$

In Eqn.1, $\mathrm{E}_{\mathrm{f}}, \mathrm{t}_{\mathrm{f}}$, and $\varepsilon_{\mathrm{fu}}$ represent the modulus of elasticity, thickness, and tensile strain of FRP, respectively. D is the diameter of the circular concrete cross-section. Normally, the theoretical value of $f_{l u}$, which the manufacturer provides, does not accurately represent the actual ultimate confining pressure of the FRP materials (Pessiki et al., 2001; Lam and Teng, 2004; Ozbakkaloglu and Oehlers, 2008). The ultimate hoop strain $\left(\varepsilon_{\mathrm{h}, \text { rup }}\right)$ reached in the FRP jacket is often smaller than the ultimate tensile strain of fiber $\left(\varepsilon_{\mathrm{fu}}\right)$. Therefore, it is mandatory to define a strain-reduction factor, $\mathrm{k}_{\varepsilon}$ as given in Eqn.2 in order to calculate the actual confining pressure, $\mathrm{f}_{\mathrm{lu}, \mathrm{a}}(\mathrm{Eqn} .3)$.

$\mathrm{k}_{\varepsilon}=\frac{\varepsilon_{\mathrm{h}, \mathrm{rup}}}{\varepsilon_{\mathrm{fu}}}<1.0$

$\mathrm{f}_{\mathrm{lu}, \mathrm{a}}=\frac{2 \times \mathrm{E}_{\mathrm{f}} \times \mathrm{t}_{\mathrm{f}} \times \mathrm{k}_{\varepsilon} \times \varepsilon_{\mathrm{fu}}}{\mathrm{D}}$

In the GFRP -FFRP hybrid groups, the ultimate confinement pressure was calculated as the summation of the confinement pressure provided by each material. This assumption was based on the observed simultaneous rupture of all FRP sheets of hybrid confinement. However, no such calculation was performed in the FFC-50 test group since the specimens were partially confined with CFRP. In some of the test specimens, the hoop rupture strain could not be obtained; hence, the ultimate confining pressure in these specimens was calculated using the average values from the remaining specimens of the same group. As previously mentioned, the ultimate hoop strain $\left(\varepsilon_{\mathrm{h}, \text { rup }}\right)$ reached in the FRP jacket is often smaller than the ultimate tensile strain of FRP $\left(\varepsilon_{\mathrm{fu}}\right)$, which may either be obtained by tensile coupon tests or provided by the manufacturer. In this study, the strain reduction factors were estimated for each specimen using the strain values obtained by the coupon test $\left(\varepsilon_{\mathrm{fu}}\right)$ and presented in Table 4.2. In the FG and FFG hybrid test groups, $\mathrm{k}_{\varepsilon}$ was calculated by considering the coupon test results of both inner and outer FRP and shown separately in Table 4.2 . 
Table 4.2 Details of the specimens and main test results

\begin{tabular}{|c|c|c|c|c|c|c|c|c|c|c|c|c|}
\hline Specimen & $\begin{array}{l}\mathbf{f}_{\mathrm{co}} \text { or } \mathbf{f}_{\mathrm{cc}} \\
(\mathrm{MPa})\end{array}$ & $\begin{array}{l}\varepsilon_{\mathrm{cu}} \\
(\%)\end{array}$ & $\begin{array}{l}\varepsilon_{\text {h,rupt }} \\
\text { Avg. } \\
\text { (\%) }\end{array}$ & $\begin{array}{l}\varepsilon_{\mathrm{h}, \text { rupt }} \\
\text { Avg. } \\
(\%)\end{array}$ & $\mathbf{k}_{\varepsilon}$ & $\begin{array}{l}\mathbf{k}_{\varepsilon} \\
\text { Avg. } \\
-\end{array}$ & $\begin{array}{l}\mathbf{f}_{\mathrm{lu}} / \mathbf{f}_{\mathrm{co}} \\
-\end{array}$ & $\begin{array}{l}\mathbf{f}_{\mathrm{lu}} / \mathbf{f}_{\mathrm{co}} \\
\text { Avg. } \\
-\end{array}$ & $\begin{array}{l}\mathbf{f}_{\mathrm{cc}} / \mathbf{f}_{\mathrm{co}} \\
-\end{array}$ & $\begin{array}{l}\mathbf{f}_{c c} / f_{c o} \\
\text { Avg. } \\
-\end{array}$ & $\begin{array}{l}\varepsilon_{\mathrm{cu}} / \varepsilon_{\mathrm{co}} \\
-\end{array}$ & $\begin{array}{l}\varepsilon_{\mathrm{cu}} / \varepsilon_{\mathrm{co}} \\
\mathrm{Avg} . \\
-\end{array}$ \\
\hline REF-1 & 11.2 & - & - & & - & & - & & - & & - & \\
\hline REF-2 & 11.5 & - & - & - & - & & - & - & - & - & - & - \\
\hline REF-3 & 10.1 & - & - & & - & & - & & - & & - & \\
\hline FF-1 & 14.6 & 1.9 & - & & - & & 0.10 & & 1.34 & & 5.85 & \\
\hline FF-2 & 13.4 & 1.4 & 1.0 & 09 & 0.85 & & 0.11 & & 1.23 & & 4.48 & \\
\hline FF-3 & 15.8 & 1.9 & - & 0.9 & - & 0.19 & 0.10 & 0.10 & 1.45 & 1.34 & 6.01 & 5.02 \\
\hline FF-4 & 14.7 & 1.2 & 0.9 & & 0.74 & & 0.09 & & 1.35 & & 3.74 & \\
\hline FFF-1 & 18.9 & 1.7 & 1.5 & & 1.23 & & 0.23 & & 1.73 & & 5.26 & \\
\hline FFF-2 & 18.3 & 1.7 & 1.4 & 1.4 & 1.15 & 1.19 & 0.22 & 0.23 & 1.67 & 1.74 & 5.43 & 5.86 \\
\hline FFF-3 & 19.7 & 2.2 & - & & - & & 0.23 & & 1.80 & & 6.90 & \\
\hline FFFF-1 & 20.2 & 2.0 & 1.2 & & 1.05 & & 0.27 & & 1.85 & & 6.43 & \\
\hline FFFF-2 & 22.0 & 3.0 & 1.6 & 1.4 & 1.39 & 1.20 & 0.35 & 0.31 & 2.02 & 1.89 & 9.56 & 7.65 \\
\hline FFFF-3 & 19.7 & 2.2 & 1.4 & & 1.17 & & 0.30 & & 1.81 & & 6.97 & \\
\hline FG-1 & 20.2 & 3.0 & 1.1 & & $0.93^{1} ; 0.55^{2}$ & & 0.19 & & 1.85 & & 9.46 & \\
\hline FG-2 & 21.1 & 2.6 & 1.1 & 1.2 & $0.89^{1} ; 0.53^{2}$ & $0.96^{\prime}$ & 0.19 & 0.20 & 1.93 & 1.98 & 8.14 & 8.96 \\
\hline FG-3 & 23.6 & 2.9 & 1.3 & & $1.11^{1} ; 0.65^{2}$ & & 0.23 & & 2.16 & & 9.28 & \\
\hline FFG-1 & 23.1 & 2.6 & - & & - & & 0.36 & & 2.12 & & 8.35 & \\
\hline FFG-2 & 26.0 & 3.1 & - & & - & $1.33^{1}$ & 0.36 & & 2.38 & & 9.85 & \\
\hline FFG-3 & 25.7 & 3.2 & 1.7 & 1.6 & $1.42^{1} ; 0.84^{2}$ & $0.78^{2}$ & 0.39 & 0.36 & 2.36 & 2.26 & 10.25 & 8.94 \\
\hline FFG-4 & 24.0 & 2.3 & 1.5 & & $1.23^{1} ; 0.73^{2}$ & & 0.33 & & 2.20 & & 7.33 & \\
\hline FFC-50-1 & 25.7 & 2.6 & 0.8 & & - & & - & & 2.35 & & 8.17 & \\
\hline FFC-50-2 & 26.8 & 3.6 & 1.1 & 0.9 & - & - & - & - & 2.46 & 2.35 & 11.48 & 9.57 \\
\hline FFC-50-3 & 24.4 & 2.9 & 0.9 & & - & & - & & 2.23 & & 9.06 & \\
\hline
\end{tabular}

${ }_{2} \varepsilon_{\mathrm{fu}}$ was assumed as the strain capacity of the FFRP

${ }^{2} \varepsilon f u$ was assumed as the strain capacity of the GFRP 


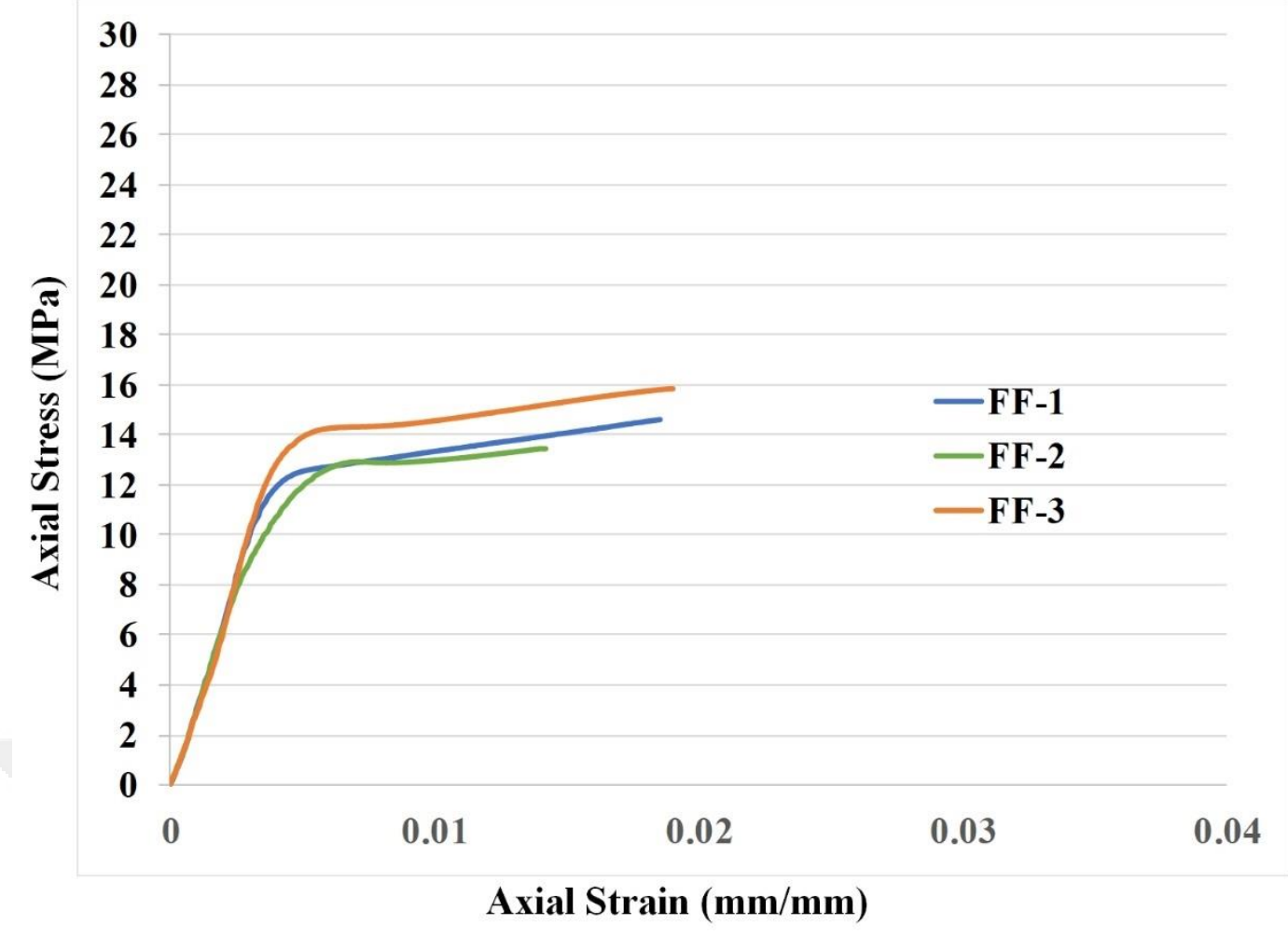

Figure 4.7 Axial stress-strain diagrams of FF group

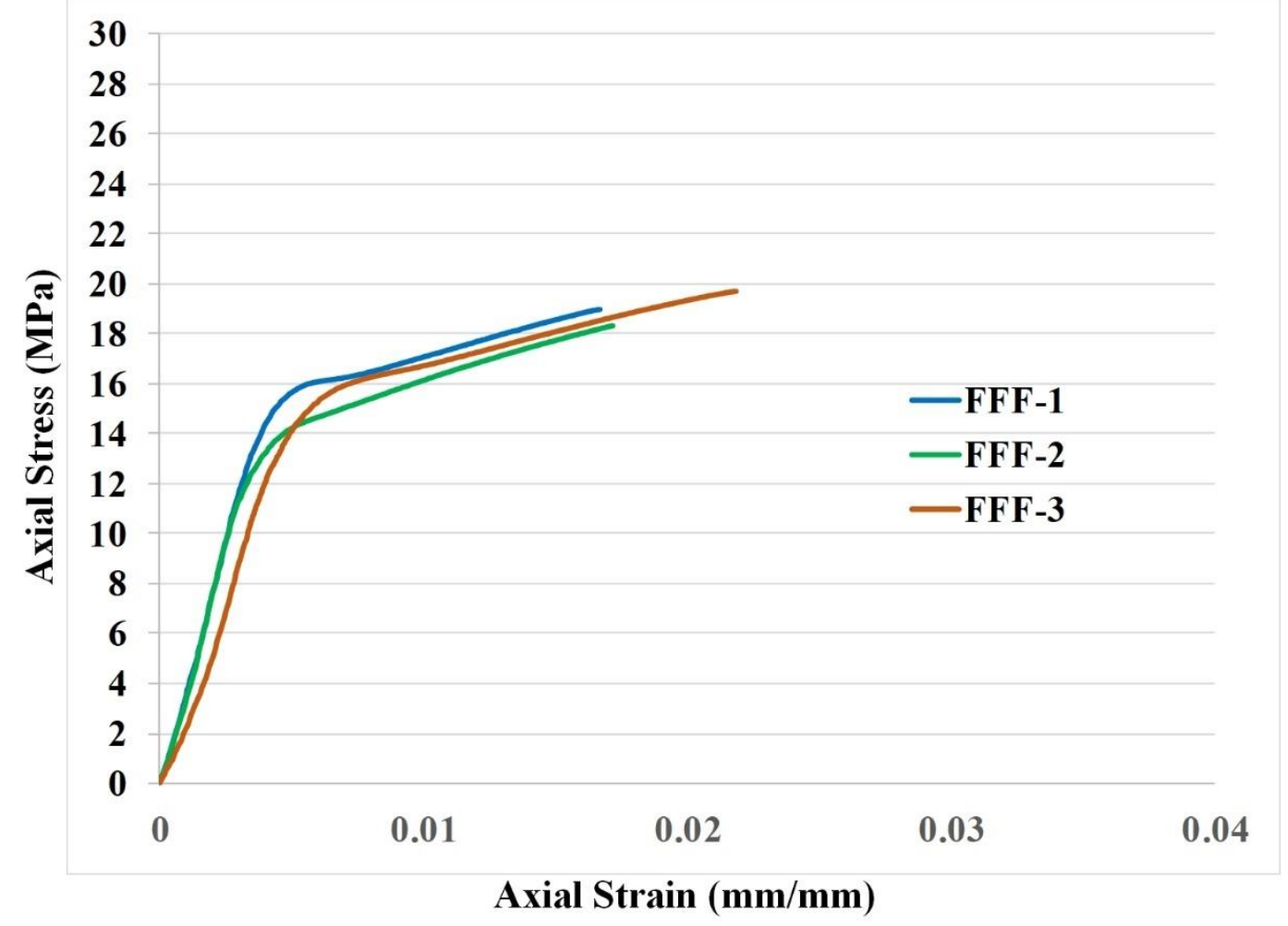

Figure 4.8 Axial stress-strain diagrams of FFF group 


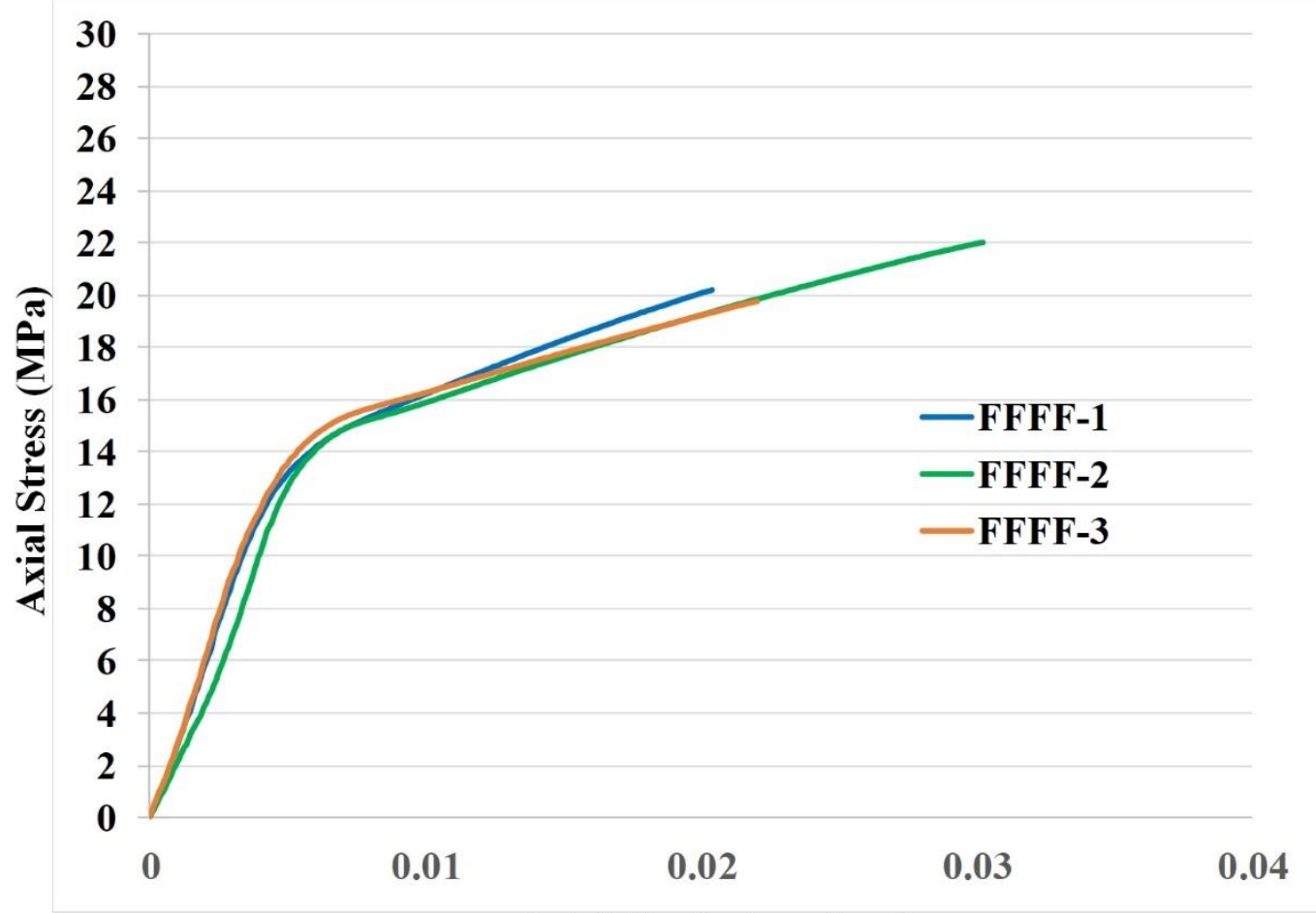

Axial Strain (mm/mm)

Figure 4.9 Axial stress-strain diagrams FFFF group

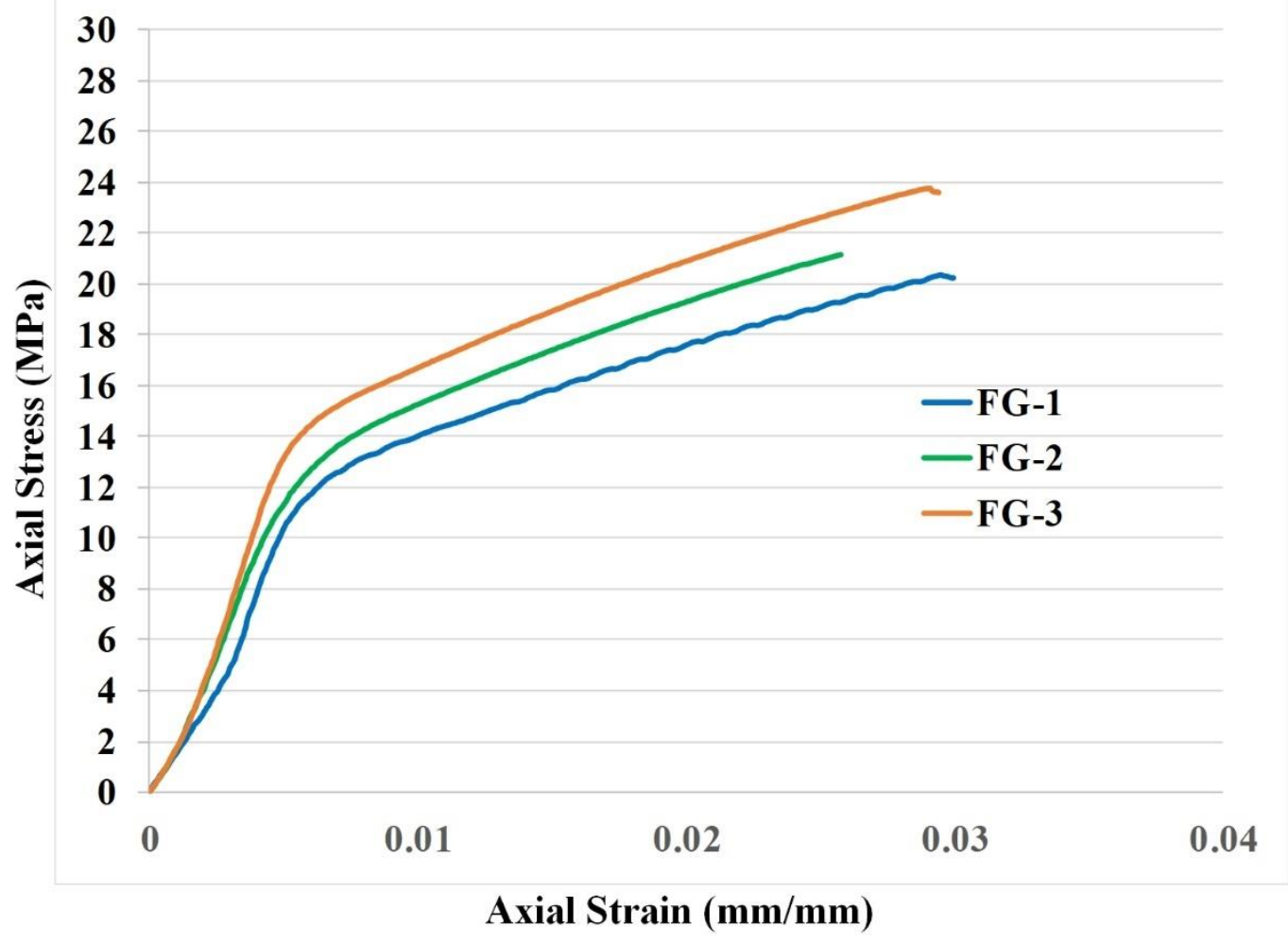

Figure 4.10 Axial stress-strain diagrams FG group 


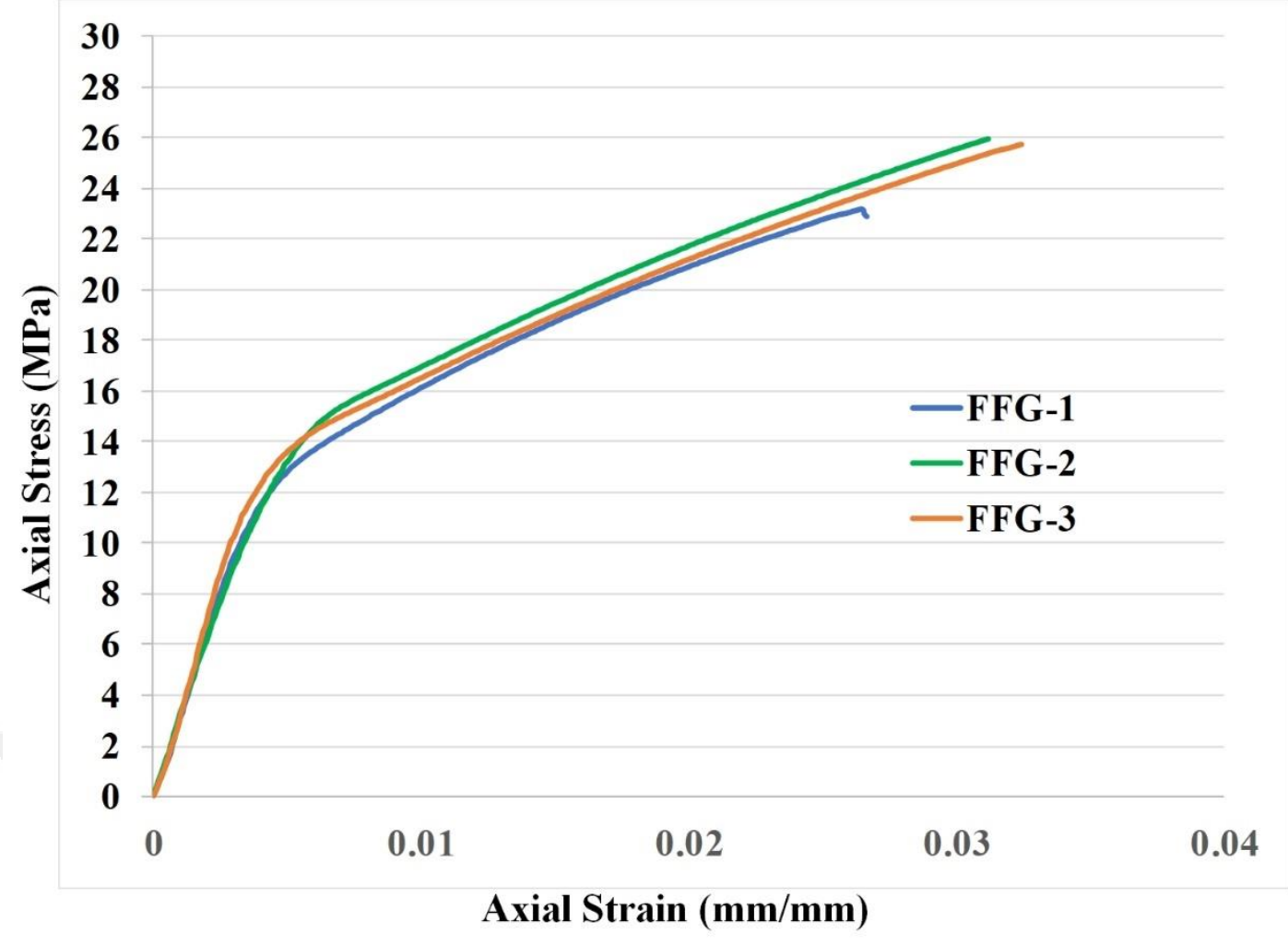

Figure 4.11 Axial stress-strain diagrams FFG

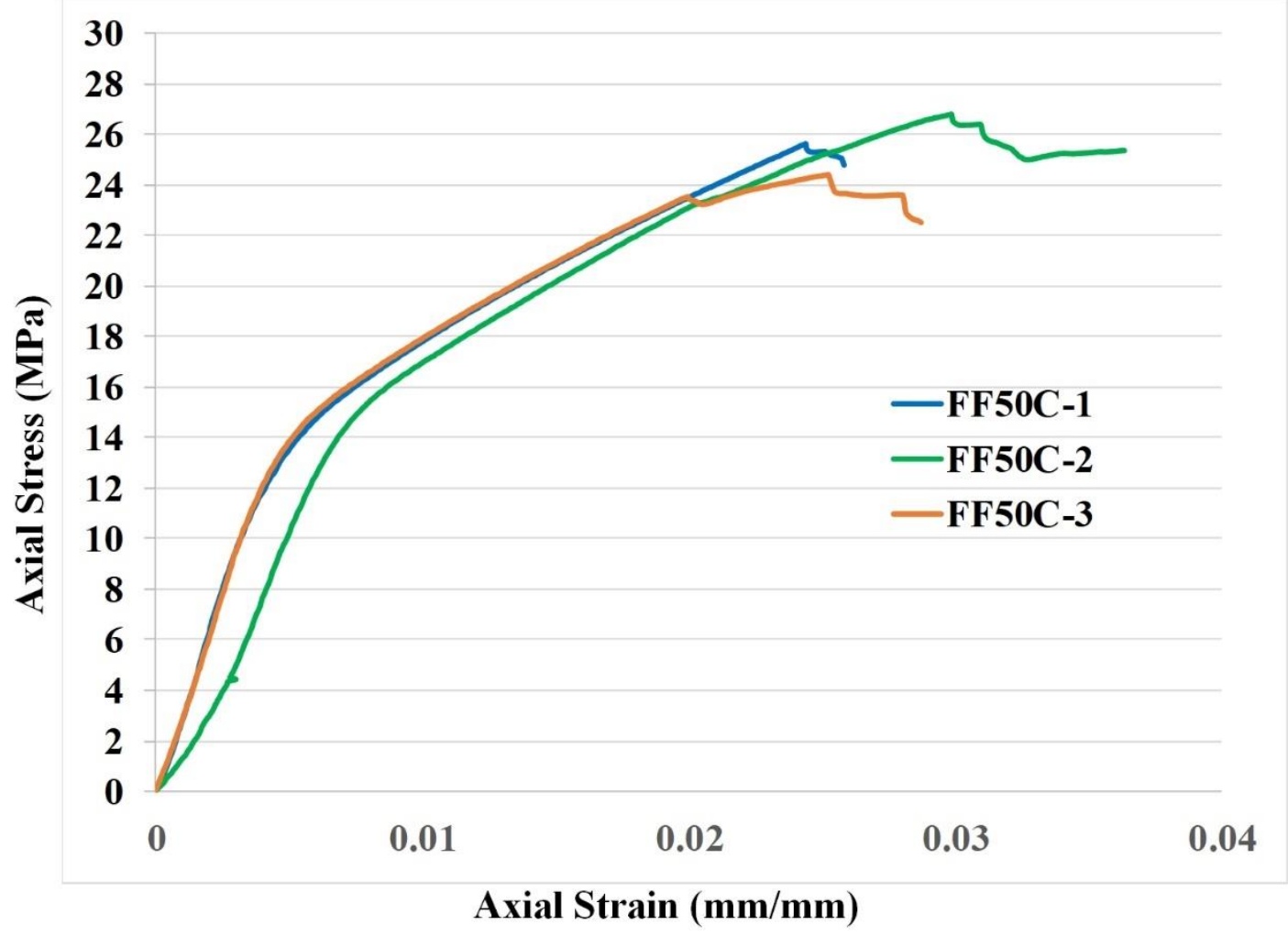

Figure 4.12 Axial stress-strain diagrams FFC-50 


\subsection{Effects of Applied Confinement on the Stress-Strain Curves}

In all confined specimens, the stress-strain curves are composed of two portions. The first ascending portion is terminated at a point where the confinement was activated at a stress level that is close to unconfined concrete strength (Figure 4.13). The second ascending portion with a lower slope initiates at the same point and designates that all the FRP jackets could provide a sufficient confinement pressure.

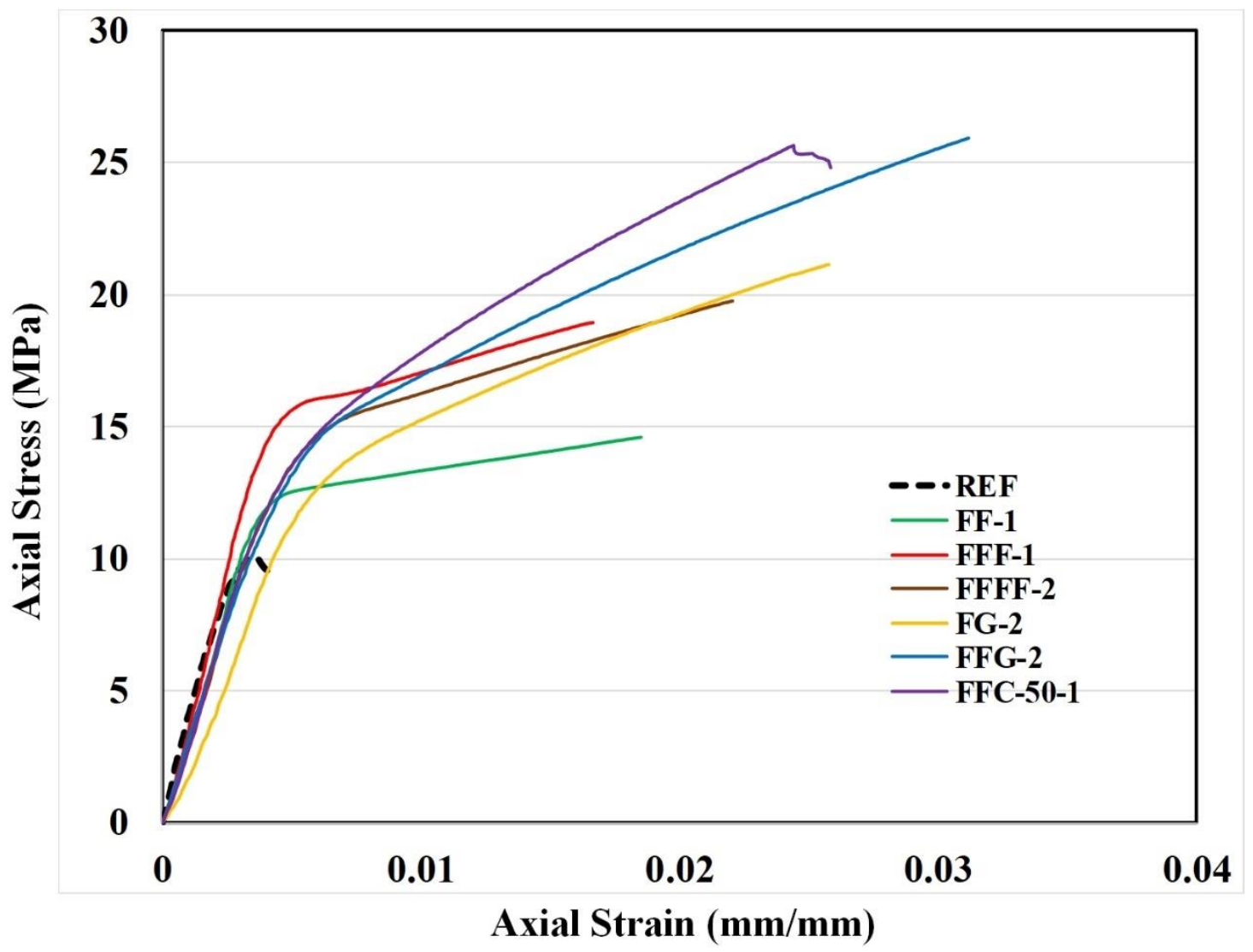

Figure 4.13 Stress-strain curves of all specimens

The second portion of the stress-strain graph is influenced by the number of confining layers and the type of confinement (i.e. FFRP alone or hybrid). While in the case of two layers of FFRP confinement, the slope is slightly flat and increases by the number of confining layers. In the hybrid confined specimens, the contribution of glass and carbon FRP resulted in a further increase in this slope (Figure 4.13). In the stress-strain curves of the FFC50 test group, a rippled part is observed, as shown in Figure 4.13. This is due to the gradual 
rupture of FFRP layers in between CFRP strips. The enhancement in the $\mathrm{f}_{\mathrm{cc}} / \mathrm{f}_{\mathrm{co}}$ and $\boldsymbol{\varepsilon}_{\mathrm{cu}} / \boldsymbol{\varepsilon}_{\mathrm{co}}$ ratios are presented in Figure 4.14 and Figure 4.15.

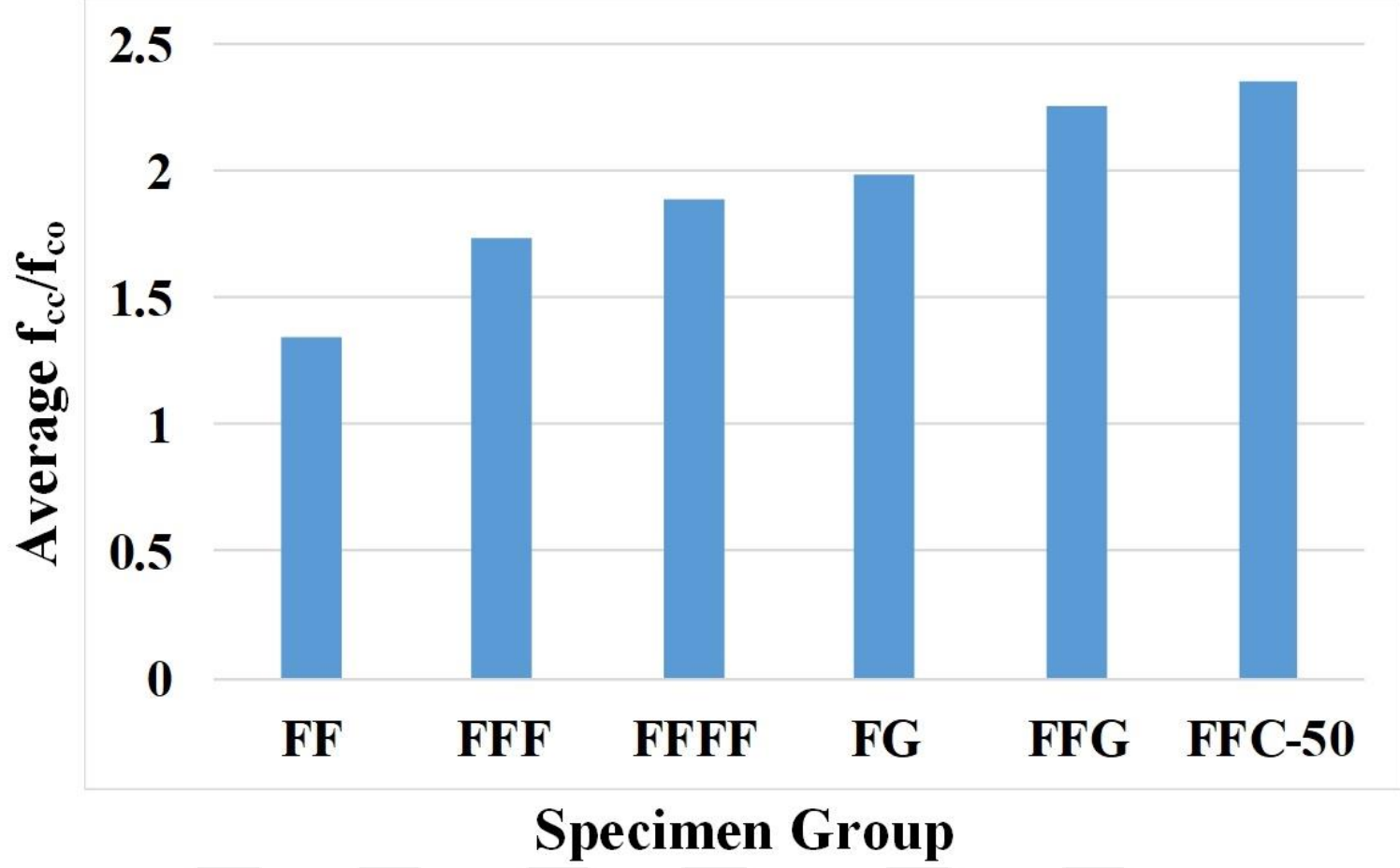

Figure 4.14 The enhancement in the $\mathrm{f}_{\mathrm{cc}} / \mathrm{f}_{\mathrm{co}}$ ratio

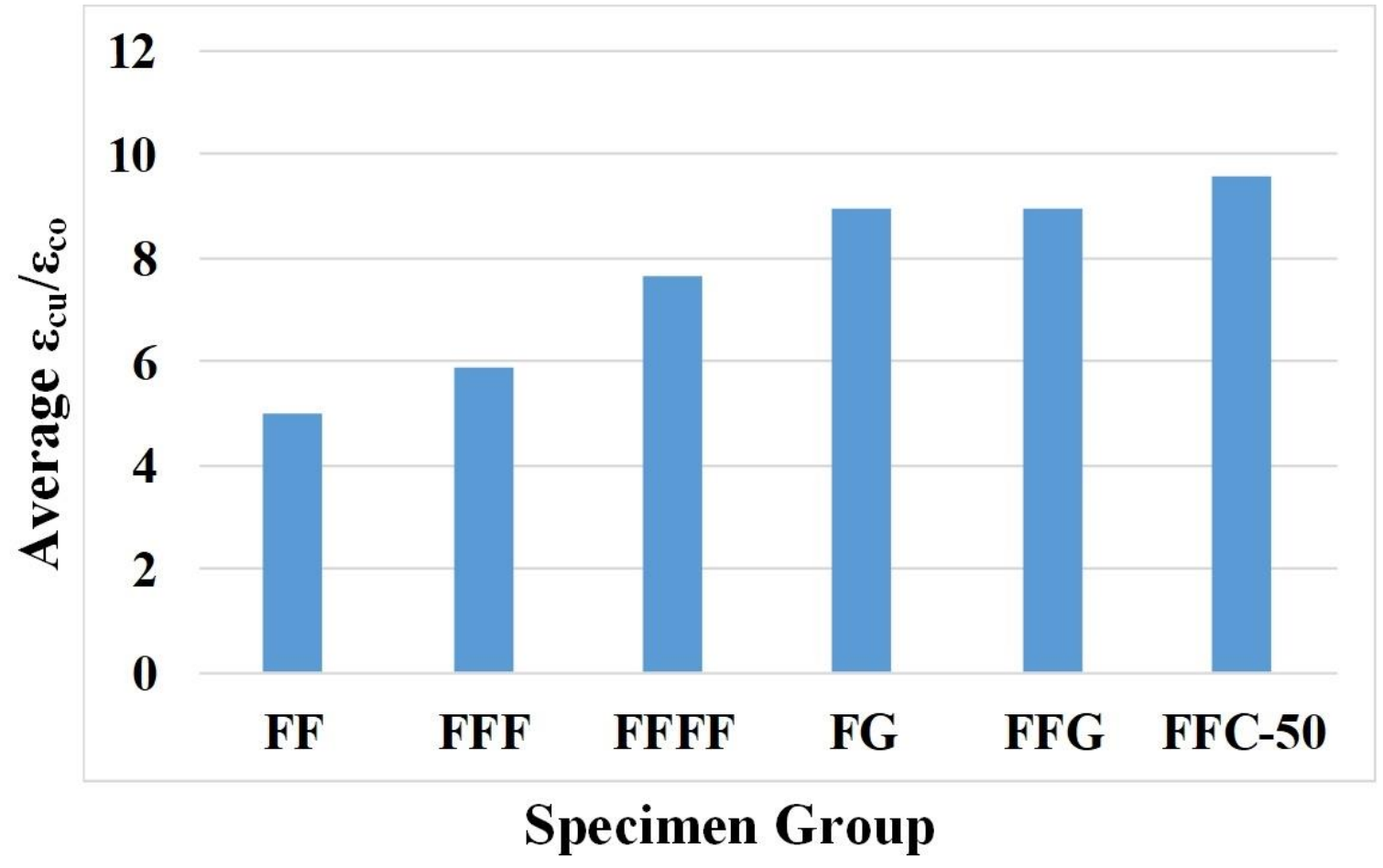

Figure 4.15 The enhancement in the $\varepsilon_{\mathrm{cu}} / \varepsilon_{\mathrm{co}}$ ratio 


\section{COMPARISON WITH EXISTING MODELS}

\subsection{General information}

In this chapter, some of the well-known existing models available in the literature are assessed by a comparison with the compressive behavior provided by FFRP in this study. The general compressive behavior of FRP confined concrete is introduced first. Then, the design models (Lam and Teng, 2003; We et al., 2008 and TEC-2018) that are used for comparison purpose are briefly explained. Finally, the experimental results of FRP confined concrete specimens are compared with the design models.

\subsection{Compressive Behavior of Confined and Unconfined Concrete}

The lateral confinement provided by an FRP jacket on the concrete core is a passive type. The FRP confinement is not active and the axial response of confined concrete is similar to that of unconfined concrete up to a stress level of approximately $0.90 \mathrm{f}_{\mathrm{co}}$. As the axial stress increases beyond that level, the lateral strain starts to increase, and concrete expands laterally. When concrete is confined with FRP and subject to axial compression, the FRP jacket exerts a uniform pressure in the hoop direction to avoid the expansion of concrete (Figure 5.1). As a reaction, tensile stresses form on the fibers of FRP along the hoop direction. The confining pressure increases with the lateral strain of concrete and is related to the amount, strength, and radius of the concrete core (Lam and Teng, 2003).

The general trend of the stress-strain diagram of unconfined, insufficiently confined, and sufficiently confined concrete is presented in Figure 5.2. The trend of the stress-strain diagram depends on the level of confinement. After reaching the first peak, the strength may decrease, remain almost constant or increase continuously until the ultimate point where the concrete crushes (Ozbakkaloglu and Akin., 2012). 

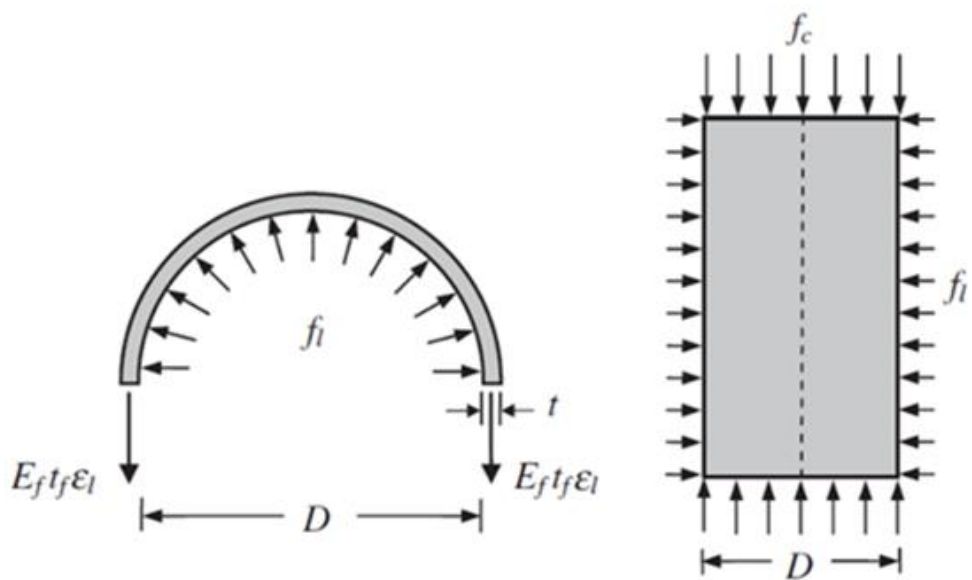

Figure 5.1 The confining action of FRP-confined concrete (Ozbakkaloglu et al., 2013)

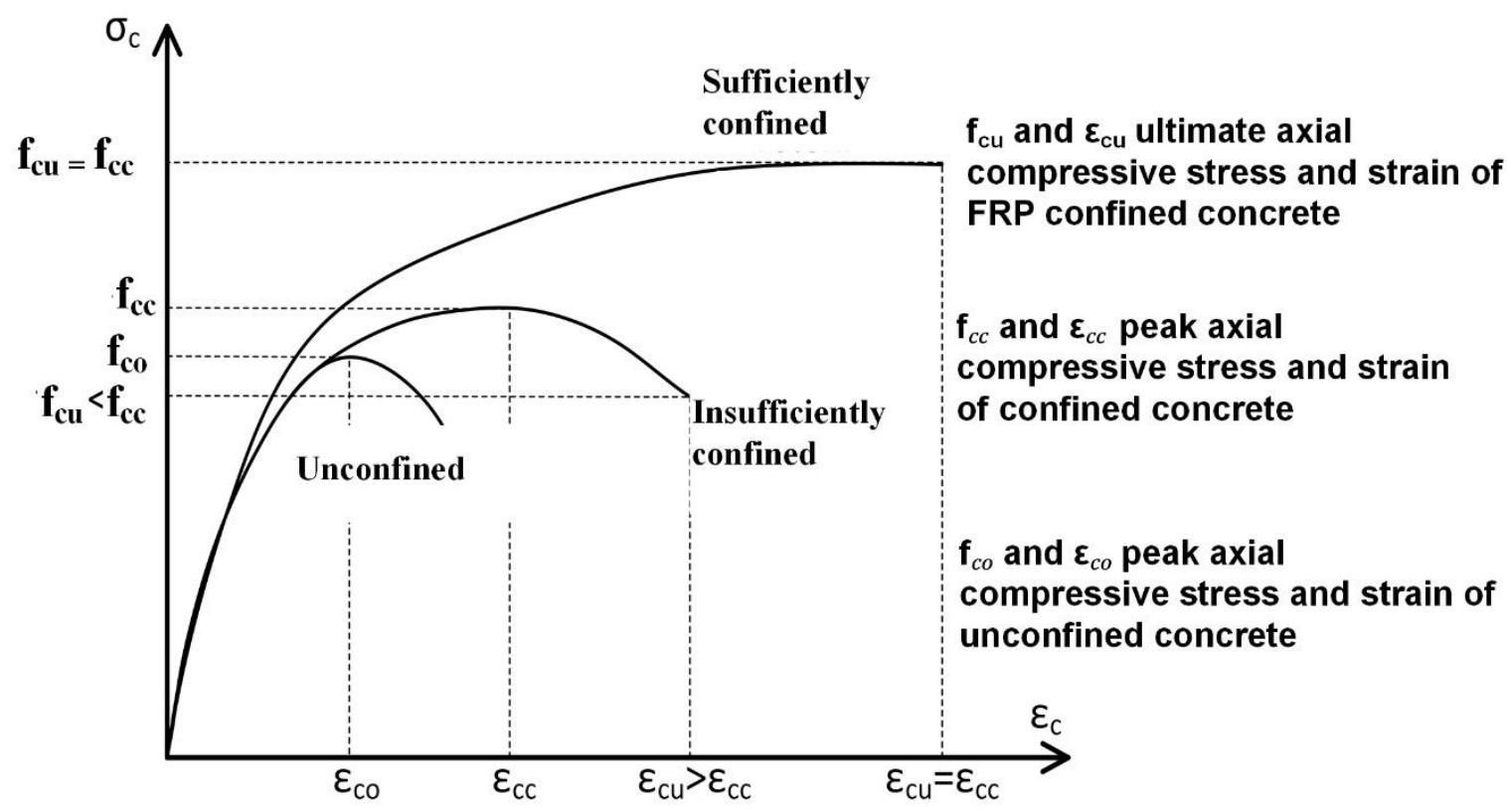

Figure 5.2 Behavior of confined and unconfined concrete under monotonic axial loading

In Figure 5.2,

$\mathrm{f}_{c o} \quad$ : Peak axial compressive stress of unconfined concrete

$\varepsilon_{c o} \quad$ : Peak axial strain of unconfined concrete

$\mathrm{f}_{c c} \quad$ : Peak axial compressive stress of FRP confined concrete

$\varepsilon_{c c} \quad$ : Peak axial strain of FRP confined concrete

$\mathrm{f}_{c \mathrm{u}} \quad$ : Ultimate axial compressive stress of confined concrete at failure

$\varepsilon_{c u} \quad$ : Ultimate axial strain of confined concrete at failure 


\subsubsection{Lam and Teng (2003) Model}

Lam and Teng (2003) proposed a design-oriented model to estimate the axial strength and ultimate strain of FRP confined concrete, as presented in Eqns.4 and 5, respectively.

$\frac{f_{c c}}{f_{c o}}=1+3.3 \frac{f_{l u, a}}{f_{c o}}$

$\frac{\varepsilon_{\mathrm{cu}}}{\varepsilon_{\mathrm{co}}}=1.75+12\left(\frac{\mathrm{f}_{\mathrm{lu}, \mathrm{a}}}{\mathrm{f}_{\mathrm{co}}}\right)\left(\frac{\varepsilon_{\mathrm{h}, \mathrm{rup}}}{\varepsilon_{\mathrm{co}}}\right)^{0.45}$

In Eqns.4 and 5, the constants "3.3" and "12" represent strength- and strainenhancement coefficients $\left(\mathrm{k}_{1}\right.$ and $\left.\mathrm{k}_{2}\right)$, respectively. And $\mathrm{f}_{\mathrm{cc}} / \mathrm{f}_{\mathrm{co}}$ and $\varepsilon_{\mathrm{cu}} / \varepsilon_{\mathrm{co}}$ are termed as strength- and strain-enhancement ratios, respectively. Based on various assumptions, Lam and Teng (2003) proposed a model for the stress-strain diagram of FRP-confined concrete under monotonic axial loading, shown in Figure 5.3. The stress-strain curve of this model consists of a parabolic first portion and a straight line second portion.

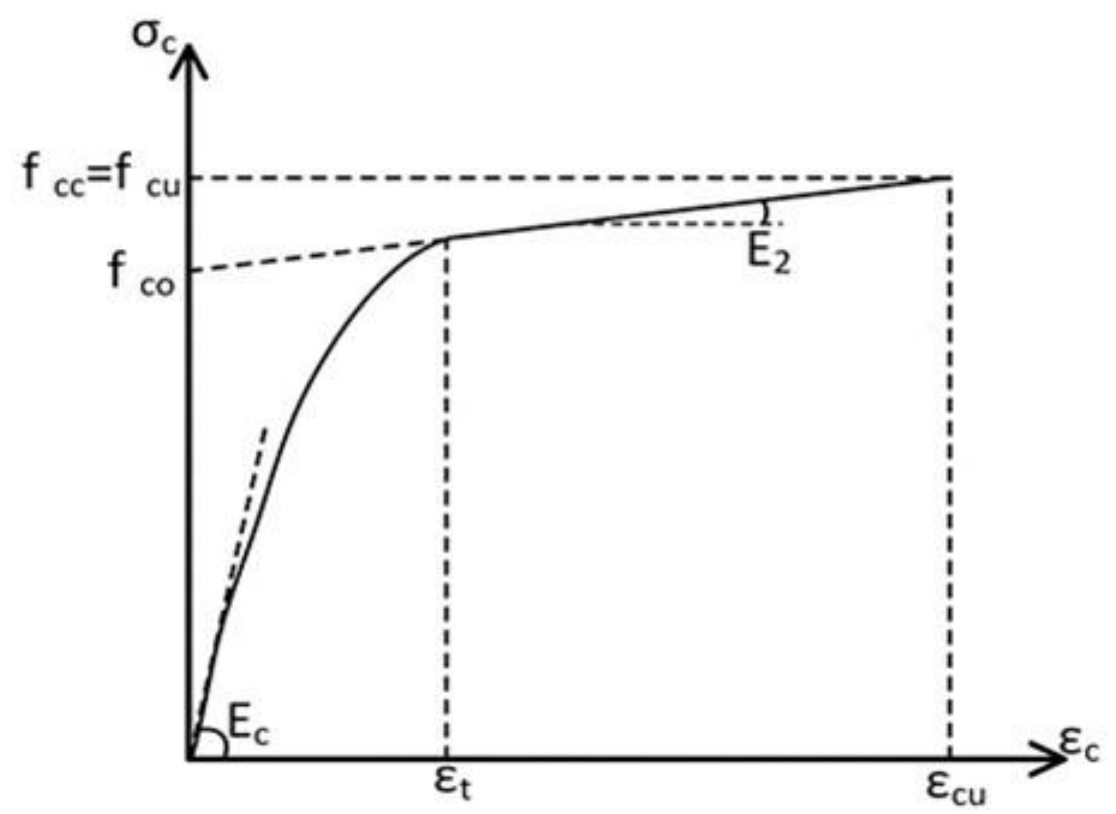

Figure 5.3 Model presented by Lam and Teng (2003) for the axial behavior of FRP confined concrete 
This model is based on the following expressions:

$$
\begin{aligned}
& \sigma_{\mathrm{c}}=\mathrm{E}_{\mathrm{c}} \times \varepsilon_{\mathrm{c}}-\frac{\left(\mathrm{E}_{\mathrm{c}}-\mathrm{E}_{2}\right)^{2}}{4 \mathrm{f}_{\mathrm{co}}} \times \varepsilon_{\mathrm{c}}^{2} \quad \text { for } \quad\left(0 \leq \varepsilon_{\mathrm{c}} \leq \varepsilon_{t}\right) \\
& \sigma_{\mathrm{c}}=\mathrm{f}_{\mathrm{co}}+\mathrm{E}_{2} \times \varepsilon_{\mathrm{c}} \quad \text { for } \quad\left(\varepsilon_{\mathrm{t}} \leq \varepsilon_{\mathrm{c}} \leq \varepsilon_{\mathrm{cu}}\right)
\end{aligned}
$$

In these equations, $\sigma_{\mathrm{c}}$ and $\varepsilon_{\mathrm{c}}$ are the stress and strain values of concrete at any step of axial loading. And $\varepsilon_{\mathrm{t}}$ is the transition point where the parabolic first portion meets the linear second portion, $\mathrm{E}_{2}$ is the slope of the linear second portion which are defined by Eqns. 8 and 9, respectively.

$$
\begin{aligned}
& \varepsilon_{\mathrm{t}}=\frac{2 \mathrm{f}_{\mathrm{co}}}{\left(\mathrm{E}_{\mathrm{c}}-\mathrm{E}_{2}\right)} \\
& \mathrm{E}_{2}=\frac{\mathrm{f}_{\mathrm{cc}}-\mathrm{f}_{\mathrm{co}}}{\varepsilon_{\mathrm{cu}}}
\end{aligned}
$$

\subsubsection{Turkish Earthquake Code (TEC) - 2018 Model}

In the Turkish Building Earthquake Code (TEC-2018), Eqns.10 and 11 are proposed for the axial compressive strength and ultimate strain capacity of FRP confined concrete, respectively. In these equations, unconfined concrete strength $f_{c m}$ is the equivalent of $f_{c o}$ presented in previous statements.

$$
\begin{aligned}
& \mathrm{f}_{\mathrm{cc}}=\mathrm{f}_{\mathrm{cm}}\left[1+2.4\left(\mathrm{f}_{\mathrm{l}} / \mathrm{f}_{\mathrm{cm}}\right)\right] \geq 1.2 \mathrm{f}_{\mathrm{cm}} \\
& \varepsilon_{\mathrm{cc}}=0.002\left[1+15\left(\mathrm{f}_{\mathrm{l}} / \mathrm{f}_{\mathrm{cm}}\right)^{0.75}\right]
\end{aligned}
$$


$\mathrm{f}_{\mathrm{l}}=0.5 \kappa_{\mathrm{a}} \rho_{\mathrm{f}} \varepsilon_{\mathrm{f}} \mathrm{E}_{\mathrm{f}}$

$\rho_{f}=\frac{\pi \times D \times t_{f} \times H}{\left(\pi \times D^{2} / 4\right) \times H}=\frac{4 t_{f}}{D}$

In the above equations, $\left(\mathrm{f}_{\mathrm{l}}\right)$ is the amount of lateral pressure provided by the FRP materials, $\left(\kappa_{\mathrm{a}}\right)$ is the cross-sectional shape efficiency coefficient considered as equal to "1" for circular sections and $\left(\rho_{\mathrm{f}}\right)$ is the volumetric ratio of FRP.

\subsubsection{Wu et al. (2008) Model}

Wu et al. (2008) proposed Eqn.14 for the prediction of strength-enhancement ratio in the hybrid confinement. In this equation, the effect of unconfined concrete strength is taken into account by taking $\mathrm{k}$ as equal to " $2 \alpha$ ", where $\alpha$ is considered $30 / \mathrm{f}_{\mathrm{co}}$. Wu et al. (2008) defined strain-enhancement ratio in Eqn.15 as a function of the ultimate Poisson's ratio of the confined concrete, $v_{u}$ (Eqn.16). The effect of unconfined concrete strength in the prediction of strain-enhancement ratio is considered by dividing the results of Eqn. 15 into the $\alpha$ coefficient.

$\frac{f_{c c}}{f_{c o}}=1+k \frac{f_{l u}}{f_{c o}}$

$\frac{\varepsilon_{\mathrm{cu}}}{\varepsilon_{\mathrm{co}}}=\frac{\varepsilon_{\mathrm{h}, \mathrm{rupt}}}{\varepsilon_{\mathrm{co}} \times v_{\mathrm{u}}}$

$v_{\mathrm{u}}=0.56\left(\frac{\mathrm{f}_{\mathrm{lu}}}{\mathrm{f}_{\mathrm{co}}}\right)^{-0.66}$

Wu et al. (2008) also suggested a confinement classification for the failure mechanism of hybrid confined concrete. In this confinement classification, a strength ratio $(\beta)$ is defined. As given in Eqn.17, $\beta$ is the confinement ratio of high-strain to the low-strain FRP. It was suggested that in hybrid confinement, when $(\beta)$ value is between 1.45 and 4.26 intervals, it is 
assumed to be effective compared to the use of the single type of FRP. And when $\beta$ value is smaller than 1.45 , they indicated that all confining layers rupture simultaneously due to lack of capability of high-strain FRP to absorb the energy released by the rupture of low-strain FRP.

$\beta=\frac{f_{\mathrm{f} 2} \times t_{\mathrm{f} 2}}{\mathrm{f}_{\mathrm{f} 1} \times \mathrm{t}_{\mathrm{f} 1}}$

In this equation, $\mathrm{f}_{\mathrm{f}}$ and $\mathrm{t}_{\mathrm{f}}$ represent the average ultimate tensile strength and thickness of FRP material. The subscript "1" and "2" in these representations are given for the FFRP and GFRP of the hybrid confinement, respectively. It is worth mentioning that the related values are presented in Chapter 4.1.

\subsection{Comparison with the Existing Models}

In this section, the test results are compared with the Lam and Teng. (2003), Wu et al. (2008) and TEC-2018 models. The comparison of the experimentally obtained ultimate conditions (strength- and strain-enhancement) values with the model predictions are shown in Figure 5.4 and Figure 5.5. The rupture strain values obtained by the coupon tests or supplied by the manufacturer were not used for the model prediction. The model predictions were based on the hoop-rupture strain values obtained during the compression tests to eliminate any error that may be caused by taking the values of the coupon tests or the manufacturer. The main purpose of this was to assess the models alone. In the hybrid confinement, the ultimate confining pressure was assumed as the summation of the ultimate confining pressure provided by each material. This assumption was based on the observation of simultaneous rupture of different FRP materials in this study with hybrid confinement (except for the FFC-50 group) (Ispir et al., 2018; Wu et al., 2008).

For comparison purposes, the test results of $\mathrm{f}_{\mathrm{cc}} / \mathrm{f}_{\mathrm{co}}$ and $\varepsilon_{\mathrm{cu}} / \varepsilon_{\mathrm{co}}$ are presented in Figure 5.6 and Table 5.1 with the predictions of Lam and Teng. (2003), Wu et al. (2008) and TEC-2018 models. Almost in all tested groups, the strength-enhancement ratios could be successfully predicted by Lam and Teng 2003 model. However, it should be noted that for the hybrid 
specimens ( $\mathrm{FG}$ and $\mathrm{FFG}$ ), the $\mathrm{f}_{\mathrm{cc}} / \mathrm{f}_{\mathrm{co}}$ were generally underestimated slightly by Lam and Teng (2003) model (Figure 5.6.a). This may be due to the "hybrid effect" since Lam and Teng (2003) model is based on single type of FRP confinement. On the other hand, (Wu et al., 2008) model overestimated the strength enhancement for all the specimens (Figure 5.6.b). The only difference between these two models is the strength-enhancement coefficient. In the Lam and Teng (2003), the strength-enhancement coefficient was suggested to be 3.3, while the $\mathrm{Wu}$ et al. (2008) model assumed it to be a function of unconfined concrete strength that provides a value of approximately 5.5 for $\mathrm{f}_{\mathrm{co}}=10.9 \mathrm{MPa}$. For significantly low-strength concrete $\mathrm{Wu}$ et al. (2008) model tends to exaggerate this coefficient.

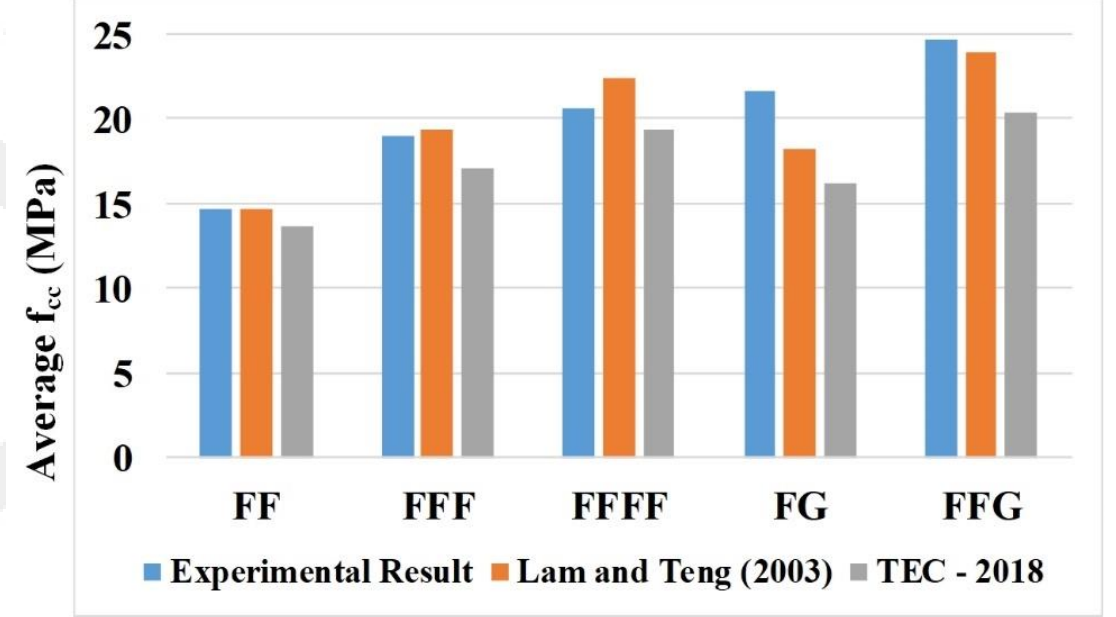

\section{Specimen Group}

Figure 5.4 Axial compressive strength of FRP confined concrete

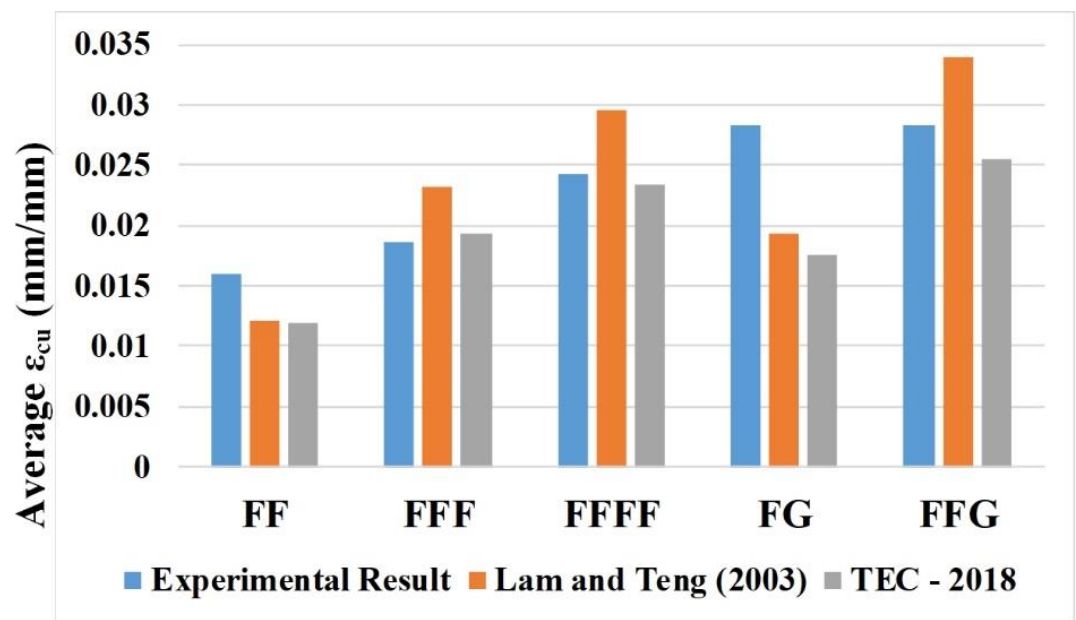

Specimen Group

Figure 5.5 Axial compressive strain of FRP confined concrete 

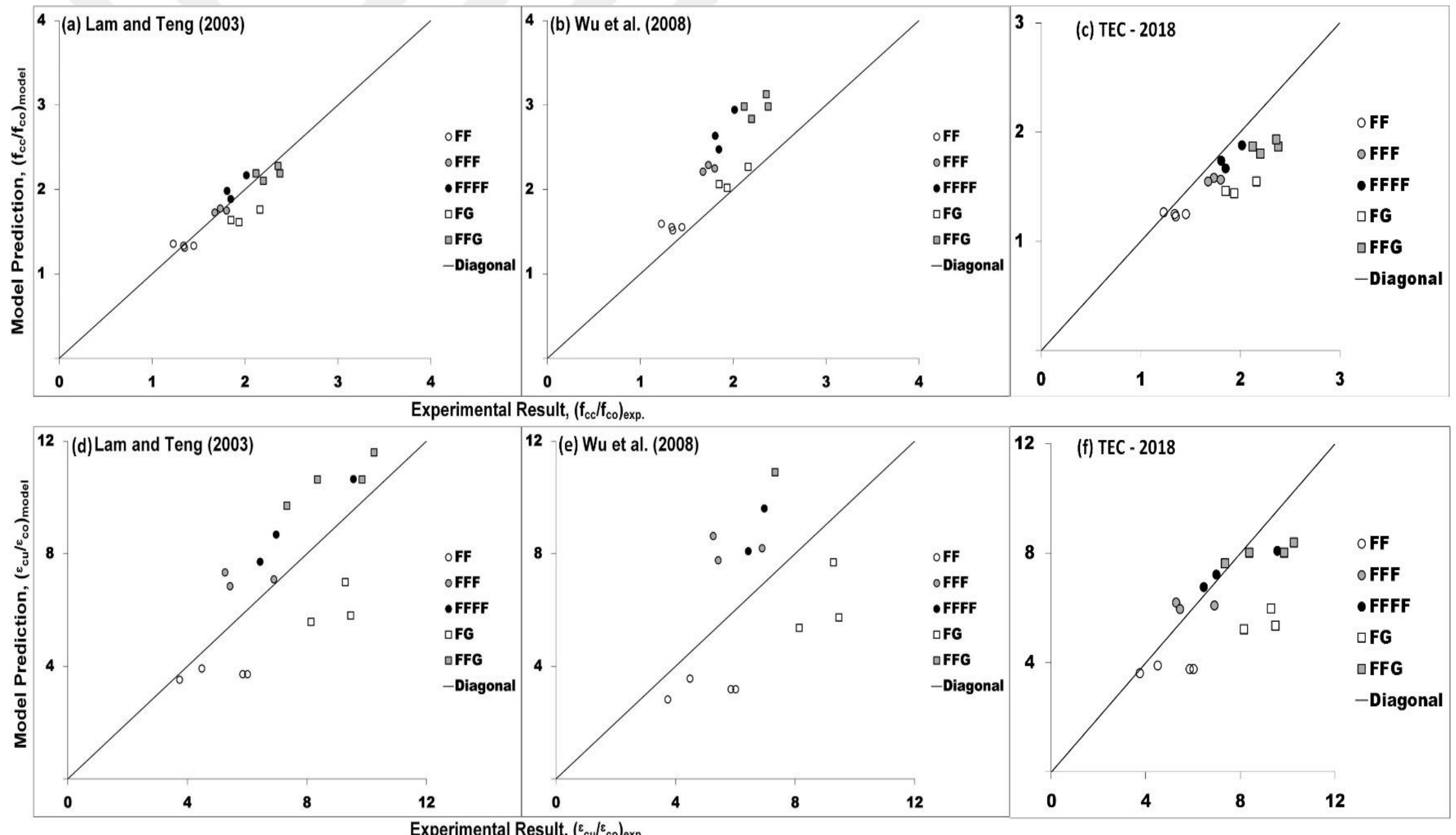

Figure 5.6 Comparison of the model predictions of strength- and strain-enhancement ratios with the experimental results 
The strain-enhancement ratio predictions of the Lam and Teng (2003) model deviated from the test results by $23 \%$ as an average value. This deviation increased to $39 \%$ for the FG1 specimen as the maximum value. In the model of Wu et al. (2008), the deviation of strain enhancement ratio was estimated with an average value of $36 \%$ and a maximum value of $64 \%$. The predictions of both models underestimated the strain-enhancement ratios in the FF and FG test groups where the lowest ultimate confining pressures took place (Figure 5.6.d and e). TEC-2018 model underestimated the strain and strength-enhancement ratios for all the specimens (Figure 5.6.c and f). However, this estimation is more cautious and safer as may be expected from an earthquake regulation code.

As explained at the beginning of this chapter, Lam and Tang (2003) model provide expressions that give the overall compressive stress-strain curves for the confined concrete under axial monotonic loading. The stress-strain curve predictions for the test specimens were obtained by using Eqn.6-9 for all the specimens and compared with the experimental results. These curves are shown in Figure 5.7 by selecting the specimens which have the closest result in each group. In these calculations, the ultimate strength $\left(f_{c c}\right)$ and strain $\left(\varepsilon_{c u}\right)$ values of the specimens are taken directly from the test result.

As demonstrated in Figure 5.7, the stress-strain prediction of Lam and Tang (2003) model is close to experimental results in all cases where the flax fiber is used alone or in hybrid confinement with glass fiber. The transition strain value $\left(\varepsilon_{t}\right)$ was calculated by the model as slightly smaller in all specimens compared to the experimental results. These slight variations in the model prediction, compared to the experimental results, cause the curves to appear more rigid in the first part of the response.

If the ultimate strength $\left(f_{c c}\right)$ and strain $\left(\varepsilon_{c u}\right)$ values in Lam and Teng (2003) model is taken from the results of equations 4 and 5, rather than experimental results, the stress-strain curves do not appear to be close to each other, as seen in Figure 5.8.a. However, it is understood that this deviation is caused by $\varepsilon_{\mathrm{cu}}$ calculation according to Eqn.5 rather than $\mathrm{f}_{\mathrm{cc}}$, which was calculated according to Eqn.4. When only the $\mathrm{f}_{\mathrm{cc}}$ value is taken into account from the model calculation for the "FF-1" specimen (Figure 5.8.b), the proximity between the experimental and analytical curves is not different from the situation given in Figure 5.8.a. In the same way, when only $\varepsilon_{\mathrm{cu}}$ value is taken from the model (Figure 5.8.c), the difference between experimental and analytical curves became similar to Figure 5.8.a. 


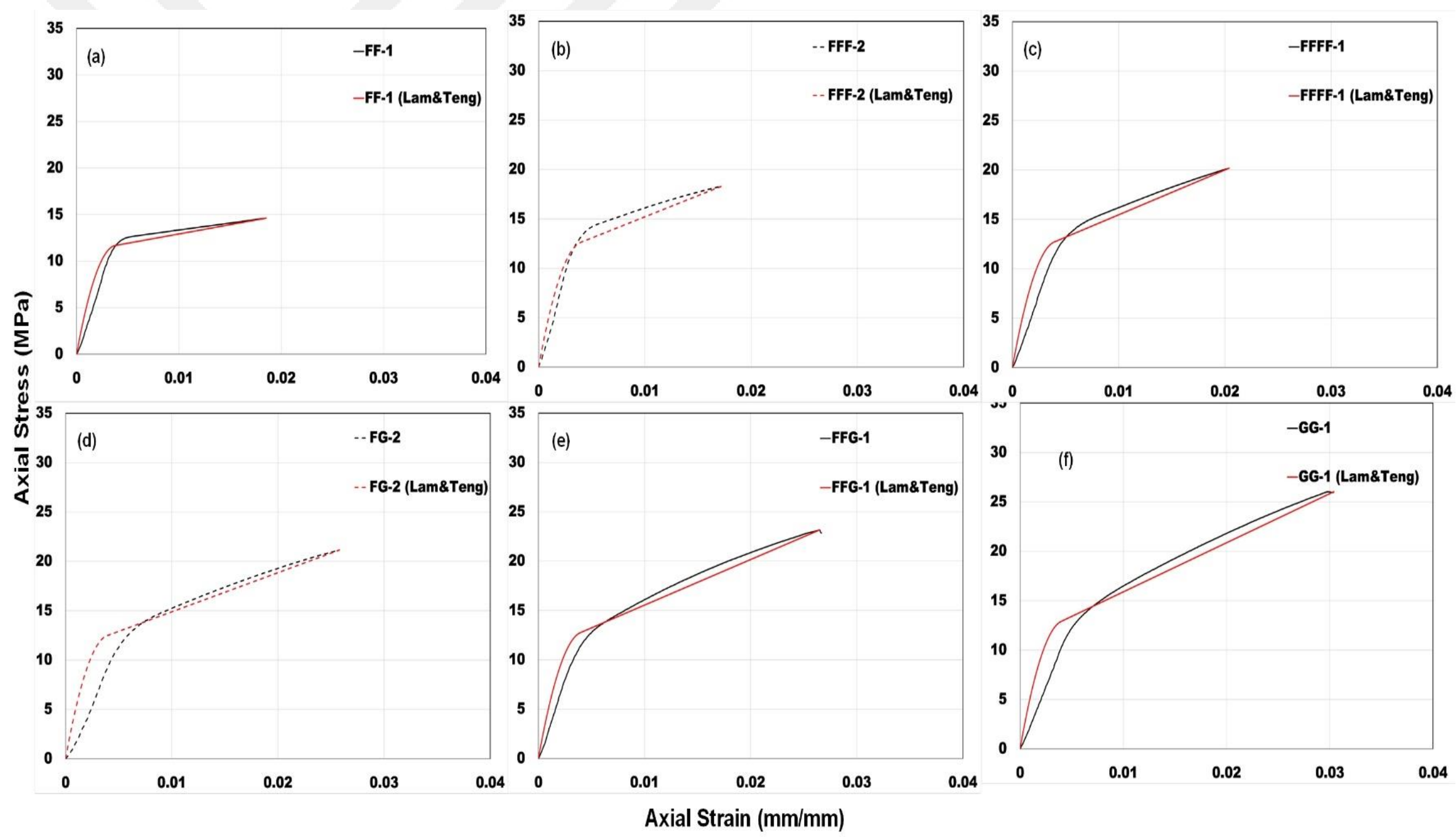

Figure 5.7 Comparison of the axial stress-strain curves with Lam and Teng (2003) model 
Table 5.1 Experimental and model prediction comparison of $\mathrm{f}_{\mathrm{cc}} / \mathrm{f}_{\mathrm{co}}$ and $\varepsilon_{\mathrm{cu}} / \varepsilon_{\mathrm{co}}$

\begin{tabular}{|c|c|c|c|c|c|c|}
\hline \multicolumn{2}{|c|}{ Experimental Result } & Lam and Teng (2003) & \multicolumn{2}{c|}{ TEC - 2018 } \\
\hline Specimen & $\begin{array}{c}\mathrm{f}_{\mathrm{cc}} / \mathrm{f}_{\mathrm{co}} \\
\mathrm{Avg} .\end{array}$ & $\begin{array}{c}\varepsilon_{\mathrm{cu}} / \varepsilon_{\mathrm{co}} \\
\text { Avg. }\end{array}$ & $\begin{array}{c}\mathrm{f}_{\mathrm{cc}} / \mathrm{f}_{\mathrm{co}} \\
\mathrm{Avg} .\end{array}$ & $\begin{array}{c}\varepsilon_{\mathrm{cu}} / \varepsilon_{\mathrm{co}} \\
\text { Avg. }\end{array}$ & $\begin{array}{c}\mathrm{f}_{\mathrm{cc}} / \mathrm{f}_{\mathrm{co}} \\
\text { Avg. }\end{array}$ & $\begin{array}{c}\varepsilon_{\mathrm{cu}} / \varepsilon_{\mathrm{co}} \\
\text { Avg. }\end{array}$ \\
\hline FF & 1.34 & 5.02 & 1.35 & 3.80 & 1.25 & 3.77 \\
\hline FFF & 1.74 & 5.86 & 1.78 & 7.31 & 1.57 & 6.09 \\
\hline FFFF & 1.89 & 7.65 & 2.05 & 9.31 & 1.77 & 7.36 \\
\hline FG & 1.98 & 8.96 & 1.67 & 6.11 & 1.49 & 5.53 \\
\hline FFG & 2.26 & 8.94 & 2.20 & 10.71 & 1.87 & 8.02 \\
\hline
\end{tabular}

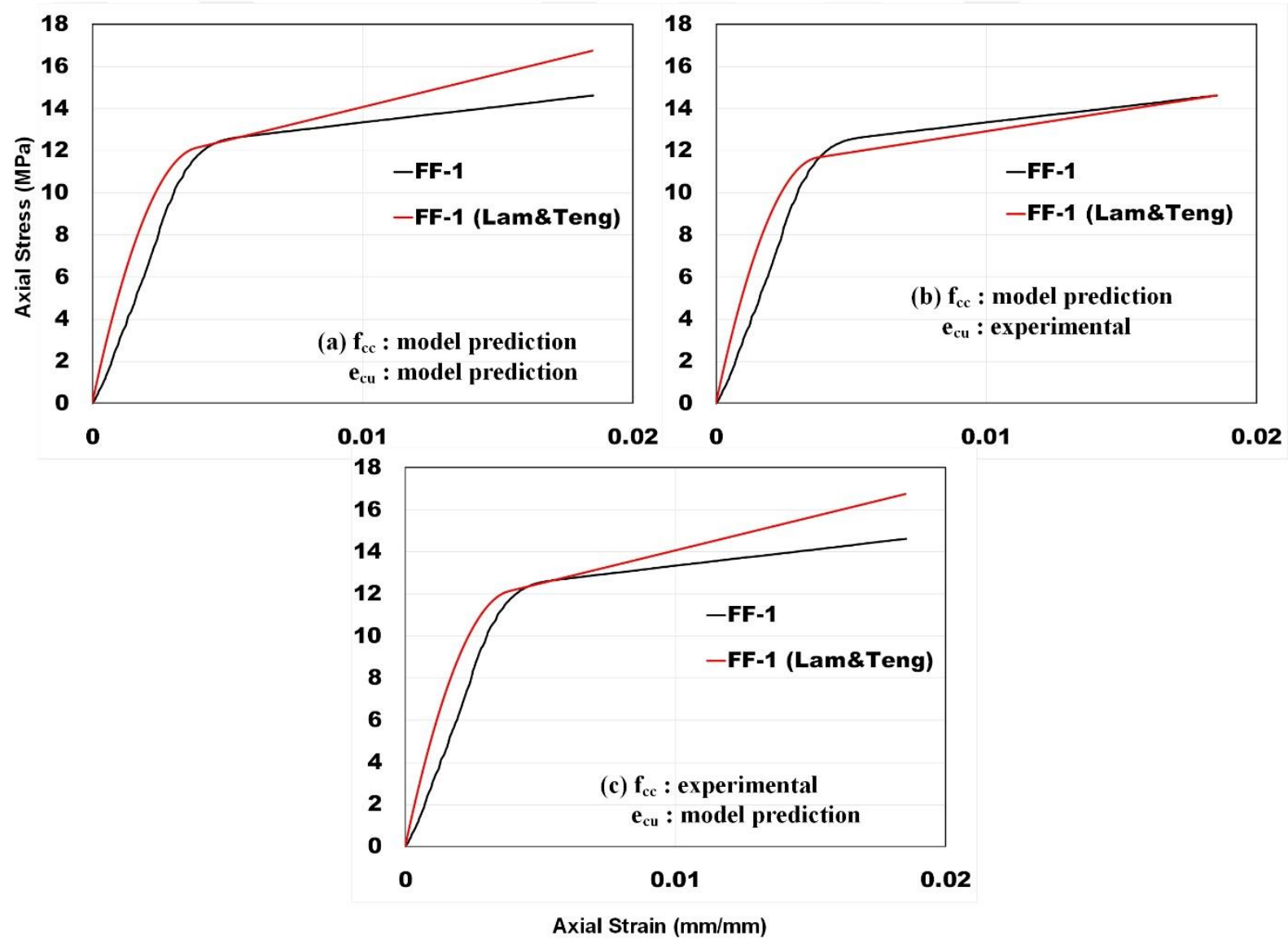

Figure 5.8 Experimental results and Lam and Teng (2003) model prediction for stress-strain curve with different approaches 


\section{DISCUSSION}

In this section, all the key parameters such as the ultimate conditions of the test specimens in different groups $\left(\mathrm{f}_{\mathrm{cc}} / \mathrm{f}_{\mathrm{co}}\right.$ and $\left.\varepsilon_{\mathrm{cu}} / \varepsilon_{\mathrm{co}}\right)$, the hoop-rupture strain, strain-reduction factor and normalized ultimate confining pressure $\left(\mathrm{f}_{\mathrm{lu}} / \mathrm{f}_{\mathrm{co}}\right)$ are compared and discussed.

The stress-strain diagram of all confined specimens has an increasing trend after the first peak, as demonstrated in Figure 4.7-11. By using only FFRP, a significant increase in strength and especially ductility could be achieved depending on the number of layers. The increase in the strength- and strain-enhancement ratios $\left(\mathrm{f}_{\mathrm{cc}} / \mathrm{f}_{\mathrm{co}}\right.$ and $\left.\varepsilon_{\mathrm{cu}} / \varepsilon_{\mathrm{co}}\right)$ obtained in the specimens confined only with two layers of FFRP was 1.34 and 5.02, respectively (Table 4.2). The average $f_{l u} / f_{\text {co }}$ ratio was equal to 0.10 for these specimens confined with two layers of FFRP (Table 4.2). This value may be regarded as a threshold value for sufficient FFRP confinement of the concrete specimens of this study, having an approximate unconfined strength of $11 \mathrm{MPa}$.

When three and four layers of FFRP were used for confinement, there was a further increase in the ultimate condition. In the three layers of FFRP confinement, which provided strength and strain enhancement ratios of 1.74 and 5.86, respectively, the ultimate confining pressure was doubled. In the case of four layers of FFRP confinement, the $\mathrm{f}_{\mathrm{cc}} / \mathrm{f}_{\mathrm{co}}$ and $\varepsilon_{\mathrm{cu}} / \varepsilon_{\mathrm{co}}$ ratios were as high as 1.89 and 7.65, respectively. Although the tensile properties of FFRP's are lower relative to synthetic FRP materials, it was an intriguing result to have such an enhancement in the ultimate conditions of FFRP confined concrete.

For the specimens confined with two layers of FFRP materials, the hoop-rupture strain values and strain reduction factors are close to the strain capacity of the material obtained from the coupon test. These values are even higher in the case of three and four layers of confinements $\left(\mathrm{k}_{\varepsilon}\right.$ values were approximately 1.20 in the FFF and FFFF test groups) as presented in Table 4.2. As mentioned previously, this is not a prevalent result for synthetic materials. The hoop strain capacities for the synthetic materials are commonly lower than the coupon tensile capacity (i.e. $\mathrm{k}_{\varepsilon}$ values lower than 1.0). This behavior of FFRP materials may have contributed to the enhancement of ultimate conditions of concrete.

The ultimate confining pressure of the FF test group was increased by replacing one layer of flax fiber with one layer of glass fiber. In the FG hybrid test group, the ultimate 
confining ratio $\left(\mathrm{f}_{\mathrm{lu}} / \mathrm{f}_{\mathrm{co}}\right)$ was approximately two times higher (i.e. an average value of 0.20$)$. In the FFG test group, this ratio was approximately 0.36 . The ultimate confining pressures supplied by FG and FFG test groups are almost equivalent to those in the FFF and FFFF test groups, respectively. Therefore, it can be reported that the substitution of two layers of flax fiber with one layer of GFRP produced approximately the same level of ultimate confining pressure. It should be noted that, in the case of hybrid confinement, the strength- and strainenhancement ratios were higher relative to the corresponding test groups confined only with FFRP having similar ultimate confining pressure values (Table 4.2)

The average tensile strength values $\left(f_{f 1} \& f_{f 2}\right)$ of FFRP and GFRP are presented in Table 4.1. And their thicknesses $\left(\mathrm{t}_{\mathrm{f} 1}\right.$ and $\left.\mathrm{t}_{\mathrm{f} 2}\right)$ are 0.40 and $0.20 \mathrm{~mm}$, respectively. According to these values, the confinement ratio of high-strain to the low-strain FRP ( $\beta$ ) is calculated for FG and FFG test groups by utilizing Eqn.15, which are equal to 4.60 and 2.30, respectively. Among the test groups of this study, only the FFG group may be regarded as effective in terms of hybridization according to the definition of $\mathrm{Wu}$ et al. (2008). Besides, all of the specimens in the hybrid test groups of this study have experienced simultaneous rupture of low and highstrain fibers with $\beta$ greater than 1.45, which contradict the failure mechanism classification defined by Wu et al. (2008)

In the design of FRP confinement, the strain reduction factor is an important parameter to predict the rupture strain of confining jacket without conducting any compression tests. In the hybrid confinement, the main concern is the choice of strain capacity of FRP sheet $\left(\varepsilon_{\mathrm{fu}}\right)$ that will be used to calculate strain reduction factor $\mathrm{k}_{\varepsilon}$. The strain-reduction factors in the FG and FFG test groups were determined using the $\varepsilon_{\mathrm{fu}}$ values of the inner FFRP and outer GFRP separately, as shown in Table 4.2. By considering the strain capacity of the outer sheet (GFRP), as suggested by (Ispir et al., 2018), the strain-reduction factors were estimated as 0.58 and 0.78 for the FG and FFG groups, respectively. These values become 0.96 and 1.33 , respectively, when the inner sheet (FFRP) strain capacity was taken into account. When the rupture strain capacity of outer FRP is considered, this may lead to underestimation of the rupture strain of the hybrid jacket. The average strain reduction factor of the FFG test group by consideration of the outer GFRP rupture strain is 0.78 , which is close to the value estimated for the FF test group (i.e. 0.79). However, the results show that the rupture strain and effectiveness of confinement was much higher in the FFG compared to the FF test group. On the other hand, considering the $\varepsilon_{\mathrm{fu}}$ of the inner layer (FFRP) sheet overestimate the strain 
reduction factor. This inference necessitates further experimental studies to develop a correct expression for the strain-reduction factor of hybrid confinement.

The FFC-50 test group demonstrated the highest enhancement in the axial strength and strain, as shown in Table 4.2. The failure mechanism in this group was such that only the two layers of FFRP sheets between the CFRP strips ruptured at a strain approximately the same as in the FF test group. However, by providing additional confining pressure, the CFRP strips nearly doubled the strength- and strain-enhancement ratios compared to the FF test group.

In the model prediction, Lam and Tang (2003) model generally demonstrated compatible results of strength-enhancement ratio $\left(\mathrm{f}_{\mathrm{cc}} / \mathrm{f}_{\mathrm{co}}\right)$ compared to $\mathrm{Wu}$ et al. (2008) and TEC-2018. In the hybrid confinement, this model underestimated the strength-enhancement ratio slightly. In the prediction of the stress-strain curve, $f_{c c}$ values of Lam and Tang (2003) model were compatible with the experimental result. This compatibility resulted in a stressstrain curve that matched the test results. In the TEC-2018, the strength enhancement ratio $\left(\mathrm{f}_{\mathrm{cc}} / \mathrm{f}_{\mathrm{co}}\right)$ was underestimated in all specimens groups whereas, this ratio was overestimated by $\mathrm{Wu}$ et al. (2008) for all specimens, especially those in the FFG and FFFF groups. In the prediction of strain enhancement ratio, Lam and Tang (2003) model predictions deviated from the test results. This deviation caused a divergence between the stress-strain curves of the model and test results. However, this deviation was considerably lower compared to Wu et al. (2008). Similarly, the results of TEC-2018 are also deviated from the test results by underestimating the strain-enhancement ratio of all test groups. 


\section{CONCLUSIONS}

In this experimental study, the axial compressive behavior of low strength concrete confined with flax FRP alone either in hybrid form with GFRP and CFRP has been presented and discussed. Besides, the test results were compared with two available models in terms of ultimate conditions of FRP confined concrete. The following conclusions, which should not be generalized without due judgment or experimental validation, may be outlined.

1. The specimens confined only by FFRP sheets failed in an explosive manner, with the confining jacket rupturing along the specimens' height. In the hybrid test groups (FG and FFG), the observed rupture was more localized and took place simultaneously for the inner and outer FRP sheets. In the FFC-50 test group, only FFRP sheets in between the CFRP strips failed. And no damage was observed on the CFRP strips.

2. A significant enhancement in axial strength and deformability of low strength concrete confined by FFRP sheets was achieved depending on the number of layers of FFRP. By adding one layer of GFRP, the confining pressure was further increased and resulted in higher strength and deformability compared to a single layer of FFRP.

3. The specimens confined only by FFRP sheets revealed a strain-reduction factor equal to unity or even higher value. This may demonstrates the efficiency of FFRP materials in confinement despite having much lower mechanical properties.

4. The FFC-50 test group demonstrated the highest increase in axial strength and deformability. In this group, the strength- and strain-enhancement was doubled compared to the FF test group despite having identical rupture strain of FFRP.

5. The failure mechanism in this study for the hybrid confinement did not match well with those described by previous studies according to certain parameters of hybrid confinement.

6. Further studies are required to provide a practical definition of the strainreduction factor that will be used in hybrid confinement. 
7. Almost in all tested groups, the axial strength could be successfully predicted by Lam and Teng. (2003) model even though this model was based on a single type of synthetic FRP confinement. On the other hand, Wu et al. (2008) model overestimated the axial strength in all the specimens, which could be due to the exaggerated strength-enhancement coefficient of this model. The error in the axial strain capacity predictions of both models was high. TEC - 2018 predicted more conservative results for the axial strength as it is usually expected from any earthquake regulation code.

8. The model of Lam and Tang (2003) which was suggested for the overall monotonic stress-strain response matched well with the experimental results when the ultimate strength and strain values attained during the tests were used. The same accuracy was valid when the model predicted ultimate strength $\left(f_{c c}\right)$ values were used in the model for the monotonic stress-strain behavior. However, when the inaccurately predicted ultimate strain capacity $\left(\varepsilon_{\mathrm{cu}}\right)$ values were used in the model, this led to a considerable deviation between the predicted and experimental stress-strain curves. 


\section{REFERENCES}

Akın, E. (2011). Strengthening of brick infilled RC frames with CFRP reinforcement-general principles. https://open.metu.edu.tr/handle/11511/21132

American Society for Testing and Materials. (2014), Standard Test Method for Tensile Properties of Polymer Matrix Composite Materials (ASTM D3039/D3039M-14). U.S. ASTM International, West Conshohocken, PA. https://www.astm.org/Standards/D3039

Bal, İ. E., Crowley, H., Pinho, R., Gülay, F. G. (2008). Detailed assessment of structural characteristics of Turkish RC building stock for loss assessment models. Soil Dynamics $\begin{array}{lll}\text { and } \quad \text { Earthquake } \quad \text { Engineering, } & \text { 28(10), }\end{array}$ https://doi.org/10.1016/j.soildyn.2007.10.005

Fam, A. Z., \& Rizkalla, S. H. (2001). Confinement Model for Axially Loaded Concrete Confined by Circular Fiber-Reinforced Polymer Tubes. Structural Journal, 98(4), 451461. https://doi.org/10.14359/10288

Faruk, O., Bledzki, A. K., Fink, H.-P., \& Sain, M. (2014). Progress Report on Natural Fiber Reinforced Composites. Macromolecular Materials and Engineering, 299(1), 9-26. https://doi.org/10.1002/mame.201300008

Ghalieh, L., Awwad, E., Saad, G., Khatib, H., \& Mabsout, M. (2017). Concrete Columns Wrapped with Hemp Fiber Reinforced Polymer - An Experimental Study. Procedia Engineering, 200, 440-447. https://doi.org/10.1016/j.proeng.2017.07.062

Ispir, M., Dalgic, K. D., \& Ilki, A. (2018). Hybrid confinement of concrete through use of low and high rupture strain FRP. Composites Part B: Engineering, 153, 243-255. https://doi.org/10.1016/j.compositesb.2018.07.026

Joshia, S., Drzalb, L. T., Mohanty, A. K., \& Arorac, S. (2004). Are natural fiber composites environmentally superior to glass fiber reinforced composites? Composites Part A: Applied Science and Manufacturing, 35(3), 371-376. https://doi.org/10.1016/j.compositesa.2003.09.016 
Lam, L., \& Teng, J. G. (2004). Ultimate Condition of Fiber Reinforced Polymer-Confined Concrete. Journal of Composites for Construction, 8(6). https://doi.org/10.1061/(ASCE)1090-0268(2004)8:6(539)

Lam, L., \& Teng, J. G. (2003). Design-Oriented Stress- Strain Model for FRP-Confined Concrete. Construction and Building Materials, 17, 471-489. https://doi.org/10.1016/S0950-0618(03)00045-X

Mirmiran, A., \& Shahawy, M. (1997). Behavior of Concrete Columns Confined by Fiber Composites. Journal of Structural Engineering, 123(5), 583-590. https://doi.org/10.1061/(ASCE)0733-9445(1997)123:5(583)

Ozbakkaloglu, T., \& Akin, E. (2012). Behavior of FRP-Confined Normal- and High-Strength Concrete under Cyclic Axial Compression. Journal of Composites for Construction, 16(4). Retrieved from https://trid.trb.org/view/1216348

Ozbakkaloglu, T. (2013). Compressive behavior of concrete-filled FRP tube columns: Assessment of critical column parameters. Engineering Structures, 51, 188-199. https://doi.org/10.1016/j.engstruct.2013.01.017

Ozbakkaloglu, T., \& Akın, E. (2011). Behavior of FRP-Confined Normal- and High-Strength Concrete under Cyclic Axial Compression. Journal of Composites for Construction, 16, 451-463. https://doi.org/10.1061/(ASCE)CC.1943-5614.0000273

Ozbakkaloglu, T., \& Oehlers, D. J. (2008). Manufacture and testing of a novel FRP tube confinement system. Engineering Structures, 30(9), 2448-2459. https://doi.org/10.1016/j.engstruct.2008.01.014

Pessiki, S., Harries, K. A., Kestner, J. T., Sause, R., \& Ricles, J. M. (2001). Axial Behavior of Reinforced Concrete Columns Confined with FRP Jackets. Journal of Composites for Construction, 5(4). https://doi.org/10.1061/(ASCE)1090-0268(2001)5:4(237)

Sen, T., \& Jagannatha Reddy, H. N. (2014). Efficacy of bio derived jute FRP composite based technique for shear strength retrofitting of reinforced concrete beams and its comparative analysis with carbon and glass FRP shear retrofitting schemes. Sustainable Cities and Society, 13, 105-124. https://doi.org/10.1016/j.scs.2014.04.010

Sunter, D., Morrow, I., William, Cresko, J., \& Liddell, H. (2015). The manufacturing energy intensity of carbon fiber reinforced polymer composites and its effect on life cycle energy use for vehicle door lightweighting. 
Tan, H., Yan, L., Huang, L., Wang, Y., Li, H., \& Chen, J. (2017). Behavior of sisal fiber concrete cylinders externally wrapped with jute FRP. Polymer Composites, 38(9), 1910-1917. https://doi.org/10.1002/pc.23761

Tepfers, R., \& Rousakis, T. (2002). Experimental investigation of concrete cylinders confined by carbon FRP sheets under monotonic and cyclic axial compressive loads. Twelft International Conference on Mechanics of Composite Materials, MCM 2002, June 913, 2002, Riga, Latvia, 172-173.

Wu, G., Wu, Z., Lu, Z., \& Ando, Y. (2008). Structural Performance of Concrete Confined with Hybrid FRP Composites. Journal of Reinforced Plastics and Composites - J $\begin{array}{llll}\text { REINF PLAST } & \text { COMPOSITE, }\end{array}$ https://doi.org/10.1177/0731684407084989

Yan, L. (2016). Plain concrete cylinders and beams externally strengthened with natural flax fabric reinforced epoxy composites. Materials and Structures, 49(6), 2083-2095. https://doi.org/10.1617/s11527-015-0635-1

Yan, L., \& Chouw, N. (2013). Behavior and analytical modeling of natural flax fibrereinforced polymer tube confined plain concrete and coir fibre-reinforced concrete. Journal of Composite Materials, 47(17), 2133-2148. https://doi.org/10.1177/0021998312454691

Yan, L., \& Chouw, N. (2014). Natural FRP tube confined fibre reinforced concrete under pure axial compression: A comparison with glass/carbon FRP. Thin-Walled Structures, 82, 159-169. https://doi.org/10.1016/j.tws.2014.04.013

Yan, L., Chouw, N., \& Jayaraman, K. (2014). Effect of column parameters on flax FRP confined coir fibre reinforced concrete. Construction and Building Materials, 55, 299312. https://doi.org/10.1016/j.conbuildmat.2014.01.061 
T.C.

AYDIN ADNAN MENDERES UNIVERSITY

GRADUATE SCHOOL OF NATURAL AND APPLIED SCIENCES

\section{SCIENTIFIC ETHICAL STATEMENT}

I hereby declare that I composed all the information in my master's thesis entitled "Axial Behavior of Concrete Confined with Flax Fiber-Reinforced Polymers" within the framework of ethical behavior and academic rules, and that due references were provided and for all kinds of statements and information that do not belong to me in this study in accordance with the guide for writing the thesis. I declare that I accept all kinds of legal consequences when the opposite of what I have stated is revealed.

Marouf RASHIDI

$25 / 05 / 2021$ 